IMPACTS OF THE CLEAN AIR ACT ON THE POWER SECTOR FROM 1938-1994: ANTICIPATION AND ADAPTATION

Karen Clay

Akshaya Jha

Joshua A. Lewis

Edson R. Severnini

WORKING PAPER 28962 


\title{
NBER WORKING PAPER SERIES \\ IMPACTS OF THE CLEAN AIR ACT ON THE POWER SECTOR FROM 1938-1994: \\ ANTICIPATION AND ADAPTATION
}

\author{
Karen Clay \\ Akshaya Jha \\ Joshua A. Lewis \\ Edson R. Severnini \\ Working Paper 28962 \\ http://www.nber.org/papers/w28962 \\ NATIONAL BUREAU OF ECONOMIC RESEARCH \\ 1050 Massachusetts Avenue \\ Cambridge, MA 02138 \\ June 2021, Revised December 2022
}

We are grateful for invaluable comments and suggestions from Becka Brolinson, Raphael Calel, Caroline Flammer, Don Fullerton, Geoff Heal, Maggie Jones, Matt Kotchen, Ashley Langer, Derek Lemoine, Arik Levinson, Chiara Lo Prete, Erin Mansur, Nick Muller, and Matthew Zaragoza-Watkins. We also appreciate feedback from seminars participants at Carnegie Mellon University, Columbia University — SIPA, New York University (Wagner), PERC, University of Arizona - Tucson, University of California - Berkeley, University of Illinois - UrbanaChampaign, University of Manchester - UK, University of Maryland, Université de Montréal, and the United States Environmental Protection Agency. Finally, we thank conference participants at the ASSA Annual Meetings, NBER Summer Institute - Development of the American Economy, AEA Session by the Committee on the Status of LGBTQ+ Individuals in the Economics Profession, Occasional Workshop in Environmental and Resource Economics (UC Santa Barbara), Northeast Workshop on Energy Policy and Environmental Economics, Midwest Energyfest, Annual Workshop on Empirical Methods in Energy Economics (EMEE), CEPREBRD-EoT-LSE Symposium on Environmental Economics and the Green Transition, the Annual Research Roundtable on Energy Regulation, Technology, and Transaction Costs, the Canadian Economic Association Meetings (CNEH), and the Berkeley-Harvard-Yale Environmental Economics Seminar. The authors also gratefully acknowledge financial support from the Center for Electricity Industry Studies, Heinz College, the Berkman fund at Carnegie Mellon University, National Science Foundation Grant SES-1627432, and the Université de Montréal. The views expressed herein are those of the authors and do not necessarily reflect the views of the National Bureau of Economic Research.

NBER working papers are circulated for discussion and comment purposes. They have not been peer-reviewed or been subject to the review by the NBER Board of Directors that accompanies official NBER publications.

(C) 2021 by Karen Clay, Akshaya Jha, Joshua A. Lewis, and Edson R. Severnini. All rights reserved. Short sections of text, not to exceed two paragraphs, may be quoted without explicit permission provided that full credit, including (C) notice, is given to the source. 
Impacts of the Clean Air Act on the Power Sector from 1938-1994: Anticipation and Adaptation Karen Clay, Akshaya Jha, Joshua A. Lewis, and Edson R. Severnini

NBER Working Paper No. 28962

June 2021, Revised December 2022

JEL No. K32,N52,N72,Q41,Q48,Q52,Q58

\section{ABSTRACT}

This study leverages newly digitized data on virtually every fossil-fuel power plant in the United States from 1938-1994 to provide the first assessment of the impacts of the 1970 Clean Air Act (CAA) that accounts for anticipation. The extended pre-regulation benchmark allows us to account for anticipatory behavior by electric utilities in the years leading up to the Act's passage. Guided by predictions from a simple theoretical framework, we use a difference-in-differences approach to examine the impacts of the Act's nonattainment designations on coal-fired power plants of different vintages. We find that nonattainment designation led to large and persistent decreases in plant productivity, which would be substantially underestimated without data from well before the passage of the 1970 CAA. The productivity losses were concentrated only among plants built before 1963. This timing aligns with the passage of the original 1963 CAA, which served as a signal of impending federal regulation. We provide empirical and historical evidence of anticipatory responses by utilities in the design and siting of plants that opened after 1963. Finally, we find that the aggregate productivity losses of the CAA borne by the power sector were substantially mitigated by the reallocation of output away from older less productive power plants.

\author{
Karen Clay \\ Heinz College \\ Carnegie Mellon University \\ 5000 Forbes Avenue \\ Pittsburgh, PA 15213 \\ and NBER \\ kclay@andrew.cmu.edu
}

Akshaya Jha

H. John Heinz III College

Carnegie Mellon University

4800 Forbes Avenue

Pittsburgh, PA 15213

and NBER

akshayaj@andrew.cmu.edu
Joshua A. Lewis

University of Montreal

Département de sciences économiques

3150 rue Jean-Brillant

Montréal, QC, H3T 1N8

joshua.lewis@umontreal.ca

Edson R. Severnini

H. John Heinz III College

Carnegie Mellon University

4800 Forbes Ave \#2114B

Pittsburgh, PA 15213

and NBER

ersevernini@gmail.com

An online appendix is available at http://www.nber.org/data-appendix/w28962 


\section{Introduction}

The 1970 Clean Air Act (CAA) is the centerpiece of local air pollution regulation in the United States and a model for environmental policy around the world. Not surprisingly, there is a large literature examining its impacts, but prior studies lack data from well before the 1970 CAA was implemented (see reviews by Currie and Walker, 2019; Aldy et al., 2022). This poses challenges for policy evaluation because economic agents may have taken actions in the years prior to the Act's passage to facilitate the transition to a post-regulation regime. As a result, outcomes in the years leading up to the Act's passage may not provide a valid pre-regulation benchmark.

This study leverages newly digitized data on virtually every fossil-fuel power plant in the United States from 1938-1994 to provide the first assessment of the impact of the 1970 CAA that accounts for anticipatory responses. The extended pre-regulation benchmark allows us to account for anticipatory behavior by electric utilities in the years leading up to the Act's passage. We contrast these results to policy estimates based on the shorter pre-regulation time horizons that have been used by the existing literature studying the 1970 CAA.

To understand why the extended pre-regulation benchmark is essential, we specify a simple theoretical framework that illustrates whether and how plants of different vintages will adjust to future regulation. The model makes clear that anticipatory responses are likely to occur in settings where capital expenditures are large, durable, and expensive to modify. The framework also shows that adjustment may occur gradually across plant vintages depending on when regulation is expected over the plant's lifespan (the "lifecycle channel"). Alternatively, adjustment may occur suddenly in response to a new information shock that alters expectations over the probability and stringency of future regulation (the "information channel"). The historical literature suggests that the original 1963 CAA was one such information shock. The 1963 CAA was the first legislation that authorized the federal government to "control" air pollution, and served as a strong signal that future regulation was impending.

We utilize a difference-in-differences approach that compares outcomes across coalfired plants built before the 1970 CAA located in attainment versus nonattainment coun- 
ties. ${ }^{1}$ The 1970 CAA established the National Ambient Air Quality Standards, which classifies areas as in versus out of attainment for several criteria pollutants. Such designations depend on whether pollution levels are below or above the relevant standard. Power plants located in attainment counties are subject to limited regulation while plants in nonattainment counties are pressured by state and local regulators to take costly actions to reduce pollution levels. Our extended pre-regulation benchmark allows us to exploit variation in enforcement driven by both the initial nonattainment designations in 1972 as well as subsequent changes in attainment status. ${ }^{2}$ In contrast, the prior literature has relied primarily on switches in attainment status after $1972 .^{3}$

The paper has three main findings. First, without data spanning well before the passage of the 1970 CAA, one would substantially underestimate the effects of the CAA on power plant productivity. ${ }^{4}$ Using our entire sample period, we find that nonattainment designation led to a $14 \%$ reduction in productivity. The magnitude of the main estimates diminish, however, as the pre-regulation sample period is artificially shortened, and the results are not statistically significant for samples beginning in the mid-1960s. This pattern is consistent with predictions from our theoretical framework, in which high retrofit costs may induce electric utilities to make preemptive investments in anticipation of impending regulation. ${ }^{5}$

Second, nonattainment designation led to large and persistent decreases in plant productivity, but only for plants built before 1963. The magnitude of nonattainmentinduced decreases in productivity are stable across different vintages of plants that opened in the decades prior to 1963. However, the effects of nonattainment attenuate sharply for plants that opened after the $1963 \mathrm{CAA}$. This is consistent with the "information

\footnotetext{
${ }^{1}$ We also estimate event study models based on the methodology from Callaway and Sant'Anna (2021); estimates from this methodology are robust to potential biases generated when the timing of treatment is staggered and treatment effects are heterogeneous.

${ }^{2}$ For the years 1972-1977, we use the attainment status designations specified in Greenstone (2002). Our results remain similar if we instead use the designations assigned to air quality control regions as mapped into counties by Cropper et al. (2022).

${ }^{3}$ Decompositions using the Goodman-Bacon (2021) technique show that identification of the main estimates is based primarily on comparisons across plants that never versus ever faced nonattainment rather than the timing of switches in attainment status after 1972.

${ }^{4}$ Our measure of productivity focuses on how input quantities translate to output electricity, without incorporating the external costs of pollution borne by society at large. We estimate "pollutionunadjusted" total factor productivity (PU-TFP) using the method developed by Ackerberg, Caves and Frazer (2015).

${ }^{5}$ Event study graphs support the parallel trends assumption. This is consistent with historical evidence that electric utilities anticipated some form of impending regulation, but were unable to predict the exact timing of the CAA or which counties would ultimately face nonattainment.
} 
channel" in our theoretical framework. Namely, our estimates suggest a sharp change in firm beliefs following the passage of the 1963 CAA rather than gradual cross-vintage adjustments due to differing lifecycle incentives. Put more simply, our findings suggest that the 1963 CAA was a large information shock, sufficient to immediately incentivize electric utilities to account for future environmental regulation when constructing new plants.

We present additional empirical and historical evidence suggesting that electric utilities updated their beliefs following the passage of the 1963 CAA. Historical sources document preemptive design changes among plants that opened after 1963, including increased stack height and installation of pollution abatement technology. We document a sharp increase in patenting related to power systems between 1963-1971. We also find that electric utilities were less likely to site plants in counties with pollution monitors after 1963. Taken together, this evidence points to anticipation having played a key role in reducing the productivity losses incurred by newer vintage plants.

Third, we find that the distributional impacts of the CAA substantially mitigated the aggregate productivity losses from the regulation. We calculate that roughly half of the aggregate plant-level productivity losses due to the CAA were offset by the productivity gains from CAA-induced reallocation of output away from older vintage plants to new plants that opened after 1972. A simple calculation that accounts for this regulatoryinduced reallocation implies that aggregate average productivity decreased by roughly $2 \%$ due to the CAA, resulting in annual total productivity losses of about $\$ 2.6$ billion (2020 USD).

This paper makes four contributions to existing literature. First, it contributes to the extensive literature documenting the impacts of the 1970 CAA on firm behavior (again, see reviews by Currie and Walker, 2019; Aldy et al., 2022). ${ }^{6}$ Almost all of these prior studies have relied on post-1972 variation in attainment status, and none have included data from before 1963. By leveraging newly digitized data on plant operations from 1938-1994, we provide the first causal estimates of the impact of the 1970 CAA on plant productivity that account for preemptive adjustments in the years leading up to the Act's

\footnotetext{
${ }^{6}$ For impacts on manufacturing, see, for example, Henderson (1996); Becker and Henderson (2000); Greenstone (2002); Gray and Shadbegian (2003); Greenstone, List and Syverson (2012); Ryan (2012); Kahn and Mansur (2013); Curtis (2018). For impacts on the power sector, see, for example, Gollop and Roberts (1983, 1985); Nelson, Tietenberg and Donihue (1993); Carlson et al. (2000); Ferris, Shadbegian and Wolverton (2014); Sheriff, Ferris and Shadbegian (2019).
} 
implementation.

Our second contribution is to the literature studying anticipatory behavior prior to the passage of regulations. Previous work has documented anticipatory responses to a wide range of policies (Lueck and Michael, 2003; Di Maria, Lange and van der Werf, 2014; Malani and Reif, 2015; Lemoine, 2017; Keiser and Shapiro, 2019). ${ }^{7}$ We contribute to this literature by providing evidence on the key role played by improvements in information in generating the anticipatory responses that ultimately mitigated the costs of regulatory compliance under the 1970 CAA.

Third, our findings contribute to existing work demonstrating that the distributional impacts of government policy can have first-order effects on aggregate outcomes through reallocative responses (Kline and Moretti, 2014; Hornbeck and Rotemberg, 2019). In our setting, we show that the reallocation of output away from older less productive plants substantially offset the aggregate productivity losses from the 1970 CAA. $^{8}$

Fourth, our paper complements a growing literature in economic history that relies on extended historical time horizons to study the external costs of polluting activities (Clay, Lewis and Severnini, 2016; Beach and Hanlon, 2018; Hanlon, 2020; Heblich, Trew and Zylberberg, 2021). Our analysis draws on detailed data on power plant operations spanning seven decades to provide new insights on the economic impacts of environmental regulation. Our evidence suggests that the productivity costs borne by the U.S. power sector - one of the largest sources of pollution emissions (Tschofen, Azevedo and Muller, 2019) — are small relative to the public health benefits of air pollution regulation. ${ }^{9}$

The remainder of the paper is organized as follows. Section 2 presents background information on the evolution of environmental policy in the United States. Section 3 highlights the theoretical conditions under which firms engage in anticipatory behavior. Section 4 describes the data sources, presents summary statistics, and introduces our difference-in-differences approach to estimating the effects of nonattainment on power plant operations. Section 5 reports the main findings, along with robustness checks

\footnotetext{
${ }^{7} \mathrm{~A}$ related literature on the "green paradox" suggests that firms may shift polluting production forward in anticipation of increases in the stringency of future climate policy (see reviews by Jensen et al., 2015; Van der Ploeg and Withagen, 2015). This is not feasible for power plants because long-duration electricity storage is prohibitively expensive and electricity demand is close to perfectly inelastic.

${ }^{8}$ These reallocative effects may have also helped to mitigate the costs of provisions in the CAA that imposed more stringent regulations on plants built after 1972 (List, Millimet and McHone, 2004).

${ }^{9}$ For example, the US Environmental Protection Agency estimates that the 1970 CAA generated more than $\$ 22$ trillion in public health benefits from 1970 to 1990 (EPA, 1997).
} 
and heterogeneity analyses. Section 6 presents a back-of-the-envelope calculation of the aggregate effect of the 1970 CAA on productivity in the U.S. power sector. Lastly, Section 7 concludes by discussing the policy implications of our findings.

\section{Background}

This section describes three phases of air pollution regulation in the United States. The first phase was up to 1962, when most of the federal efforts were directed towards data collection. The second phase was 1963-1971, when the passing of the Clean Air Act (CAA) of 1963 provided a credible signal that comprehensive regulation was coming. The third phase was from 1972 onward when the 1970 CAA legislation took effect.

\section{$2.1 \quad$ Up to 1962}

The modern clean-air movement arose in the postwar period following a number of high profile incidents of extreme air pollution, notably the 1948 Donora smog and the 1952 London smog (Clay, 2018). These events received international publicity, raised public awareness of the relationship between air quality and health, and created the impetus for federal action. ${ }^{10}$

Federal legislation under the 1955 Air Pollution Control Act provided funding for research and technical assistance related to air pollution control. One outcome of this legislation was the creation of the air pollution monitoring network. Although initially small, the network included 270 monitors in 205 counties by 1962 . The 1955 Act authorized a modest research budget and left the responsibility of prevention and control of air pollution to the states. A report by the U.S. Advisory Commission on Intergovernmental Relations offers an assessment of the impact of the 1955 Air Pollution Control Act: "It legislated little and, correspondingly, accomplished little." (ACIR, 1981, p.12)

\footnotetext{
${ }^{10}$ Around the same time, severe ongoing smog problems in Los Angeles led California's state officials to begin lobbying for federal legislation.
} 


\section{$2.2 \quad 1963-1971$}

The Clean Air Act of 1963 (1963 CAA) signalled an important shift in the role of the federal government in combating air pollution. The 1963 CAA was the first legislation to give the federal government the authority to control air pollution. ${ }^{11}$ Despite this transformation in the federal government's role in combating air pollution, its effective authority was limited. A total of just 11 "abatement conferences" were held through $1971 . .^{12,13}$

The 1967 Air Quality Act strengthened the role of the federal government in tackling air pollution. However, enforcement remained an issue. The Act required the establishment of air quality control regions and clean air criteria, with states responsible for implementing these criteria. Three years later, however, "only 21 states had submitted implementation plans, none of which had been approved in Washington. This, of course, made enforcement impossible" (ACIR, 1981, p.23).

Contemporary historical accounts document a change in the behavior of electric utilities following the 1963 CAA that is consistent with anticipation. For example, the 1966 "Steam-Electric Plant Construction Cost and Annual Production Expenses" report dedicates, for the first time, a section on "environmental influences on plant design, construction, and operation." It points out that, among other factors, air pollution was "emerging as a major social-economic issue affecting the electric power industry" (FPC, 1967, p.ix). ${ }^{14}$ The 1968 reports adds that "[u]tilities are giving increasing attention to the location and design of new plants and to lessening the impact of these facilities on the environment. (...) Most new coal and oil fired plants include high efficiency electrostatic precipitators to remove particulate matter from stack discharges. (...) High stacks are frequently used to obtain greater dispersion and reduce ground level concentration of oxides of sulfur, and greater attention is being given to the selection of coal and oil fuels

\footnotetext{
${ }^{11}$ Namely, the $1963 \mathrm{CAA}$ included a conference procedure in section 115.

${ }^{12}$ Interestingly, these procedures were not new. Similar procedures were included in the 1956 Federal Water Pollution Control Act and had been used beginning in 1957 (EPA, 1973).

${ }^{13}$ Between 1960 and 1966, ten states set their own air quality standards (Stern, 1982). Our primary specifications account for these state-level standards through the inclusion of state-by-year fixed effects. We also explore the impact of state-level standards in sensitivity analyses.

${ }^{14}$ The report also states that "[t]echnology for the removal of particulate matter has been available for some time; however, the demand for very high efficiency (99 percent + ) electrostatic precipitators is growing rapidly. Commercial devices for the removal of oxides of sulfur from the flue gases are not yet available (...) In the meantime, (...) higher boiler stacks are being installed to attain greater dispersion" (FPC, 1967, pp. ix-x).
} 
of lower sulfur content" (FPC, 1969, p.ix). The 1970 report states that "[e]nvironmental factors are now a major, and often dominant, consideration in the siting and design of new steam-electric generating facilities. (...) All coal-fired units will employ electrostatic precipitators, wet scrubbers, or other efficient methods for controlling particulate emissions and many will be designed for later application of stack systems for removal of sulfur oxides which are now under development" (FPC, 1972, p.x).

Changes in the design of power plants that opened after 1963 are consistent with anticipatory behavior by electric utilities. Appendix Figure A.1 shows an increase in average smokestack height in the late 1960s that does not align with the more gradual increase in generator size. Appendix Figure A.2 and Table A.1 show that installation of flue gas particulate (FGP) collectors such as electrostatic precipitators and fabric filters (baghouses) was already common before 1970. Finally, Appendix Figure A.3 shows a sharp increase in the number of patents granted for power systems beginning in the mid1960s, potentially reflecting the increased incentive for regulatory-induced innovation. ${ }^{15}$

Changes in the siting of plants that opened after 1963 are also consistent with anticipatory behavior. As documented in Appendix Table A.2, plants built between 1963 and 1971 were systematically less likely to be sited in counties with an air pollution monitor than plants built before 1963. Interestingly, there are no cross-vintage differences in the likelihood that plants were sited in counties that would later face nonattainment, suggesting that electric utilities were unable to predict which counties would ultimately be targeted under the 1970 CAA.

Preemptive changes by electric utilities may also contribute to the increase in construction costs of coal plants beginning in the mid-1960s (see Appendix Figure A.4). ${ }^{16}$ Since electric utilities were subject to rate-of-return regulation, plant construction costs as well as the costs of installing and operating pollution abatement technology were largely passed on to consumers through rate increases approved in public utility commission

\footnotetext{
${ }^{15}$ The data do not permit a more disaggregate decomposition of either the holders of the new patents or the innovations underlying these patents. We are able, however, to provide a few examples: (i) the Pennsylvania Electric Company obtained a patent in 1967 to optimize the operation of a coal-fired power plant and generate metals from the collected ash; and (ii) the Babcock \& Wilcox Company, New York, obtained a patent in 1966 for a combined cycle power plant where the second steam generator uses as fuel the particulate matter emitted when burning coal to power the first generator.

${ }^{16}$ Joskow and Rose (1985) comment that this trend in construction costs surprised them: they "expected to see the major increases appear later as a result of new plants' coming on line with state-ofthe-art environmental control equipment in response to regulations introduced in the 1970s; but costs clearly begin to increase by the late 1960s" (p. 21).
} 
hearings (Fowlie, 2010).

\section{$2.3 \quad 1972$ onward}

The 1970 Clean Air Act (CAA) marked the first federal effort to regulate air quality on a national scale. It emerged after an extended period of mounting public pressure for federal action on air pollution. Nevertheless, the timing and scope of the regulation came as somewhat of a surprise. A confluence of high profile events - the 1969 Cuyahoga River Fire, a massive oil spill off the coast of Santa Barbara in 1969, and the first Earth Day in the spring of 1970 - triggered a groundswell of public sentiment favoring environmental action. Despite his anti-regulatory tendencies, President Nixon supported the 1970 CAA to outflank Senators Muskie and Jackson, two pro-environment legislators who were widely considered his strongest rivals for the 1972 presidency (ACIR, 1981). In the end, the 1970 CAA "was clearly beyond the technological capability which industry was known to possess at the time" (ACIR, 1981, p.24). ${ }^{17}$

The 1970 CAA established the National Ambient Air Quality Standards (NAAQS) for five criteria air pollutants: particulate matter, carbon monoxide, sulfur dioxide, nitrogen dioxide, and ambient ozone. ${ }^{18}$ Beginning in 1972, each county received an annual designation of nonattainment or attainment for each criteria pollutant, depending on whether air pollution concentrations exceeded the federally mandated standard. ${ }^{19}$

Each state was required to submit a state implementation plan (SIP) outlining how any nonattainment regions would be brought into compliance with the NAAQS. Typically, states totaled up estimated emissions from all stationary sources of pollution in each nonattainment area, and divided this amount by an estimate of the maximum level of emissions that would ensure compliance with the NAAQS. Each plant was ordered to

\footnotetext{
${ }^{17}$ As mentioned in ACIR (1981), "[t]hroughout the period, lobbying was intense from both industry and environmental groups, but public attention to the debate made industry the sure loser" (p.23). In fact, a 1970 Gallup poll inquired: Which three of these national problems would you like to see government devote most of its attention to? In contrast to a 1967 poll, " $53 \%$ of the polled population named reducing air and water pollution as [one of the three] most serious national problem[s], second only to crime" (p.18).

${ }^{18}$ Airborne lead was later added as a criteria pollutant.

${ }^{19}$ The Code of Federal Regulations (CFR) began to publish annual county-level attainment status in 1978. For the period 1972-1977, we follow Greenstone (2002) and classify a county as nonattainment for a pollutant in a year if it had a pollution monitor reading in the year exceeding the relevant federal standard. Our results remain similar if we instead use the designations assigned to air quality control regions as mapped into counties by Cropper et al. (2022).
} 
reduce emissions by this ratio (Roberts and Farrell, 1978). All states, territories, and the District of Columbia submitted SIPs by the end of 1972 (EPA, 1973). ${ }^{20}$

Power plants in nonattainment counties faced greater constraints on emissions than plants in attainment counties. One way for plants to meet regulatory requirements was to decrease output. Indeed, Appendix Figure C.5 shows a large drop in output among plants built before 1963 located in nonattainment counties after the passage of the 1970 CAA. This decline in output seems to have been driven by utilities scaling back production at older vintage plants rather than shuttering capacity, which remained stable in the post-1972 period. Reductions in output from pre-1963 plants were offset primarily by increases in production from new plants built after $1972 .{ }^{21}$

To reduce emissions, existing plants in nonattainment counties could also burn more expensive, lower sulfur coal or install pollution abatement technology - either flue gas desulfurization (FGD) systems or flue gas particulate collectors (FGP). However, installing a FGD system was costly and risked subjecting the plant to the New Source Performance Standards (NSPS), a set of strict standards that applied to the plant regardless of its county's attainment status. ${ }^{22}$ Despite these concerns, both FGP and FGD installation rates increased after 1970 (see Appendix Figures A.2 and A.5).

The 1970 CAA led to a sharp drop in emissions from power plants. By 1975, the EPA reported that 261 of the 394 coal-fired power plants in the United States were in compliance with SIP emission limitations or abatement schedules. ${ }^{23}$ During the first three years of the CAA, total suspended particle (TSP) emissions fell from 4.2 million tons in 1970 to 2.9 million tons in 1974, and sulfur oxide $\left(\mathrm{SO}_{x}\right)$ emissions fell from 15.4

\footnotetext{
${ }^{20}$ The documentary record on SIPs is complicated by the fact that the SIPs were frequently modified or litigated. Still, in 1974, the EPA noted that "[w]ith a few notable exceptions (e.g. sulfur oxide emission limitations in the State of Ohio) all States now have fully enforceable emission limits affecting stationary sources" (EPA, 1975, p.12).

${ }^{21}$ Similar descriptive plots broken down by vintage group and the number of years that the plant faced nonattainment are displayed in Appendix Figure C.6. The corresponding plots for plant productivity are displayed in Appendix Figures C.7 and C.8.

${ }^{22}$ In nonattainment counties, abatement technologies had to meet the "lowest achievable emissions rate" regardless of costs. In contrast, plants in attainment counties were required to install the "best available control technology", which allowed for the consideration of costs. The 1977 amendments required the use of scrubbers for coal-fired plants built after 1978.

${ }^{23}$ Of the 133 plants not in compliance, 47 were located in Ohio, 29 were located in Indiana, and 26 were located in Illinois. In these states, there was significant delay and litigation around $\mathrm{SO}_{x}$ control plans (EPA, 1976a). Of the remaining 31 plants not in compliance, ten were part of the Tennessee Valley Authority and were subject to a consent decree (see Appendix Table A.3); SIP revisions were underway for 7 plants; and the remaining plants were in litigation or otherwise subject to EPA action.
} 
million tons to 13.6 million tons (EPA, 1976b). These reductions in pollution emissions accelerated a downtrend trend in monitored TSP concentration levels that pre-dated the Act's passage (see Appendix Figure A.6).

\section{Theoretical Framework}

In this framework, we outline the conditions under which anticipation of future environmental regulation will cause producers to preemptively shift activity to cleaner production technologies. We consider a three period model. At $t=0$, the utility builds a power plant, deciding the share of its generating capacity, $\theta$, to allocate across two technologies: a "dirty" technology, $F_{D}\left(\theta, V_{D}\right)$, and a "clean" technology, $F_{C}\left(1-\theta, V_{C}\right) .{ }^{24}$ The plant operates in periods $t=1,2$ (young and old), and chooses variable inputs $V_{D}$ and $V_{C}$ in order to maximize the profits earned from each technology in the period, $\Pi_{D}(\theta)$ and $\Pi_{C}(1-\theta)$. Future profits are discounted by a constant discount factor $\beta{ }^{25}$

At the start of periods $t=1,2$, the government may enact environmental regulation. This regulation permanently lowers the relative profitability of the "dirty" technology, so that $\Pi_{D}(\theta)$ decreases to $\delta \Pi_{D}(\theta)$ in every period, where $\delta \in(0,1)$. After the regulation, the plant can choose to pay a one-time fixed cost, $c$, to reallocate capacity across the production technologies. Intuitively, $c$ can be interpreted as the cost of retrofitting "dirty" boilers with pollution abatement technology. ${ }^{26}$

At $t=0$, electric utilities form expectations over the likelihood and stringency of future environmental regulation. Let $\lambda_{1}$ and $\lambda_{2}$ be the utility's subjective probabilities that legislation will be enacted in periods 1 and 2, respectively. The expected stringency of enforcement is denoted $(1-\delta)$. Given this setup, we can derive optimal responses to regulation for existing plants at $t=1,2$, and through backwards induction, solve for the initial capacity allocation chosen at $t=0$.

\footnotetext{
${ }^{24}$ We assume that $F_{D}($.$) and F_{C}($.$) are differentiable in both arguments and concave, allowing us$ to focus on interior solutions. However, the implications of this model remain the same if the initial equilibrium is a corner solution. Our setup reflects the fact that plants can install multiple boilers with differing technologies, where differences in emissions across the two production technologies can arise either because of specific boiler design characteristics or installed abatement technology.

${ }^{25} \mathrm{We}$ assume that producers face a constant inelastic demand for electricity, and do not model the initial decision about whether to open a plant or subsequent decisions to expand total generating capacity.

${ }^{26}$ The empirical predictions are similar if this adjustment cost depends on the amount of capacity shifted from the dirty technology to the clean technology.
} 


\subsection{Plant decisions at $t=1,2$}

Given an initial capacity allocation, $\theta^{*}$, per-period profits are reduced to $\Pi\left(\theta^{*}\right)=$ $\delta \Pi_{D}\left(\theta^{*}\right)+\Pi_{C}\left(1-\theta^{*}\right)$ if regulation passes. Alternatively, the plant can pay fixed cost $c$ to re-optimize and shift capacity away from the dirty technology to $\hat{\theta}<\theta^{*}$. ${ }^{27}$ Plants will choose to adjust capacity if and only if the following inequality holds:

$$
\Pi(\hat{\theta})-\Pi\left(\theta^{*}\right) \geq\left\{\begin{array}{cc}
\frac{c}{1+\beta} & \text { if regulation passes when young }(t=1), \\
c & \text { if regulation passes when old }(t=2)
\end{array}\right.
$$

where the difference between adjusted and unadjusted profits is given by

$$
\Pi(\hat{\theta})-\Pi\left(\theta^{*}\right)=\int_{\hat{\theta}}^{\theta^{*}} \Pi_{C}^{\prime}(1-x)-\delta \Pi_{D}^{\prime}(x) d x \approx \frac{1}{2}\left(\theta^{*}-\hat{\theta}\right)(1-\delta) \Pi_{D}^{\prime}\left(\theta^{*}\right)
$$

Intuitively, the per-period gain from adjustment is the difference in marginal profits earned from the capacity that is reallocated. ${ }^{28}$ The probability of adjustment increases with the stringency of the regulation, $(1-\delta)$, and the gap between the plant's existing versus desired capacity allocation under regulation, $\left(\theta^{*}-\hat{\theta}\right)$. Meanwhile, higher fixed costs, $c$, reduce the likelihood that the plant will reallocate capacity. The constraint is less binding at $t=1$ than $t=2$; plants are more willing to pay the fixed cost to adjust capacity when young since the benefits accrue over a longer time horizon. ${ }^{29}$

\subsection{Plant decisions at $t=0$}

The plant's initial choice of capacity, $\theta$, depends on whether it will choose to reallocate capacity in later periods in response to the enactment of regulation. The plant's initial choice can be summarized by the three following cases:

Case 1: Always adjust (AA) - Adjust capacity if regulation passes in $t=1$ or $t=2$

\footnotetext{
${ }^{27}$ If plants choose to re-optimize, they will choose $\hat{\theta}$ that solves $\delta \Pi_{D}^{\prime}(\hat{\theta})=\Pi_{C}^{\prime}(1-\hat{\theta})$.

${ }^{28}$ The last approximation is obtained by taking a first-order Taylor expansion of each marginal profit function around $\theta^{*}$.

${ }^{29}$ Once a plant has opened, it is never optimal to adjust capacity in anticipation of future regulation. That is, changes in $\lambda_{2}$ have no influence on decision-making at $t=1$. This result contrasts with a framework with endogenous environmental regulation (e.g., Puller, 2006; Lyon and Maxwell, 2008), in which plants may strategically reduce emissions in an effort to reduce the stringency of future regulations.
} 
This case will arise when the fixed adjustment cost, $c$, is so small that the inequality in equation (1) always holds. In this case, the optimal initial $(t=0)$ capacity allocation solves the following first-order condition: ${ }^{30}$

$$
\Pi_{D}^{\prime}\left(\theta_{A A}^{*}\right)=\Pi_{C}^{\prime}\left(1-\theta_{A A}^{*}\right)
$$

This allocation choice, $\theta_{A A}^{*}$, is the same as the allocation in a setting in which producers face no anticipated future regulation. Intuitively, because plants know that they will adjust capacity if regulation is ever passed, they do not account for any profit losses that might arise from their initial allocation choice.

Case 2: Never adjust (NA) - Do not adjust capacity if regulation passes in $t=1$ or $t=2$

This case arises when the fixed adjustment cost, $c$, is so large that the inequality in equation (1) never holds. In this case, the initial capacity allocation solves the following first-order condition:

$$
\left[1-\lambda_{1}(1-\delta)-\lambda_{2}(1-\delta) \frac{\beta}{1+\beta}\right] \Pi_{D}^{\prime}\left(\theta_{N A}^{*}\right)=\Pi_{C}^{\prime}\left(1-\theta_{N A}^{*}\right)
$$

Because the term in brackets is less than one, the plant preemptively allocates capacity towards the clean production technology, so that $\theta_{N A}^{*}<\theta_{A A}^{*}$. The magnitude of this preemptive shift increases with the expected losses from regulation, $(1-\delta)$, and the probabilities of regulation in both periods. The probability of regulation when the plant is young $\left(\lambda_{1}\right)$ has a larger impact on the ex-ante allocation than the probability of regulation when the plant is old $\left(\lambda_{2}\right)$, both because early regulation affects plants for more of their lifespan and because the effects of regulation in the distant future are discounted more heavily.

Case 3: Sometimes adjust (SA) - Adjust capacity if regulation passes at $t=1$, but do not adjust capacity if regulation passes at $t=2$

This case arises for intermediate adjustment costs, when $\frac{c}{1+\beta} \leq \Pi(\hat{\theta})-\Pi\left(\theta^{*}\right) \leq c$. In this

\footnotetext{
${ }^{30}$ See Appendix B for more details on the derivation of the optimal initial allocation.
} 
case, the initial capacity allocation solves the following first-order condition:

$$
\left[1-\frac{\lambda_{2}}{1-\lambda_{1}}(1-\delta) \frac{\beta}{1+\beta}\right] \Pi_{D}^{\prime}\left(\theta_{S A}^{*}\right)=\Pi_{C}^{\prime}\left(1-\theta_{S A}^{*}\right)
$$

The term in brackets is again less than one, implying that anticipated regulation causes plants to preemptively allocate capacity towards the clean production technology, so that $\theta_{S A}^{*}<\theta_{A A}^{*}$. Again, the magnitude of the adjustment increases with the expected losses from regulation $(1-\delta)$ and the probability of regulation in both periods.

However, since the plant will re-optimize capacity only if regulation passes at $t=1$, the probability of regulation when the plant is young $\left(\lambda_{1}\right)$ has a smaller impact on the ex-ante allocation than the probability of regulation when old $\left(\lambda_{2}\right) .{ }^{31}$ Provided that $\lambda_{2}$ is not too large relative to $\lambda_{1}$, the plant will choose to allocate more capacity to the dirty technology than in Case 2, that is, $\theta_{S A}^{*}>\theta_{N A}^{*}{ }^{32}$

\subsection{Empirical Predictions}

This simple framework highlights how anticipation of future regulatory actions will cause producers to preemptively shift capacity towards cleaner production technologies, particularly when the costs of ex-post adjustment are large. In our setting, the Clean Air Act (CAA) of 1970 reduces the profitability of polluting technologies, but high retrofit costs may limit the extent to which existing plants shift towards cleaner production technologies.

Our framework also shows how anticipatory responses may have differed across plants built before versus after 1963. First, to the extent that the 1963 CAA signalled future regulatory actions, utilities may have updated their priors on the probability and expected stringency of future environmental regulation. This informational channel would result in a larger preemptive shift in capacity towards cleaner production technologies among post1963 plants, in an effort to increase plant productivity in a post-regulation environment.

Second, even if pre- and post-1963 plants held similar priors about whether and when regulation would pass, the incentive to preemptively respond might differ due to

\footnotetext{
${ }^{31} \lambda_{1}$ only affects the initial allocation choice by changing the conditional probability that the plant will be regulated in $t=2$ given that the regulation does not pass in $t=1$.

${ }^{32}$ The plant will choose $\theta_{S A}^{*}>\theta_{N A}^{*}$ whenever $\frac{\lambda_{2}}{1-\lambda_{1}} \frac{\beta}{1+\beta} \leq 1$.
} 
differences in when in the plant's lifespan the regulation was expected to be enacted. The effect of this lifecycle channel across pre- and post-1963 plants is theoretically ambiguous. On the one hand, anticipatory responses among pre-1963 plants may have been smaller, since regulation was not expected until later in their lifespan and so would be discounted more heavily (as in Case 2). On the other hand, anticipatory responses may have been larger among pre-1963 plants for intermediate values of the fixed retrofit cost $c$, which results in adjustment if young but not old (as in Case 3).

Our framework predicts that the information shock from the 1963 CAA should have led to a shift towards cleaner production technologies among plants that opened after 1963. Thus, the productivity losses from subsequent regulation should be smaller for plants that opened after 1963. If the informational channel dominates, we should not expect to observe differences in the effects of subsequent regulation across vintages for plants built before 1963 .

In contrast, because the magnitude of the lifecycle channel depends on expected lifetime exposure to regulation, preemptive anticipatory responses should decrease or increase monotonically with plant vintage depending on whether our setting corresponds to Case 2 versus Case 3. ${ }^{33}$ Either way, if the lifecycle channel dominates, the productivity effects of future regulation should differ with plant vintage more broadly, not just across plants built before versus after 1963. We test these competing hypotheses in the empirical analysis.

\section{Data and Empirical Strategy}

\subsection{Data Description}

The analysis uses annual plant-level data that covers the vast majority of fossil-fuel-fired power plants in the United States and spans the period 1938-1994. ${ }^{34}$ The Federal Power Commission (FPC), later renamed the Federal Energy Regulatory Commission (FERC),

\footnotetext{
${ }^{33}$ In Case 1, plants do not respond in anticipation of regulation regardless of vintage.

${ }^{34}$ Our sample ends in 1994 because the market-based components of the Clean Air Act of 1990 were implemented in 1995. Moreover, some U.S. states decided to shift the provision of electricity generation from output price regulation to market mechanisms beginning in 1998 (Fowlie, 2010; Cicala, 2015). Market-based plants face both a different set of incentives and a different set of reporting requirements than price-regulated plants.
} 
began publishing detailed plant-level information in $1948 .{ }^{35}$ The initial volume included retrospective data beginning in 1938. We digitized the data for 1938-1981, and use similar data collected by FERC for 1982-1994. ${ }^{36}$ Further details on the data construction process are provided in Appendix Section C.

There are 790 fossil-fuel-fired power plants in the data, located in approximately 565 U.S. counties (see Appendix Figure C.2). Although we use all of these coal-, gas-, and oil-fired plants in sensitivity analyses, our main sample focuses on the 373 "existing" coal-fired plants that opened before $1972 .{ }^{37,38}$ In auxiliary analysis, we also include the 123 "new" coal plants built after 1972, which were subject to more stringent regulation under the New Source Performance Standards (NSPS).

We assign each county an annual nonattainment status based on whether the county was in noncompliance with the standards associated with any of the five regulated criteria pollutants - particulate matter, carbon monoxide, sulfur dioxide, nitrogen dioxide, and ambient ozone. These designations are obtained from the Code of Federal Regulation (CFR) for the period 1978-1994. For the period 1972-1977, we follow Greenstone (2002) and classify a county as nonattainment if it had a monitor reading in the year that exceeded the federal standard. However, Appendix Table D.5 documents that the primary findings remain similar when instead using the attainment status designations for 1972-1977 based on Air Quality Control Regions constructed by Cropper et al. (2022).

Appendix Table C.1 presents the number of existing and new coal plants in our data that never versus ever faced nonattainment between 1972-1994. The share of plants that never faced nonattainment between 1972-1994 is 0.30 for plants built before 1963 and 0.37 for plants built between 1963-1971. ${ }^{39}$ This suggests that there were no crossvintage differences in the siting of existing plants across always-attainment versus ever-

\footnotetext{
${ }^{35}$ As an example, Appendix Figure C.1 displays a page from the 1957 report.

${ }^{36}$ Part of the digitization for 1938-1981 was done with resources from the NSF grant SES 1627432. We thank Ron Shadbegian and other researchers at the USEPA for providing the data for 1982-1994.

${ }^{37}$ For each plant and fuel type, we calculate the aggregate total heat input (in mmBTU) generated from burning the fuel in the plant's first five years of operation. The plant is assigned the fuel type corresponding to the largest total heat input across the three fuel types (coal, oil, and natural gas).

${ }^{38}$ We focus on coal plants in part because Congress authorized the Federal Energy Administration (FEA) to prohibit certain power plants from burning natural gas or petroleum products as a primary energy source in response to the oil embargo of 1973. In some cases, the FEA explicitly mandated the use of coal (EPA, 1977).

${ }^{39}$ Appendix Figure C. 3 plots the annual proportion of coal-fired electricity generation produced in nonattainment counties, separately for existing versus new plants. The top panel considers nonattainment with any pollutant while the bottom panels plot nonattainment by pollutant.
} 
nonattainment counties. In contrast, new plants were systematically more likely to be built in "always-attainment" counties (i.e., counties that never faced nonattainment between 1972-1994).

Attainment status is persistent. Conditional on facing attainment (nonattainment) in year $t-1$, the empirical probability that a coal plant faces attainment (nonattainment) in year $t$ is 0.92 (0.94) (see Appendix Table C.2). Thus, the vast majority of the variation in nonattainment status stems from the initial designations set forth in 1972 rather than post-1972 switches in attainment status. ${ }^{40}$

Our annual plant-level data provide detailed information on a range of outcomes, including electricity output, electricity generating capacity, number of employees, input fuel use, and fuel prices. We model the plant production process as in Fabrizio, Rose and Wolfram (2007) - a function of capital and labor is a perfect complement to fuel - and combine data on input and output quantities to estimate annual plant-level productivity using the method developed by Ackerberg, Caves and Frazer (2015). See Appendix Section C.2 for the details on how we estimate productivity. ${ }^{41}$ Appendix Table C.3 provides summary statistics for the variables utilized in the analysis.

\subsection{Empirical Strategy}

We use the following difference-in-differences specification to study the effects of nonattainment on power plant operations:

$$
Y_{i t}=\alpha_{i}+\lambda_{v t}+\theta_{s t}+\beta \text { Nonattain } \text { ct }+\epsilon_{i t}
$$

where $i$ indexes a plant in vintage group $v$ located in county $c$ in state $s$, and $t$ indexes year. In our primary specifications, the vintage groups are pre-1963 plants, 1963-1971 plants, and post-1972 plants (if applicable to the specification). Equation (1) includes plant fixed effects, $\alpha_{i}$, to control for time-invariant plant characteristics. The term $\lambda_{v t}$ represents a vector of vintage-group-by-year fixed effects that allow for differential evolution in operations across different cohorts of plants. Finally, our primary specifications include state-by-year fixed effects, $\theta_{s t}$, to account for any state-level energy or pollution control

\footnotetext{
${ }^{40}$ The distribution of the number of years that a county faced nonattainment between 1972-1994 is displayed in Appendix Figure C.9.

${ }^{41}$ The production function parameter estimates are reported in Appendix Table C.4.
} 
policies implemented either before or after the introduction of the CAA. ${ }^{42}$ However, Figure D.2 documents that the estimates remain similar when excluding state-by-year fixed effects.

The independent variable of interest is Nonattain $_{c t}$, an indicator that takes on the value one if the county is out of attainment with the NAAQS for any pollutant in year t. We also estimate a generalized version of Equation (1) that allows the effects of nonattainment to differ by vintage group. Unless otherwise noted, our estimated coefficients are accompanied by standard errors that are two-way clustered by county and year (Cameron, Gelbach and Miller, 2011).

\section{Impacts of the CAA on Power Plant Operations}

\subsection{Impacts on Output, Inputs, and Productivity, and the Im- portance of an Extended Pre-Regulation Benchmark}

Panel A of Table 1 presents estimates of the impacts of nonattainment on various annual plant-level outcomes from Equation (1). Power plants located in nonattainment counties experienced decreases in pollution-unadjusted total factor productivity (PU-TFP) and output relative to plants located in attainment counties (Panel A, cols. 1, 2). The estimated coefficients are statistically significant and large in magnitude. The negative effect of nonattainment on PU-TFP is due to the fact that declines in plant output were not fully offset by adjustments in inputs (cols. 3-5). In practice, investment in plant generating capacity is essentially irreversible. ${ }^{43}$ Similarly, the number of employees required to operate a plant is largely independent of output levels. ${ }^{44}$ Meanwhile, reductions in plant output may have increased input fuel use per MWh of generation because the new production levels are technically sub-optimal or because plants facing nonattainment may be forced to adjust output levels more frequently.

\footnotetext{
${ }^{42}$ Our primary specifications focus on coal plants built before 1972. For sensitivity analyses that include plants of all fuel types, we include fuel-type-by-year fixed effects that account for input price shocks that might differentially impact plants that burn different types of fuel (i.e., coal, oil, or gas).

${ }^{43}$ The negative effect of nonattainment on capacity reflects a decrease in the rate of growth of installed capacity for plants located in nonattainment counties relative to plants located in attainment counties.

${ }^{44}$ In nonattainment counties, plants may have actually required additional workers whose roles were geared towards environmental compliance (Sheriff, Ferris and Shadbegian, 2019).
} 
To assess the importance of our extended pre-regulation benchmark, we compare the main results to policy estimates based on shorter pre-regulatory sample periods. Figure 1 plots the nonattainment effects estimated for different pre-regulatory sample horizons. Each point on the x-axis denotes the initial sample year; the estimated effect for 1938, for example, coincides with the full sample. Moving rightwards along the x-axis shows how the effects change as we artificially shorten the pre-regulatory sample period used for estimation. For each initial sample year, Figure 1 presents the coefficient estimate and 95 percent confidence interval.

The estimated impact of nonattainment on PU-TFP is negative and statistically significant for samples starting as late as 1962. The effects diminish slightly for samples beginning in the late 1950 s and converge rapidly towards zero for samples after $1963.45,46$ These patterns align with the timing of the 1963 CAA. Specifically, the diminishing treatment effects in the post-1963 period may partly stem from preemptive adjustments, as plants updated expectations regarding future regulatory enforcement. We explore this possibility in more detail in the next subsection.

The patterns in Figure 1 suggest that we would substantially underestimate the productivity effects of the 1970 CAA without an extended pre-regulatory time horizon. These patterns are striking, given that all prior research on the CAA has relied on sample periods beginning after 1963. Indeed, the vast majority of studies have relied on data that begin after the CAA's implementation in 1972. Identification in these studies relies on switches in the county's annual attainment status after 1972. Much of this variation stems from trends in county-level air quality that may have been largely foreseeable by local polluters (e.g., Grosset and Schlenker, 2022).

To explore empirical identification in our setting relative to existing work, Appendix Table D.2 decomposes the overall difference-in-differences estimates into the three components proposed by Goodman-Bacon (2021): (i) the effect of first nonattainment on outcomes using plants that never faced nonattainment as the control group, (ii) the effect for plants first facing nonattainment earlier (later) in the sample using plants first facing

\footnotetext{
${ }^{45}$ Appendix Figure D.1 breaks these results down by plant vintage groups. The estimated effects of nonattainment by first year included in the sample look similar to those in Figure 1 for pre-1963 plants but are small and statistically insignificant for plants built between 1963-1971 regardless of first year included.

${ }^{46}$ In Appendix Table D.1, we document that the impacts of nonattainment on productivity estimated using only the post-1972 sample period are small, positive, and statistically insignificant.
} 
nonattainment later (earlier) in the sample as the control group, and (iii) a within-plant residual component. ${ }^{47}$ The results show that more than half of the estimated impacts stem from comparisons across plants that ever versus never faced nonattainment as opposed to variation in the timing of first nonattainment across counties. These findings are consistent with the persistence of county attainment status documented in Appendix Figure C.9 and Appendix Table C.1. We would not be able to utilize the identifying variation generated from comparisons across plants that never versus ever faced nonattainment without data from before $1972 .{ }^{48}$

\subsection{Effects of the CAA by Plant Vintage}

In this section, we exploring heterogeneity in the effects of the 1970 CAA across different plant vintages. Motivated by the outsized influence of the 1963 CAA on producer expectations and the attenuation of nonattainment-induced decreases in productivity for samples that begin after this year, we focus on plants that opened before versus after 1963.

Panel B of Table 1 presents separate estimates of the impact of nonattainment on power plant operations for plants built before 1963 versus from 1963-1971. The heterogeneity in these effects is striking. For plants built before 1963, the estimated reductions in output and productivity are large and statistically significant. For plants built between 1963 and 1971, the estimates are positive, smaller in magnitude, and not statistically significant. This suggests that anticipatory investments among plants that opened after 1963 may have significantly mitigated the subsequent impacts of nonattainment on plant operations.

In Figure 3, we explore additional cross-vintage heterogeneity in the impact of the CAA. We report separate effects of nonattainment for plants built before 1955, built between 1955-1962, built between 1963-1966, and built between 1967-1971; the four periods that align with the changes in environmental policy described in the background

\footnotetext{
${ }^{47}$ To conform to the specification considered in Goodman-Bacon (2021), we consider a plant as treated for all years after the plant first faced nonattainment ("first nonattainment") rather than using annual county-level attainment status, and we report results based on a strongly balanced panel.

${ }^{48}$ Appendix Table D.3 shows that the impacts of nonattainment are driven by plants that first faced nonattainment between 1972-1977.
} 
section. ${ }^{49}$

Figure 3 provides further evidence that the 1963 CAA constituted a large information shock that drove anticipatory behavior. For pre-1963 vintages, we estimate large and negative effects of nonattainment on PU-TFP, while the effects are positive and insignificant across post-1963 vintages. Interestingly, among post-1963 plants, the estimates become more positive among successive vintages, suggesting a gradual adjustment to the information shock from the 1963 CAA. In contrast, we find no heterogeneity across plants that opened before 1955 versus those that opened from 1955-1962. The similarity in effect size across different cohorts of pre-1963 plants runs counter to the lifecycle channel, which predicts that the effects of nonattainment should change monotonically across plant vintage groups. ${ }^{50}$ Instead, the results are consistent with the information channel, in which the signal provided by the 1963 CAA led to changes in design among new plants that opened after this year.

The uneven distributional impacts across plant vintage groups also point to the potential for first-order reallocative effects. In particular, reductions in output due to nonattainment are concentrated among pre-1963 plants, noting that pre-1963 plants operated at lower average productivity levels than newer plants (see Appendix Figure C.7). As a result, the aggregate productivity losses borne by older vintage plants may have been partially offset by the productivity gains from the reallocation of output away from these older less productive plants. Section 6 explores the quantitative implications of this shift in production on the aggregate productivity cost of the CAA.

\section{Robustness Checks and Heterogeneity Analyses}

To provide evidence on the common trends assumption needed for our difference-indifferences empirical approach, we present event study graphs. These graphs are based on a version of Equation (1) that treats the first year in nonattainment as year zero in event time, and allows the effects of first nonattainment to vary in event time from $\tau \in$ $\{-12,+20\}$ for pre-1963 plants and $\tau \in\{-8,+20\}$ for 1963-1971 plants for which there

\footnotetext{
${ }^{49}$ The corresponding regression results are presented in column 1 of Appendix Table D.4.

${ }^{50}$ These findings also suggest that the 1955 Air Pollution Control Act had little impact on utility investment decisions.
} 
are only nine years of pre-regulation data. ${ }^{51}$ Figure 2 plots these coefficient estimates and their 95 percent confidence intervals. We present event studies for our central outcomeproductivity - separately for plants built before 1963 and plants built between 1963-1971.

Figure 2 highlights three key points. First, in both panels, there is no evidence of differential trends in the years preceding the first year in nonattainment. Second, PUTFP declines for plants built before 1963 in the years following first nonattainment. Third, nonattainment-induced reductions in PU-TFP appear to be persistent. The posttreatment estimated effects on PU-TFP for plants built between 1963-1971, on the other hand, are small in magnitude and are not statistically different from zero.

Appendix Figure D.2 documents the robustness of our event study estimates. The top two panels present event study estimates based on specifications with only plant fixed effects and year fixed effects (i.e., excluding state-by-year fixed effects). The bottom two panels also focus on specifications with only plant fixed effects and year fixed effects, but the event study estimates in these panels are based on the methodology in Callaway and Sant'Anna (2021) that accounts for potential bias when the timing of treatment is staggered and treatment effects are heterogeneous. Across specifications, we continue to find no evidence of differential trends in the years preceding first nonattainment. The post-treatment effects for pre-1963 plants remain negative and similar in magnitude, though we lose statistical significance at the $5 \%$ level for some post-treatment event years. Combined, the results in Appendix Figure D.2 suggest that our empirical identification is driven neither by the inclusion of state-by-year fixed effects or improper comparisons across plants treated earlier versus later.

Appendix Table D.5 replicates the main estimates from Table 1 using an alternative definition of nonattainment for years between 1972-1977. Our primary specifications are based on Greenstone (2002), which assigns county-level attainment status based on monitor readings. However, Cropper et al. (2022) note that the US EPA defined nonattainment from 1972-1977 based on Air Quality Control Regions (AQCRs), regions typically larger than counties. Comfortingly, the estimated impacts of nonattainment remain statistically significant when using the AQCR-based definition of nonattainment,

\footnotetext{
${ }^{51}$ The model is estimated including an indicator for observations with $\tau<-12(\tau<-8)$ when considering pre-1963 (1963-1971) plants; in both cases, we also include an indicator for observations with $\tau>20$. We follow convention in not reporting the estimated coefficients for these "endpoint restrictions" (see Kline, 2012).
} 
with the exception of the average effect on employment. The absolute magnitudes of the effects are larger than those based on the attainment designations from Greenstone (2002), consistent with the findings in Cropper et al. (2022) on the effect of nonattainment on pollution levels. ${ }^{52}$

In Appendix Table D.6, we assess the robustness of the main findings to alternative specifications and samples. The estimated impacts of nonattainment on PU-TFP are similar if we: (i) exclude smaller power plants, (ii) focus only on plants owned by a utility that owns no other coal plants built before 1972 (to address concerns of withinutility spillovers), or (iii) exclude states that had implemented air quality standards before $1967 .^{53}$

The main effects cannot be attributed to differential plant exit across attainment and nonattainment counties after 1972. Instead, we find that plant lifespan is positively correlated with nonattainment status (Appendix Table A.4), consistent with the provisions in the CAA that subjected newer plants to more stringent regulations than plants built before 1972 (Stavins, 2006; Revesz and Lienke, 2016).

In Appendix Table D.7, we assess the sensitivity of our main estimates to alternative specifications for the production function used to estimate PU-TFP. We estimate different measures of PU-TFP based on Translog and Cobb-Douglas production functions, and for models that do and do not include plant materials as production inputs. The estimated impacts are similar across the various specifications.

Our primary analysis focuses on coal plants because burning coal emits far more local pollution than either oil or natural gas (Jaramillo and Muller, 2016). In Appendix Table D.8, we explore how the effects of nonattainment vary by the primary type of fuel burned by the plant: coal, oil, or natural gas. In addition to coal plants, gas plants also appear to suffer a loss in productivity, though this may be due to the forced switch from gas to

\footnotetext{
${ }^{52}$ We focus on the Greenstone (2002) definition in the main text for three reasons: (1) to maintain comparability with previous literature, (2) to maintain consistency with defining attainment status at the county level (as was done post-1977), and (3) to present more conservative estimates of the impacts of nonattainment.

${ }^{53}$ Prior to 1960, there were no state-level air quality or deposited matter standards. By 1966, ten states - California, Colorado, Delaware, Missouri, Montana, New York, Oregon, Pennsylvania, South Carolina, and Texas - had adopted ambient air quality standards for a total of 14 substances, and for deposited matter (Stern, 1982).
} 
coal mandated by the Federal Energy Administration (FEA). ${ }^{54}$

Appendix Table D.9 reports estimates of the impacts of nonattainment on outcomes separately for different pollutant standards. The effect on productivity is driven primarily by noncompliance with ambient ozone and nitrogen dioxide standards. ${ }^{55}$ Interestingly, Greenstone, List and Syverson (2012) also find that the productivity losses from nonattainment in the manufacturing sector are driven by ozone and nitrogen dioxide standards. The share of counties in noncompliance with these two standards remained large throughout our sample period (see Appendix Figure C.3).

\subsection{Lack of Adaptation to the CAA Among Existing Plants}

Did innovation and adaptation among older plants mitigate the costs of environmental regulation over time? The small and statistically insignificant effects of nonattainment for plants built after 1963 suggest that preemptive responses may have mitigated the impacts among newer vintage plants. In this subsection, we exploit the extended lifespan of power plants to explore the longer-run impacts of nonattainment on the operations of older versus newer plants.

Table 2 reports the estimated coefficients from a generalized version of Equation (1) that allows the effects of current nonattainment status to vary with the cumulative number of past years that the plant faced nonattainment. Among plants built before 1963, the estimated reductions in productivity and output are large and persistent (Panel A). For pre-1963 plants that have faced nonattainment for more than 10 years, the estimated reductions in PU-TFP and output from nonattainment are $37 \%$ and $60 \%$, respectively, both of which are substantially larger than the short-run impacts.

Older plants in nonattainment did gradually reduce fuel use and capacity relative to

\footnotetext{
54 "In reaction to the oil embargo of 1973-74, Congress enacted the Energy Supply and Environmental Coordination Act (ESECA). ESECA, which became law on June 22, 1974, mandated the implementation of a national program to conserve petroleum products and natural gas and increase the use of coal by major fuel consumers. (...) Section 2 of ESECA (...) directs FEA to prohibit certain power plants (...) from burning natural gas or petroleum products as a primary energy source. Such prohibitions effectively mandate the use of coal. (...) On June 30, 1975, FEA issued prohibition orders to 74 generating units at 32 utilities" (EPA, 1977, p.19-20, our highlight).

${ }^{55}$ There are separate standards for ozone and nitrogen dioxide $\left(\mathrm{NO}_{2}\right)$. Because ozone is the result of a complicated chemical process that involves $\mathrm{NO}_{2}$, and the vast majority of counties that were in nonattainment for $\mathrm{NO}_{2}$ were also in nonattainment for ozone, we follow Greenstone, List and Syverson (2012) and consider the impacts of nonattainment with either ozone or $\mathrm{NO}_{2}$ standards.
} 
their counterparts in attainment counties. However, older plants facing nonattainment were unable to significantly reduce the number of workers employed at the plant site, which may explain the persistent negative effects on productivity. In contrast, we find no impacts of nonattainment on productivity, output, or inputs for plants built between 1963-1971 in either the short, medium, or long run (Panel B).

What explains the persistent negative effects of nonattainment on plants built before 1963? These findings seemingly contrast with prior research suggesting that innovation and adaptive responses by polluting producers helped mitigate the economic costs of the CAA over time (e.g., Popp, 2003, 2006). Unlike producers in many other sectors, however, existing power plants were severely constrained in their ability to adjust operations. Given the long lifespan of equipment such as boilers and turbines, power plants are difficult to modify after being built, even over the span of decades (Aminov, Shkret and Garievskii, 2016). In addition, retrofit installations of pollution abatement technology were especially costly for existing plants, and "major modifications" risked subjecting these plants to stricter environmental regulation under the New Source Performance Standards (Stavins, 2006; Revesz and Lienke, 2016). Instead, our findings suggest that adaptation occurred primarily through the siting and design of plants built after the 1963 CAA.

\subsection{Alternate Margins of Adjustment to the CAA}

\subsubsection{No Evidence of Production Spillovers from Existing Plants in Nonat- tainment Counties to Existing Plants in Attainment Counties}

Electric utilities may have responded to the CAA by shifting output from existing plants in nonattainment counties to existing plants in attainment counties. The presence of this type of cross-county spillover might lead us to overestimate the effect of nonattainment on output, since this effect may partly reflect a relative rise in output among existing plants in attainment counties.

In this section, we assess whether output from existing plants in attainment counties is affected by nonattainment status in nearby counties. We estimate the following equation for coal plants built before 1972 located in counties that were always in attainment 
between 1972-1994:

$$
\log \left(Y_{i t}\right)=\alpha_{i}+\lambda_{v t}+\beta \text { PropNonAttain } i t+\epsilon_{i t}
$$

where $Y_{i t}$ is the output from plant $i$ in year $t$. The equation includes plant fixed effects $\alpha_{i}$ and vintage-group-by-year fixed effects $\lambda_{v t}$. The independent variable of interest, PropNonAttain $_{i t}$, is the weighted share of counties "near" plant $i$ facing nonattainment in year $t$. The results remain similar whether we define "nearby" based on (1) counties in the same state as plant $i$, or (2) counties in the same state that house existing coal capacity owned by the same utility as plant $i$ in year $t$. Moreover, the results remain similar whether weights are defined based on coal-fired generating capacity or electricity output in 1954. We choose the year 1954 to avoid the weights reflecting any possible effect of the CAA on coal-fired capacity or output. ${ }^{56}$

Table 3 reports the results. We find no evidence of shifts in production from existing coal plants in nonattainment counties to existing coal plants in attainment counties. Indeed, the point estimates, while noisy, are negative whether "nearby" counties are defined based on state or state and utility. Thus, it does not appear that the reductions in output from existing plants in nonattainment counties were offset by increased production from existing plants in attainment counties.

We provide descriptive evidence that the decreased output from existing plants facing nonattainment was instead met by increased production from new plants that opened after 1972 (Appendix Figures C.4 and C.5). Appendix Table D.10 provides suggestive evidence that new fossil fuel and nuclear generating capacity was more likely to be built in states where a larger share of the population lived in nonattainment counties. Together, the results are consistent with previous work suggesting that the CAA induced cross-border shifts in industrial activity (Henderson, 1996; Becker and Henderson, 2000; Gibson, 2019). In the electricity sector, the shift was primarily from existing plants in nonattainment counties to new plants that opened after 1972. Importantly, this type of spillover does not compromise our difference-in-differences estimation strategy, which relies solely on comparisons across existing plants.

\footnotetext{
${ }^{56}$ This independent variable is similar in spirit to the "shift-share" instruments featured most prominently in work on trade and migration (Goldsmith-Pinkham, Sorkin and Swift, 2020).
} 


\subsubsection{Other Margins of Adjustment: Fuel Switching and Scrubbers}

Coal plants can also respond to environmental regulations by switching to "cleaner" fuels. Plants can switch from burning lower-cost bituminous coal with higher sulfur and heat contents to higher-cost sub-bituminous coal with lower sulfur and heat contents. ${ }^{57}$ We assess the importance of this margin of adjustment by estimating the effect of first nonattainment on the log of the annual average coal prices paid by power plants. We focus on first nonattainment rather than nonattainment because in order to switch the type of coal burned, plants typically must sign new long-term coal supply contracts and may make irreversible changes to their boilers (Joskow, 1987).

Table 4 shows that first nonattainment led to increases in the price paid per ton of coal. This effect is driven by plants built before 1963; the effect of first nonattainment on coal prices is not statistically significant for plants built between 1963-1971 (col. 2). The magnitude of the effects do not diminish with the cumulative number of years that the plant faced nonattainment (col. 3), consistent with the evidence in Section 5.3 showing that plants are unable to adapt to reduce the costs of compliance even in the long run.

Plants may also respond to nonattainment by installing pollution abatement technology - flue gas particulate (FGP) collectors or flue gas desulfurization (FGD) units. FGP collectors, such as electrostatic precipitators and fabric filters (colloquially called "baghouses"), remove fly ash from the combustion gases associated with burning coal. FGD units, colloquially called "scrubbers", remove sulfur dioxide emissions from the exhaust of fossil-fuel plants.

Column 1 of Appendix Table A.1 documents that both plants built between 19631971 and plants built after 1972 are more likely to install FGP collectors than plants built before $1963 .^{58}$ This provides suggestive evidence that plants built between 19631971 were better able to adapt to future environmental regulation by installing pollution abatement technology. However, we see from column 2 that 1963-1971 plants were no more likely to install an FGD unit than plants built before 1963. This is consistent with the fact that FGD units were primarily only available after 1972 (see panel (b) of

\footnotetext{
${ }^{57}$ The primary source of sub-bituminous coal in the United States is the Powder River Basin (PRB) in Montana and Wyoming. The delivered price per mmBTU of PRB coal is typically higher than Appalachian bituminous coal, both because transportation costs are typically higher from PRB to the plant and because PRB coal contains less heat energy per ton of coal.

${ }^{58}$ The dependent variable is an indicator equal to one if plant $i$ had installed the relevant technology by year $t$.
} 
Appendix Figure A.2 and Appendix Figure A.5). Plants built after 1972 were far more likely to install an FGD unit than plants built before 1972. This is likely due to the fact that all plants built after 1972 were subject to the much stricter New Source Performance Standards, with coal plants built after 1978 being obligated to install FGD systems.

In Table 5, we explore how first nonattainment impacts the installation of FGD technology. We focus on FGDs because they are primarily installed after 1972, allowing us to assess the impacts of first nonattainment on subsequent retrofit installations of FGDs on plants built before 1972. In contrast, FGPs were sometimes installed well before the 1970 CAA (see panel (a) of Appendix Figure A.2), which implies that the pre-1972 plants without FGP technology by 1972 may constitute a selected sample of plants.

Column 1 of Table 5 suggests that the average impact of first nonattainment on FGD installation is not statistically significant. However, we see from column 2 that plants built before 1963 were more likely to retrofit and install a scrubber; the corresponding effect for plants built between 1963-1971 is not statistically significant. This is consistent with some pre-1963 plants having no recourse other than to install costly FGD technology in order to bring pollution levels into compliance with the NAAQS standards. In contrast, 1963-1971 plants were likely designed and sited with future environmental regulation in mind, and thus may have had other less costly means to reduce pollution levels in response to nonattainment.

We close by performing a back-of-the-envelope calculation of the costs associated with a policy under NSPS that required plants that opened after 1978 to install FGD technology (colloquially, a "scrubber"). We do so by comparing the average cost of installing and operating a scrubber to the estimated cost of switching to cleaner fuel in response to first nonattainment. We estimate that first nonattainment led to a $4.7 \%$ increase in coal prices (Table 4, col. 1), corresponding to an increase in annual fuel costs of $\$ 1.5$ million (2020 USD). This is much smaller than the annualized cost of installing and operating a scrubber incurred by the average plant built between 1978-1994, which is $\$ 8.1$ million (2020 USD). ${ }^{59}$ Given this disparity in costs, it seems likely that many plants would have continued to be built without FGD systems in the absence of the 1978 NSPS requirements.

\footnotetext{
${ }^{59}$ For simplicity, we assume that scrubbers have a 40 -year lifespan, similar to power plants.
} 


\section{Aggregate Effects of the 1970 CAA on PU-TFP}

In Section 5.2, we found significant negative effects of nonattainment on productivity and output, but only for plants built before 1963. Given the large differences in average productivity across plant vintages, the aggregate productivity losses from the $1970 \mathrm{CAA}$ may be mitigated by the reallocation of output from older less productive plants to newer more productive plants.

In this section, we calculate the aggregate productivity cost of nonattainment, accounting for both plant-level productivity losses and cross-plant reallocation of output. We apply the estimated impacts of nonattainment for each vintage group from Section 5.2 to construct the counterfactual annual plant-level output and PU-TFP that would have prevailed in the absence of the NAAQS. The results of this back-of-the-envelope calculation show that the NAAQS led to an annual average productivity decline among coal plants of roughly $2 \%$ over the period 1972-1994. This corresponds to an annual aggregate productivity loss of $\$ 2.6$ billion (2020 USD). ${ }^{60}$ Although sizeable, this economic cost is substantially smaller than the health benefits from improved air quality attributable to the CAA (see reviews by Currie and Walker, 2019; Aldy et al., 2022).

We calculate annual plant-level counterfactual PU-TFP and output for three plant vintage groups: plants built before 1963, plants built between 1963 and 1971, and plants built after 1972. For pre-1963 plants facing nonattainment, the counterfactual values are obtained by multiplying the observed value by the relevant estimate from the top panel of Table 2. ${ }^{61}$ For plants built between 1963-1971 facing nonattainment, we assume that counterfactual output and PU-TFP are equal to their observed values, given the insignificant effects of nonattainment for these plants. We also assume that nonattainmentinduced reductions in output from pre-1963 coal plants were not replaced by increases in output from existing coal plants in attainment counties, consistent with the evidence in Section 5.4.1. Instead, we assume that the decreases in output from pre-1963 plants in nonattainment counties were reallocated proportionally to plants that opened after 1972

\footnotetext{
${ }^{60}$ We obtain this annual aggregate productivity cost by multiplying the annual average reduction in productivity due to nonattainment by the total revenue earned by steam electric utilities in 1970 (Federal Power Commission, 1971).

${ }^{61}$ For example, consider a plant built before 1963 that we observe producing Output ${ }_{i, t}$ with productivity PU-TFP ${ }_{i, t}$ in year $t$. If this plant faced nonattainment in year $t$ and had faced more than 10 years of nonattainment up to that year, its counterfactual output in a world without the NAAQS would be $O_{i, t}^{C}=(1+0.598) \times O_{i, t}$ and its counterfactual productivity would be $\mathrm{PU}_{-T F P}^{C}=(1+0.371) \times \mathrm{PUTFP}_{i, t}$.
} 
within the same census division, based on the suggestive evidence in Appendix Table D. $10 .^{62}$

The impact of the NAAQS on aggregate productivity operates through two channels: (1) decreases in within-plant productivity concentrated among pre-1963 plants in nonattainment counties, and (2) the reallocation of output from pre-1963 plants in nonattainment counties to post-1972 plants. The change in annual output-weighted average productivity is calculated as follows:

$$
\Delta{\overline{\mathrm{PU}}-\mathrm{TFP}_{t}}_{t}=\sum_{i}[\underbrace{\frac{\text { Output }_{i, t}}{\sum_{i} \text { Output }_{i, t}} \cdot \Delta \mathrm{PU}_{\text {TFP }}}_{\text {Within-Plant Efficiency }}+\underbrace{\frac{\Delta \text { Output }_{i, t}}{\sum_{i} \text { Output }_{i, t}} \cdot \mathrm{PU}_{\text {TreP }}}_{\text {Across-Plant Reallocation }_{i t}}]
$$

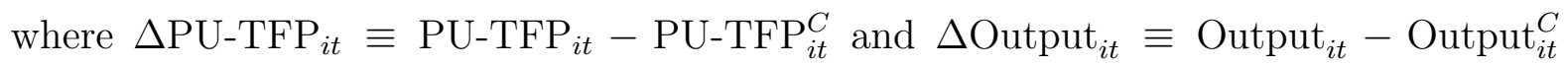
are the changes in PU-TFP and output with the NAAQS versus without the NAAQS. The first term in Equation (3) is the within-plant efficiency effect: existing plants in nonattainment counties have lower productivity due to increased regulatory requirements. The second term is the across-plant reallocation effect, which arises from regulatoryinduced shifts in output from older plants facing nonattainment to newer plants.

Figure 4 plots annual output-weighted average changes in productivity due to changes in within-plant efficiency and across-plant reallocation. The dashed red line shows the negative within-plant efficiency effect over the period 1972-1994. This effect is smaller than the estimates reported in Table 2 because it averages across both the plant-level losses incurred by pre-1963 plants in nonattainment counties and all remaining plants (again, assumed not to incur any productivity losses). The within-plant productivity losses increase through the 1970s. This trend reflects both an increase in the number of nonattainment counties and the evolving effects of nonattainment on productivity documented in Table 2. After 1978, the within-plant losses are fairly stable.

The dotted blue line shows the positive across-plant reallocation effect from 19721994. Pre-1963 plants in nonattainment counties reduced their output. The shortfall in demand due to this nonattainment-induced decline in output was met by increases in output from plants that opened after 1972. Since newer plants were typically more efficient (see Appendix Figures A.7 and C.8), this reallocation contributed to an increase

\footnotetext{
${ }^{62}$ We reallocated within census division rather than state because some states with coal plants built before 1963 did not also have coal plants built after 1972 .
} 
in average national PU-TFP in the power sector. This effect increases over the 1970s as pre-1963 plants in nonattainment further reduce output. After 1980, however, it remains fairly stable.

The solid purple line depicts the aggregate impact of nonattainment on PU-TFP: the sum of the within-plant efficiency effect and the across-plant reallocation effect. The aggregate effects are negative throughout the sample period, and become relatively stable after 1978. Overall, roughly half of the within-plant losses are offset by the reallocation of output.

Together, these findings highlight how reallocation across producers can substantially mitigate the aggregate economic costs of environmental regulation. To the extent that older and less efficient entrenched incumbents emit higher levels of pollution, environmental regulation may accelerate the process of reallocation towards higher productivity entrants. In the case of the 1970 CAA, this reallocation may have also mitigated the adverse consequences of provisions that specify less stringent regulation for incumbents (e.g., List, Millimet and McHone, 2004; Stavins, 2006).

\section{Conclusion}

This paper leverages newly digitized data on power plant operations from 1938 to 1994 to examine the impacts of the 1970 Clean Air Act (CAA) on the U.S. power sector. The long panel includes an extended benchmark period without regulation, allowing us to account for anticipatory responses by electric utilities. We find that nonattainment with the NAAQS led to relatively large reductions in output and productivity, but only among plants that opened before 1963. Both the evolution of the treatment effects across vintages and complementary historical evidence suggest that the information shock generated by the 1963 CAA led utilities to take preemptive actions when building and siting post-1963 plants that ultimately mitigated the productivity costs of regulatory compliance.

The historical experience in the United States may offer guidance to policymakers around the world. Our findings suggest that older plants were unable to adapt operations in response to new environmental regulation, even in the long run. Instead, the economic costs of regulation were mitigated primarily through the reallocation of output across 
plants. As emphasized by Stigler (1971), regulation often generates winners and losers. To the extent that entrenched incumbent producers bear the economic costs of regulatory compliance and have disproportionate political influence, environmental policy may be enacted slowly and carve out exemptions for existing emitters (Stavins, 2006; Revesz and Lienke, 2016). ${ }^{63}$

Our analysis also emphasizes that anticipatory behavior can emerge as a response to decreases in regulatory uncertainty, particularly when the expected costs of compliance are large. ${ }^{64}$ This has relevance across a wide range of policy settings. ${ }^{65}$ Notably, the historical U.S. experience may offer insights for future regulations aimed at addressing the pressing challenges associated with climate change. Our analysis suggests that credible signals of future regulatory oversight can induce substantial and immediate adjustments among producers, especially when these decisions involve costly irreversible investments.

Lastly, our findings highlight the importance of incorporating anticipation and reallocation into future assessments of the costs and benefits of environmental and climate policy. This message may be particularly relevant for policymakers in low- and middleincome countries. Although governments in many of these countries have signaled shifting environmental priorities, there remains considerable uncertainty regarding the timing and details of future regulation (Jayachandran, 2021).

\footnotetext{
${ }^{63}$ Highlighting the importance of political economy, He, Wang and Zhang (2020) find that water quality regulation in China caused large declines in productivity, but only after improvements in water quality were linked to political promotion.

${ }^{64}$ Other efforts to reduce the impacts of government oversight include industry self-regulation (DeMarzo, Fishman and Hagerty, 2005; Charoenwong, Kwan and Umar, 2019), voluntary regulation (Einav et al., 2022), lobbying for less stringent regulation for existing firms (Stavins, 2006; Kang, 2016), as well as actions that undermine the effectiveness of the regulation (Lim and Yurukoglu, 2018; Abito, 2019).

${ }^{65}$ For instance, the Federal Reserve and other central banks around the world often announce targets well in advance of policy actions. These announcements give time for individuals and firms to take anticipatory actions such as obtaining a mortgage or other loans.
} 


\section{References}

Abito, Jose Miguel. 2019. "Measuring the Welfare Gains from Optimal Incentive Regulation." Review of Economic Studies, 87(5): 2019-2048.

ACIR, U.S. Advisory Commission on Intergovernmental Relations. 1981. "The Federal Role in the Federal System: The Dynamics of Growth."

Ackerberg, Daniel A., Kevin Caves, and Garth Frazer. 2015. "Identification Properties of Recent Production Function Estimators." Econometrica, 83(6): 24112451.

Aldy, Joseph E, Maximilian Auffhammer, Maureen Cropper, Arthur Fraas, and Richard Morgenstern. 2022. "Looking back at 50 years of the Clean Air Act." Journal of Economic Literature, 60(1): 179-232.

Aminov, RZ, AF Shkret, and MV Garievskii. 2016. "Estimation of lifespan and economy parameters of steam-turbine power units in thermal power plants using varying regimes." Thermal Engineering, 63(8): 551-557.

Atkinson, Scott E., and Robert Halvorsen. 1976. "Interfuel Substitution in Steam Electric Power Generation." Journal of Political Economy, 84(5): 959-978.

Beach, Brian, and W. Walker Hanlon. 2018. "Coal Smoke and Mortality in an Early Industrial Economy." Economic Journal, 128(615): 2652-2675.

Becker, Randy, and Vernon Henderson. 2000. "Effects of Air Quality Regulations on Polluting Industries." Journal of Political Economy, 108(2): 379-421.

Boisvert, Richard N. 1982. "The Translog Production Function: Its Properties, Its Several Interpretations and Estimation Problems." Mimeo.

Callaway, Brantly, and Pedro HC Sant'Anna. 2021. "Difference-in-differences with multiple time periods." Journal of Econometrics, 225(2): 200-230.

Cameron, Colin A., Jonah B. Gelbach, and Douglas L. Miller. 2011. "Robust inference with multiway clustering." Journal of Business $\&$ Economic Statistics, 29(2): 238-249.

Carlson, Curtis, Dallas Burtraw, Maureen Cropper, and Karen L. Palmer. 2000. "Sulfur Dioxide Control by Electric Utilities: What Are the Gains from Trade?" Journal of Political Economy, 108(6): 1292-1326.

Charoenwong, Ben, Alan Kwan, and Tarik Umar. 2019. "Does Regulatory Jurisdiction Affect the Quality of Investment-Adviser Regulation?" American Economic Review, 109(10): 3681-3712.

Christensen, Laurits R., and William H. Greene. 1976. "Economies of Scale in U.S. Electric Power Generation." Journal of Political Economy, 84(4, Part 1): 655-676. 
Cicala, Steve. 2015. "When Does Regulation Distort Costs? Lessons from Fuel Procurement in US Electricity Generation." American Economic Review, 105(1): 411-444.

Clay, Karen. 2018. "The Environment in American Economic History." The Oxford Handbook of American Economic History, vol. 2, 349.

Clay, Karen, Joshua Lewis, and Edson Severnini. 2016. "Canary in a Coal Mine: Impact of Mid-20th Century Air Pollution Induced by Coal-Fired Power Generation on Infant Mortality and Property Values." NBER Working Paper No. 22155.

Cropper, Maureen L, Nicholas Z Muller, Yongjoon Park, and Victoria PerezZetune. 2022. "The Impact of the Clean Air Act on Particulate Matter in the 1970s." National Bureau of Economic Research.

Currie, Janet, and W. Reed Walker. 2019. "What Do Economists Have to Say about the Clean Air Act 50 Years after the Establishment of the Environmental Protection Agency?" Journal of Economic Perspectives, 33(4): 3-26.

Curtis, E. Mark. 2018. "Who Loses under Cap-and-Trade Programs? The Labor Market Effects of the NOx Budget Trading Program." Review of Economics and Statistics, 100(1): 151-166.

DeMarzo, Peter M., Michael J. Fishman, and Kathleen M. Hagerty. 2005. "SelfRegulation and Government Oversight." Review of Economic Studies, 72(3): 687-706.

de Roux, Nicolás, Marcela Eslava, Santiago Franco, and Eric Verhoogen. 2021. "Estimating Production Functions in Differentiated-Product Industries with Quantity Information and External Instruments." NBER Working Paper \#28323.

Di Maria, Corrado, Ian Lange, and Edwin van der Werf. 2014. "Should we be worried about the green paradox? Announcement effects of the Acid Rain Program." European Economic Review, 69: 143-162.

EIA, Energy Information Administration. 1992. "Electric Plant Cost and Power Production Expenses 1990." Washington, DC: U.S. Department of Energy.

EIA, Energy Information Administration. 2021. "Monthly Energy Review - February 2021." Washington, DC: U.S. Department of Energy.

Einav, Liran, Amy Finkelstein, Yunan Ji, and Neale Mahoney. 2022. "Voluntary Regulation: Evidence from Medicare Payment Reform." Quarterly Journal of Economics, 137(1): 565-618.

EPA, U.S. Environmental Protection Agency. 1973. "Progress in the Prevention and Control of Air Pollution in 1972: Annual Report of the Administrator of the Environmental Protection Agency to the Congress of the United States." Washington, DC: U.S. Environmental Protection Agency.

EPA, U.S. Environmental Protection Agency. 1975. "EPA Enforcement: Two Years of Progress, December 1972 to November 1974 - Air, Water, and Pesticides." Washington, DC: U.S. Environmental Protection Agency. 
EPA, U.S. Environmental Protection Agency. 1976a. "EPA Enforcement: A Progress Report, December 1974 to December 1975 - Air, Noise, Pesticides, and Water." Washington, DC: U.S. Environmental Protection Agency.

EPA, U.S. Environmental Protection Agency. 1976b. "Summary of Particulate and Sulfur Oxide Emission Reductions Achieved Nationwide for Selected Industrial Categories, 1970-1974." Washington, DC: U.S. Environmental Protection Agency, Office of General Enforcement.

EPA, U.S. Environmental Protection Agency. 1976c. "Tall Stacks and the Atmospheric Environment." Research Triangle Park, NC: U.S. Environmental Protection Agency, Office of Air and Waste Management - Office of Air Quality Planning and Standards (EPA-450/3-76-007).

EPA, U.S. Environmental Protection Agency. 1977. "EPA Enforcement: A Progress Report, 1976 - Air, Noise, Water, and Pesticides." Washington, DC: U.S. Environmental Protection Agency.

EPA, U.S. Environmental Protection Agency. 1984. "Project Summary Utility FGD Survey: October 1983 - September 1984." Washington, DC: U.S. Environmental Protection Agency, Office of Air Quality Planning and Standards (EPA-340/1-85-014).

EPA, U.S. Environmental Protection Agency. 1997. "The Benefits and Costs of the Clean Air Act, 1970 to 1990." Washington, DC: U.S. Environmental Protection Agency, Office of Air and Radiation.

Fabrizio, Kira R., Nancy L. Rose, and Catherine D. Wolfram. 2007. "Do Markets Reduce Costs? Assessing the Impact of Regulatory Restructuring on US Electric Generation Efficiency." American Economic Review, 97(4): 1250-1277.

Ferris, Ann E., Ronald J. Shadbegian, and Ann Wolverton. 2014. "The Effect of Environmental Regulation on Power Sector Employment: Phase I of the Title IV SO2 Trading Program." Journal of the Association of Environmental and Resource Economists, 1(4): 521-553.

Fowlie, Meredith. 2010. "Emissions Trading, Electricity Restructuring, and Investment in Pollution Abatement." American Economic Review, 100(3): 837-869.

FPC, Federal Power Commission. 1966. "Steam-Electric Plant Construction Cost and Annual Production Expenses: 1965." Washington, DC: U.S. Government Printing Office.

FPC, Federal Power Commission. 1967. "Steam-Electric Plant Construction Cost and Annual Production Expenses: 1966." Washington, DC: U.S. Government Printing Office.

FPC, Federal Power Commission. 1969. "Steam-Electric Plant Construction Cost and Annual Production Expenses: 1968." Washington, DC: U.S. Government Printing Office. 
FPC, Federal Power Commission. 1972. "Steam-Electric Plant Construction Cost and Annual Production Expenses: 1970." Washington, DC: U.S. Government Printing Office.

GAO, U.S. Government Accountability Office. 1980. "TVA's Clean Air Settlement with EPA (EMD-80-49)." Washington, DC: U.S. Government Accountability Office, Energy and Minerals Division.

Gibson, Matthew. 2019. "Regulation-Induced Pollution Substitution." Review of Economics and Statistics, 101(5): 827-840.

Goldsmith-Pinkham, Paul, Isaac Sorkin, and Henry Swift. 2020. "Bartik instruments: What, when, why, and how." American Economic Review, 110(8): 2586-2624.

Gollop, Frank M., and Mark J. Roberts. 1983. "Environmental regulations and productivity growth: The case of fossil-fueled electric power generation." Journal of Political Economy, 91(4): 654-674.

Gollop, Frank M., and Mark J. Roberts. 1985. "Cost-Minimizing Regulation of Sulfur Emissions: Regional Gains in Electric Power." Review of Economics and Statistics, 67(1): 81-90.

Goodman-Bacon, Andrew. 2021. "Difference-in-differences with variation in treatment timing." Journal of Econometrics, 225(2): 254-277.

Gray, Wayne B, and Ronald J Shadbegian. 2003. "Plant vintage, technology, and environmental regulation." Journal of Environmental Economics and Management, 46(3): 384-402.

Greenstone, Michael. 2002. "The Impacts of Environmental Regulations on Industrial Activity: Evidence from the 1970 and 1977 Clean Air Act Amendments and the Census of Manufacturers." Journal of Political Economy, 110(6): 1175-1219.

Greenstone, Michael, John A. List, and Chad Syverson. 2012. "The Effects of Environmental Regulation on the Competitiveness of U.S. Manufacturing." NBER Working Paper No. 18392.

Grosset, Florian, and Wolfram Schlenker. 2022. "Pushed to Cross the Line: Multiperiod Pollution Standards and the Cost of Environmental Regulation." Mimeo.

Hanlon, W. Walker. 2020. "Coal Smoke, City Growth, and the Costs of the Industrial Revolution." Economic Journal, 130(626): 462-488.

Heblich, Stephan, Alex Trew, and Yanos Zylberberg. 2021. "East-Side Story: Historical Pollution and Persistent Neighborhood Sorting." Journal of Political Economy, 129(5): 1508-1552.

He, Guojun, Shaoda Wang, and Bing Zhang. 2020. "Watering Down Environmental Regulation in China." Quarterly Journal of Economics, 135(4): 2135-2185. 
Henderson, J. Vernon. 1996. "Effects of Air Quality Regulation." American Economic Review, 86(4): 789-813.

Hornbeck, Richard, and Martin Rotemberg. 2019. "Railroads, Reallocation, and the Rise of American Manufacturing." NBER Working Paper \#26594.

Jaramillo, Paulina, and Nicholas Z Muller. 2016. "Air pollution emissions and damages from energy production in the US: 2002-2011." Energy Policy, 90: 202-211.

Jayachandran, Seema. 2021. "How Economic Development Influences the Environment." NBER Working Paper \#29191.

Jensen, Svenn, Kristina Mohlin, Karen Pittel, and Thomas Sterner. 2015. "An introduction to the green paradox: the unintended consequences of climate policies." Review of Environmental Economics and Policy.

Joskow, Paul L., and Nancy L. Rose. 1985. "The Effects of Technological Change, Experience, and Environmental Regulation on the Construction Cost of Coal-Burning Generating Units." RAND Journal of Economics, 16(1): 1-27.

Joskow, P L. 1987. "Contract Duration and Relationship-Specific Investments: Empirical Evidence from Coal Markets." The American Economic Review, 168-185.

Kahn, Matthew E., and Erin T. Mansur. 2013. "Do Local Energy Prices and Regulation Affect the Geographic Concentration of Employment?" Journal of Public Economics, 101: 105-114.

Kang, Karam. 2016. "Policy Influence and Private Returns from Lobbying in the Energy Sector." Review of Economic Studies, 83(1): 269-305.

Keiser, David A., and Joseph S. Shapiro. 2019. "Consequences of the Clean Water Act and the Demand for Water Quality." Quarterly Journal of Economics, 134(1): 349396.

Kline, Patrick. 2012. "The impact of juvenile curfew laws on arrests of youth and adults." American Law and Economics Review, 14(1): 44-67.

Kline, Patrick, and Enrico Moretti. 2014. "Local Economic Development, Agglomeration Economies, and the Big Push: 100 Years of Evidence from the Tennessee Valley Authority." Quarterly Journal of Economics, 129(1): 275-331.

Lemoine, Derek. 2017. "Green Expectations: Current Effects of Anticipated Carbon Pricing." Review of Economics and Statistics, 99(3): 499-513.

Lim, Claire S. H., and Ali Yurukoglu. 2018. "Dynamic Natural Monopoly Regulation: Time Inconsistency, Moral Hazard, and Political Environments." Journal of Political Economy, 126(1): 263-312.

List, John A., Daniel L. Millimet, and Warren McHone. 2004. "The Unintended Disincentive in the Clean Air Act." Advances in Economic Analysis \& Policy, 4(2): Article 2 . 
Lueck, Dean, and Jeffrey A. Michael. 2003. "Preemptive Habitat Destruction under the Endangered Species Act." Journal of Law \& Economics, 46(1): 27-60.

Lyon, Thomas P, and John W Maxwell. 2008. "Corporate social responsibility and the environment: A theoretical perspective." Review of environmental economics and policy, 2(2): 240-260.

Malani, Anup, and Julian Reif. 2015. "Interpreting pre-trends as anticipation: Impact on estimated treatment effects from tort reform." Journal of Public Economics, 124: $1-17$.

Nelson, Randy A., Tom Tietenberg, and Michael R. Donihue. 1993. "Differential Environmental Regulation: Effects on Electric Utility Capital Turnover and Emissions." Review of Economics and Statistics, 75(2): 368-373.

Popp, David. 2003. "Pollution Control Innovations and the Clean Air Act of 1990." Journal of Policy Analysis and Management, 22(4): 641-660.

Popp, David. 2006. "International innovation and diffusion of air pollution control technologies: the effects of NOX and SO2 regulation in the US, Japan, and Germany." Journal of Environmental Economics and Management, 51(1): 46-71.

Puller, Steven L. 2006. "The Strategic Use of Innovation to Influence Regulatory Standards." Journal of Environmental Economics and Management, 52: 690-706.

Revesz, Richard L., and Jack Lienke. 2016. Struggling for Air: Power Plants and the "War on Coal". New York, NY: Oxford University Press.

Roberts, Marc J, and Susan O Farrell. 1978. "The political economy of implementation: The Clean Air Act and stationary sources." Approaches to controlling air pollution, 152: 156-60.

Ryan, Stephen P. 2012. "The Costs of Environmental Regulation in a Concentrated Industry." Econometrica, 80(3): 1019-1061.

Sheriff, Glenn, Ann E. Ferris, and Ronald J. Shadbegian. 2019. "How Did Air Quality Standards Affect Employment at US Power Plants? The Importance of Timing, Geography, and Stringency." Journal of the Association of Environmental and Resource Economists, 6(1): 111-149.

Stavins, Robert N. 2006. "Vintage-Differentiated Environmental Regulation." Stanford Environmental Law Journal, 25(1): 29-63.

Stern, Arthur C. 1982. "History of Air Pollution Legislation in the United States." Journal of the Air Pollution Control Association, 32(1): 44-61.

Stigler, George J. 1971. "The Theory of Economic Regulation." The Bell Journal of Economics and Management Science, 2(1): 3-21. 
Tschofen, Peter, Inês L Azevedo, and Nicholas Z Muller. 2019. "Fine particulate matter damages and value added in the US economy." Proceedings of the National Academy of Sciences, 116(40): 19857-19862.

Van der Ploeg, Frederick, and Cees Withagen. 2015. "Global warming and the green paradox: A review of adverse effects of climate policies." Review of Environmental Economics and Policy. 


\section{Figures and Tables}

Figure 1: Impacts of Nonattainment on PU-TFP by Initial Sample Year

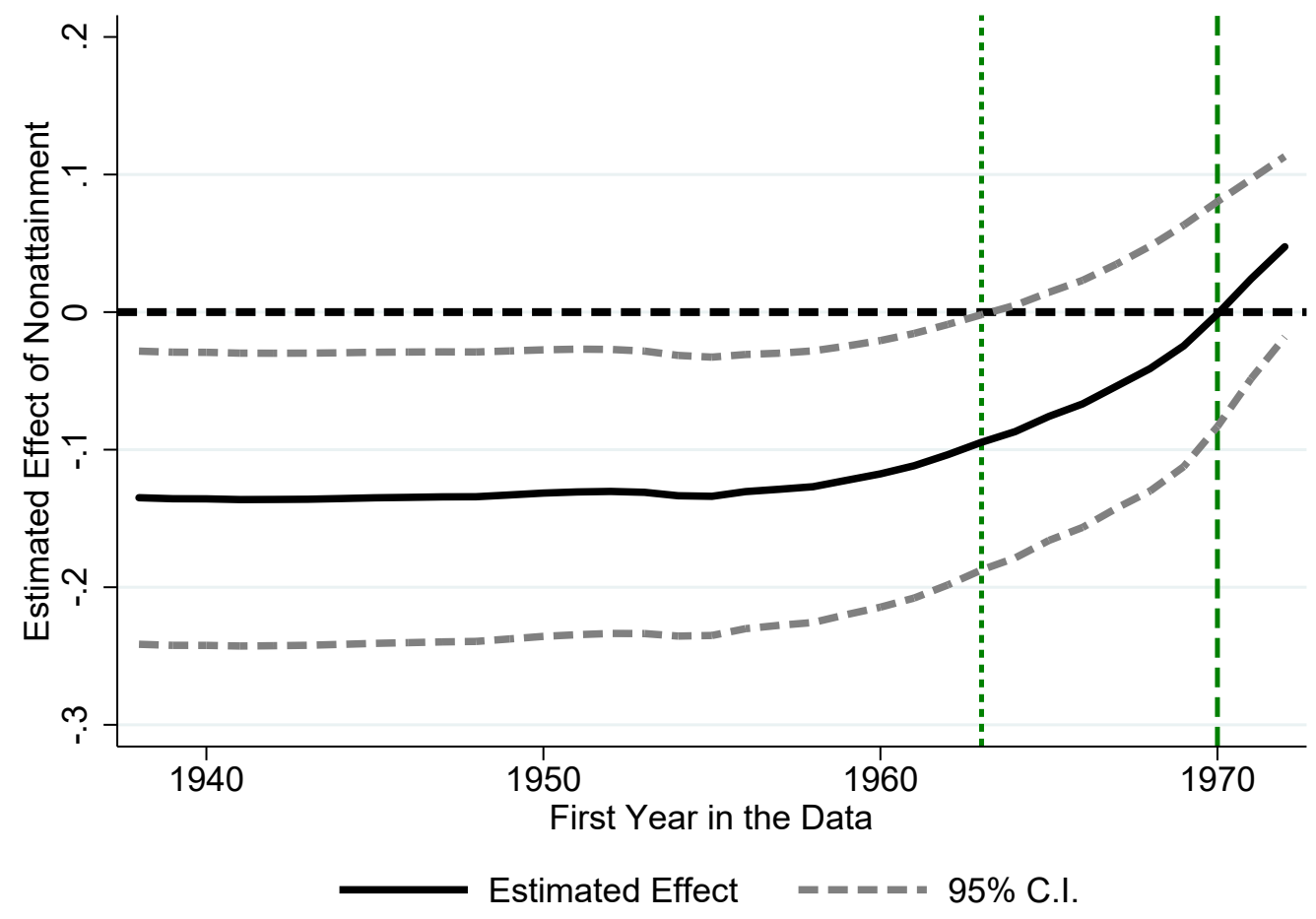

Notes: This figure displays the estimated impacts of nonattainment on the log of pollutionunadjusted total factor productivity (PU-TFP) by initial sample year. Namely, for initial year $\mathrm{X}$ on the $\mathrm{X}$-axis, we artificially restrict the sample period used to estimate the relevant effect to X-1994 (e.g., the effect for initial year 1950 is estimated using data from 1950-1994). We estimate these effects using only data from coal plants built before 1972. The short-dashed green vertical line represents the passage of the Clean Air Act of 1963 and the dashed green vertical line represents the Clean Air Act of 1970. All specifications include plant fixed effects, state by year fixed effects, and vintage group by year fixed effects; plants built before 1963 are in vintage group 1 while plants built between 1963-1971 are in vintage group 2 . The $95 \%$ confidence intervals reported in the figure are based on standard errors that are two-way clustered by county and year. 
Figure 2: Event Study Analysis of the Impacts of First Year in Nonattainment on Power Plant Productivity

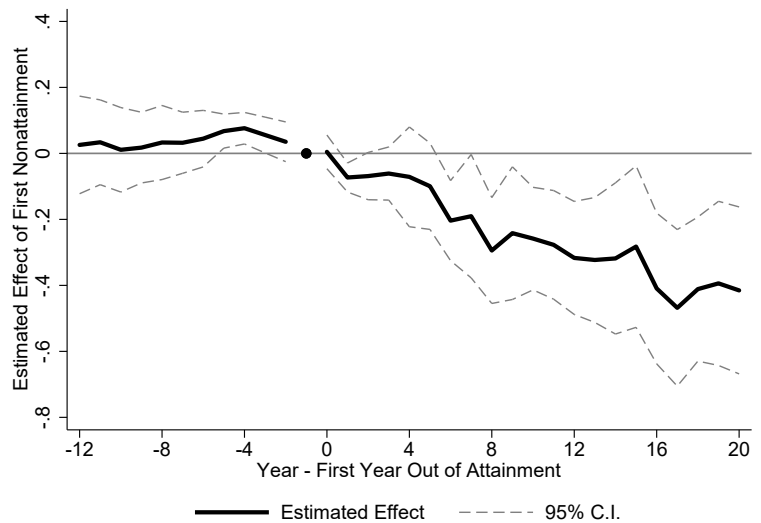

(a) Log PU-TFP, Built Before 1963

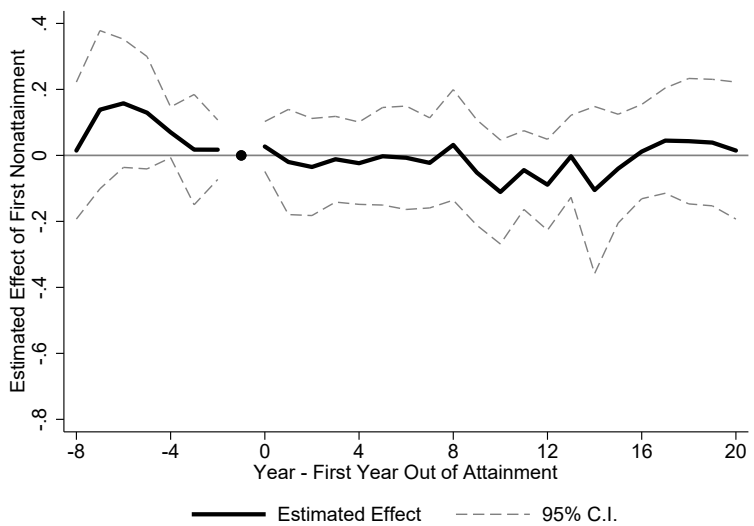

(b) Log PU-TFP, Built Between 1963-1971

Notes: This event study figure plots the estimated effect of first nonattainment on the log of pollution-unadjusted total factor productivity (PU-TFP) separately for each event year. The period of analysis is 1938-1994. All specifications include plant fixed effects and state-by-year fixed effects. The 95\% confidence intervals reported in these figures are based on standard errors that are two-way clustered by county and year. The left panel is estimated using coal plants built before 1963 and the right panel focuses on coal plants built between 1963-1971. 
Figure 3: Estimated Effect of Nonattainment on PU-TFP by Initial Year of Operation

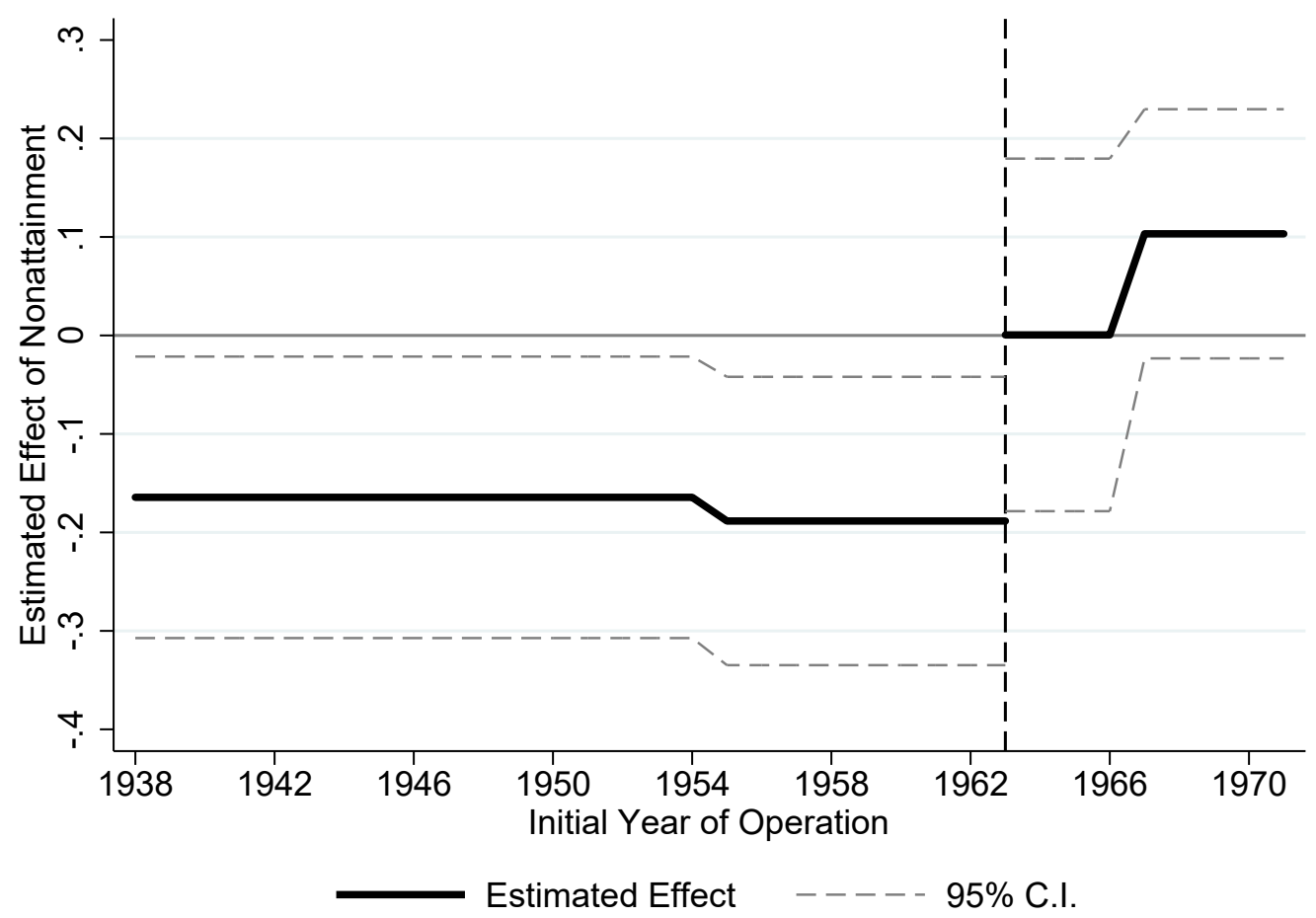

Notes: This figure plots the estimated effect of nonattainment on the log of pollution-unadjusted total factor productivity (PU-TFP) by initial year of plant operation. We estimate separate effects of nonattainment for plants built before 1955, between 1955-1962, between 1963-1967, and after 1967; the estimation considers all coal plants that were built before 1972. The vertical dashed line represents the passage of the 1963 Clean Air Act, which provided the federal government with limited authority to "control" air pollution, but served primarily as a signal of impending federal regulation. We can reject the null hypothesis that the coefficient for the 1955-1962 plants is equal to the coefficient for the 1963-1967 plants at the 10\% level (p-value of 0.092). The estimates presented in this figure correspond to the regression results reported in Appendix Table D.4. The regression specification includes plant fixed effects, state by year fixed effects, and vintage group by year fixed effects; plants built before 1955, between 1955-1962, between 1963-1967, and after 1967 are in vintage groups 1, 2, 3, and 4 respectively. The $95 \%$ confidence intervals reported in this figure are based on standard errors that are two-way clustered by county and year. 
Figure 4: Nationwide Effects of the 1970 CAA on Power Plant Productivity

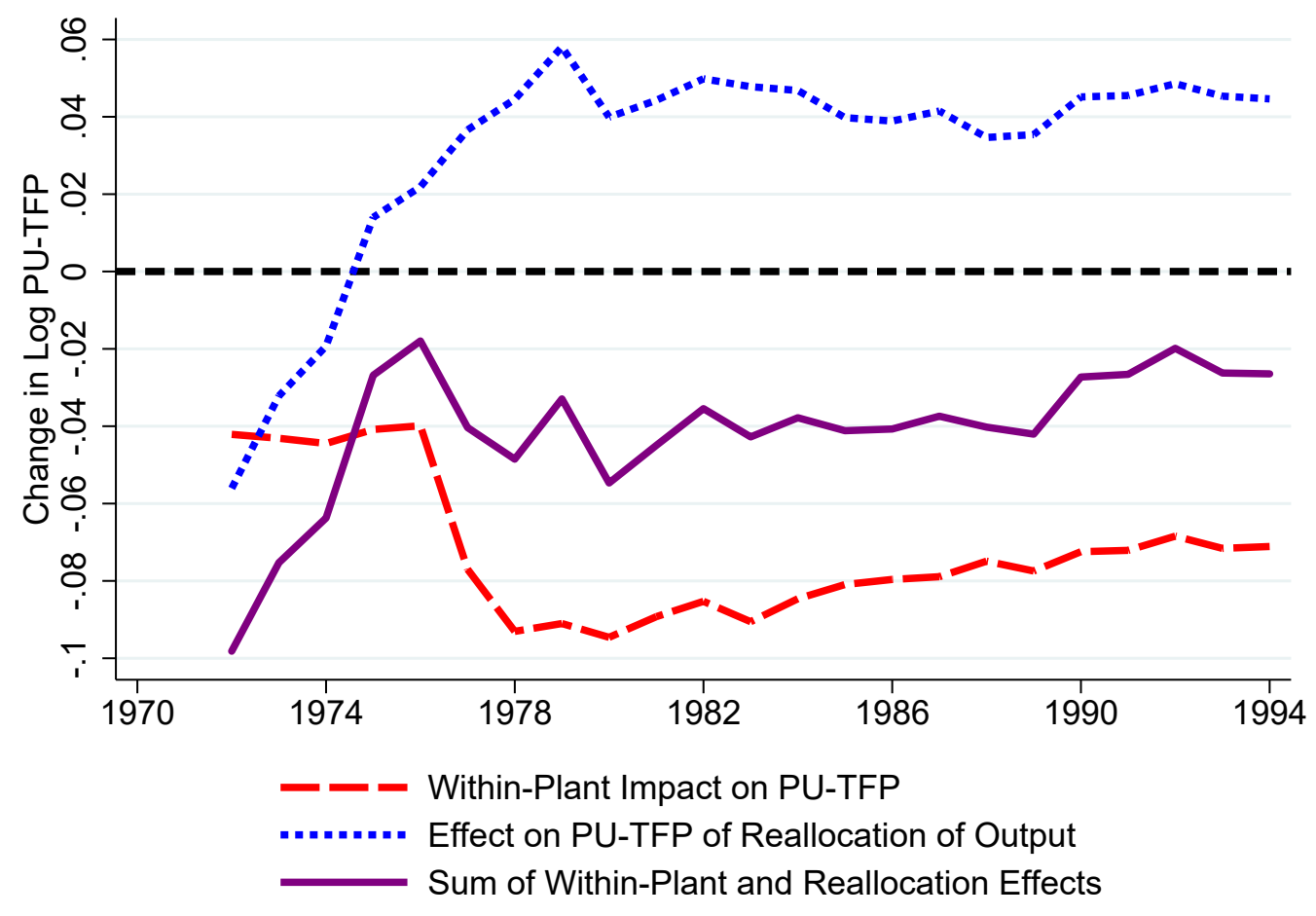

Notes: This figure depicts the estimated nationwide effects of the NAAQS on power plant productivity calculated using the methodology described in Section 6. The impact of the NAAQS on the annual output-weighted average of the log of pollution-unadjusted total factor productivity (PUTFP), represented by the solid purple line, is the sum of two offsetting effects. The long-dashed red line shows the negative within-plant efficiency effect over 1972-1994, which reflects the fact that nonattainment reduces the productivity of plants built before 1963 (see Table 2, Panel A, column 1). The short-dashed blue line shows the positive across-plant reallocative effect, which arises from shifts in output from pre-1963 plants facing nonattainment to plants built after 1972 (see Appendix Table D.10). 
Table 1: Impacts of Nonattainment on Power Plant Operations from 1938-1994

\begin{tabular}{|c|c|c|c|c|c|}
\hline Dep. Var. (in Logs): & $\begin{array}{c}(1) \\
\text { PU-TFP }\end{array}$ & $\begin{array}{c}(2) \\
\text { Output }\end{array}$ & $\begin{array}{c}(3) \\
\text { Fuel Use }\end{array}$ & $\begin{array}{c}(4) \\
\text { No. Employees }\end{array}$ & $\begin{array}{c}(5) \\
\text { Capacity }\end{array}$ \\
\hline \multicolumn{6}{|l|}{ Panel A. Average Effects } \\
\hline Nonattainment & $\begin{array}{c}-0.135^{* *} \\
(0.054)\end{array}$ & $\begin{array}{c}-0.238^{* * *} \\
(0.081)\end{array}$ & $\begin{array}{c}-0.221^{* * *} \\
(0.075)\end{array}$ & $\begin{array}{c}-0.084^{* *} \\
(0.039)\end{array}$ & $\begin{array}{c}-0.161^{* * *} \\
(0.057)\end{array}$ \\
\hline $\mathrm{R}^{2}$ & 0.707 & 0.834 & 0.781 & 0.861 & 0.905 \\
\hline \multicolumn{6}{|l|}{ Panel B. Effects by Plant Vintage } \\
\hline $\mathrm{NA} \times 1[$ Built Before 1963] & $\begin{array}{c}-0.172^{* * *} \\
(0.061)\end{array}$ & $\begin{array}{c}-0.283^{* * *} \\
(0.090)\end{array}$ & $\begin{array}{c}-0.271^{* * *} \\
(0.084)\end{array}$ & $\begin{array}{c}-0.098^{* *} \\
(0.043)\end{array}$ & $\begin{array}{c}-0.179^{* * *} \\
(0.064)\end{array}$ \\
\hline NA $\times 1$ [Built Between 1963-1971] & $\begin{array}{c}0.064 \\
(0.059)\end{array}$ & $\begin{array}{c}0.004 \\
(0.084)\end{array}$ & $\begin{array}{c}0.049 \\
(0.093)\end{array}$ & $\begin{array}{l}-0.008 \\
(0.056)\end{array}$ & $\begin{array}{l}-0.066 \\
(0.060)\end{array}$ \\
\hline $\mathrm{R}^{2}$ & 0.708 & 0.834 & 0.781 & 0.861 & 0.905 \\
\hline Plant FE & $\mathrm{Y}$ & $\overline{\mathrm{Y}}$ & $\overline{\mathrm{Y}}$ & $\overline{\mathrm{Y}}$ & $\bar{Y}$ \\
\hline State By Year FE & Y & Y & $\mathrm{Y}$ & $\mathrm{Y}$ & $\mathrm{Y}$ \\
\hline Vintage Group By Year FE & $\mathrm{Y}$ & $\mathrm{Y}$ & Y & Y & Y \\
\hline Mean Dep. Var. & 7.007 & 0.653 & 16.307 & 4.779 & 5.631 \\
\hline Number of Obs. & 12,757 & 12,757 & 12,757 & 12,757 & 12,757 \\
\hline Number of Plants & 373 & 373 & 373 & 373 & 373 \\
\hline
\end{tabular}

Notes: This table reports the impacts of nonattainment on power plant operations over the period 1938-1994. The unit of observation for the regressions in this table is plant-year, and the estimation considers all coal plants that were built before 1972. Panel A estimates how annual plant-level outcomes change with the attainment status of the county where the plant is located. Panel B estimates the impact of nonattainment on outcomes separately for plants built before 1963 versus plants built between 1963-1971. For all specifications, "nonattainment" is defined as the county being out of attainment with the NAAQS for any pollutant in the year. All specifications include plant fixed effects, state by year fixed effects, and vintage group by year fixed effects; plants built before 1963 are in vintage group 1 while plants built between 1963-1971 are in vintage group 2. PUTFP stands for pollution-unadjusted total factor productivity, and NA for nonattainment. Standard errors in parentheses are two-way clustered by county and year. ${ }^{* * *}$ denotes statistical significance at the $1 \%$ level, ${ }^{* *}$ at the $5 \%$ level, and $*$ at the $10 \%$ level. 
Table 2: Impacts of Nonattainment by Vintage and Years in Nonattainment

\begin{tabular}{|c|c|c|c|c|c|}
\hline Dep. Var. (in Logs): & $\begin{array}{c}(1) \\
\text { PU-TFP }\end{array}$ & $\begin{array}{c}(2) \\
\text { Output }\end{array}$ & $\begin{array}{c}(3) \\
\text { Fuel Use }\end{array}$ & $\begin{array}{c}(4) \\
\text { No. Employees }\end{array}$ & $\begin{array}{c}(5) \\
\text { Capacity }\end{array}$ \\
\hline \multicolumn{6}{|c|}{ Panel A. Effects for Plants Built Before 1963} \\
\hline Years in NA $\leq 5$ & $\begin{array}{l}-0.097 \\
(0.059)\end{array}$ & $\begin{array}{l}-0.156 \\
(0.098)\end{array}$ & $\begin{array}{l}-0.156^{*} \\
(0.090)\end{array}$ & $\begin{array}{l}-0.005 \\
(0.052)\end{array}$ & $\begin{array}{l}-0.094 \\
(0.072)\end{array}$ \\
\hline Years in NA $\in[6,10]$ & $\begin{array}{c}-0.304^{* * *} \\
(0.089)\end{array}$ & $\begin{array}{c}-0.476^{* * *} \\
(0.138)\end{array}$ & $\begin{array}{c}-0.409^{* * *} \\
(0.132)\end{array}$ & $\begin{array}{l}-0.112 \\
(0.069)\end{array}$ & $\begin{array}{c}-0.246^{* *} \\
(0.095)\end{array}$ \\
\hline Years in NA > 10 & $\begin{array}{c}-0.371^{* * *} \\
(0.113)\end{array}$ & $\begin{array}{c}-0.598^{* * *} \\
(0.172)\end{array}$ & $\begin{array}{c}-0.577^{* * *} \\
(0.157)\end{array}$ & $\begin{array}{l}-0.108 \\
(0.093)\end{array}$ & $\begin{array}{c}-0.396^{* * *} \\
(0.123)\end{array}$ \\
\hline $\begin{array}{l}\mathrm{R}^{2} \\
\text { Mean of Dep. Var. } \\
\text { Number of Obs. } \\
\text { Number of Plants }\end{array}$ & $\begin{array}{c}0.685 \\
0.566 \\
11,066 \\
305\end{array}$ & $\begin{array}{c}0.813 \\
6.856 \\
11,066 \\
305\end{array}$ & $\begin{array}{c}0.760 \\
16.164 \\
11,066 \\
305\end{array}$ & $\begin{array}{c}0.850 \\
4.768 \\
11,066 \\
305\end{array}$ & $\begin{array}{c}0.894 \\
5.507 \\
11,066 \\
305\end{array}$ \\
\hline \multicolumn{6}{|c|}{ Panel B. Effects for Plants Built Between 1963-1971 } \\
\hline Years in NA $\leq 5$ & $\begin{array}{l}-0.101 \\
(0.067)\end{array}$ & $\begin{array}{l}-0.163 \\
(0.096)\end{array}$ & $\begin{array}{l}-0.044 \\
(0.107)\end{array}$ & $\begin{array}{l}-0.093 \\
(0.064)\end{array}$ & $\begin{array}{l}-0.058 \\
(0.073)\end{array}$ \\
\hline Years in NA $\in[6,10]$ & $\begin{array}{c}0.002 \\
(0.090)\end{array}$ & $\begin{array}{l}-0.030 \\
(0.129)\end{array}$ & $\begin{array}{c}0.052 \\
(0.138)\end{array}$ & $\begin{array}{l}-0.081 \\
(0.100)\end{array}$ & $\begin{array}{l}0.006 \\
(0.102)\end{array}$ \\
\hline Years in NA > 10 & $\begin{array}{l}-0.033 \\
(0.092)\end{array}$ & $\begin{array}{l}-0.107 \\
(0.139)\end{array}$ & $\begin{array}{l}-0.037 \\
(0.144)\end{array}$ & $\begin{array}{l}-0.072 \\
(0.128)\end{array}$ & $\begin{array}{l}-0.054 \\
(0.115)\end{array}$ \\
\hline $\mathrm{R}^{2}$ & 0.820 & 0.940 & 0.896 & 0.944 & 0.958 \\
\hline Mean of Dep. Var. & 1.212 & 8.000 & 17.246 & 4.888 & 6.464 \\
\hline Number of Obs. & 1,691 & 1,691 & 1,691 & 1,691 & 1,691 \\
\hline Number of Plants & 68 & 68 & 68 & 68 & 68 \\
\hline Plant FE & $\overline{\mathrm{Y}}$ & $\overline{\mathrm{Y}}$ & $\overline{\mathrm{Y}}$ & $\overline{\mathrm{Y}}$ & 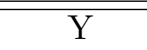 \\
\hline State By Year FE & $\mathrm{Y}$ & $\mathrm{Y}$ & $\mathrm{Y}$ & $\mathrm{Y}$ & $\mathrm{Y}$ \\
\hline Vintage Group By Year FE & $\mathrm{Y}$ & $\mathrm{Y}$ & $\mathrm{Y}$ & $\mathrm{Y}$ & $\mathrm{Y}$ \\
\hline
\end{tabular}

Notes: This table reports estimates of the impact of nonattaiment on power plant operations separately for bins defined by the cumulative number of years that a plant has faced nonattainment. The unit of observation for the regressions in this table is plant-year. For both panels, we interact the indicator for nonattainment with three bins defined by whether the plant has cumulatively faced nonattainment in five or fewer years, six to ten years, or more than ten years as of the year-ofsample. We focus on coal plants built before 1963 in the top panel while the bottom panel considers coal plants built between 1963-1971. All specifications include plant fixed effects and state by year fixed effects. PU-TFP stands for pollution-unadjusted total factor productivity, and NA for nonattainment. Standard errors in parentheses are two-way clustered by county and year. *** denotes statistical significance at the $1 \%$ level, ${ }^{* *}$ at the $5 \%$ level, and ${ }^{*}$ at the $10 \%$ level. 
Table 3: Spillover Impacts of Nonattainment in Nearby Counties on Log Output

\begin{tabular}{lcccc}
\hline \hline & $(1)$ & $(2)$ & $(3)$ & $(4)$ \\
Dependent Variable: Log Output & State & Utility & State & Utility \\
Capacity-Weighted Spillover NA & -0.182 & -0.061 & & \\
& $(0.181)$ & $(0.201)$ & & \\
& & & & \\
Output-Weighted Spillover NA & & & -0.193 & -0.026 \\
& & & $(0.189)$ & $(0.218)$ \\
$\mathrm{R}^{2}$ & & & & \\
Mean of Dep. Var. & 0.864 & 0.845 & 0.864 & 0.845 \\
Number of Obs. & 6.435 & 6.360 & 6.435 & 6.360 \\
Number of Plants & 2,912 & 2,445 & 2,912 & 2,445 \\
Plant FE & 112 & 87 & 112 & 87 \\
Vintage Group By Year FE & $\mathrm{Y}$ & $\mathrm{Y}$ & $\mathrm{Y}$ & $\mathrm{Y}$ \\
\hline \hline
\end{tabular}

Notes: This table tests whether the output of plants in attainment counties varies with measures of the annual nonattainment status of nearby counties. The unit of observation for all regressions is plant-year, considering only coal plants built before 1972 that never faced nonattainment between 1972-1994. The outcome considered in all columns is the log of annual plant-level output. The independent variable of interest is an annual weighted average share of nearby counties in nonattainment, focusing on counties: (1) in the same state (Columns 1 and 3), or (2) in the same state and home to an existing coal plant owned by the same utility (Columns 2 and 4 ). The weights are based on county-level coal-fired generating capacity in 1954 for Columns 1-2 and county-level coal-fired output in 1954 for Columns 3-4. All specifications include plant fixed effects and vintage group by year fixed effects; plants built before 1963 are in vintage group 1 while plants built between 1963-1971 are in vintage group 2. Standard errors in parentheses are two-way clustered by state and year. ${ }^{* * *}$ denotes statistical significance at the $1 \%$ level, ${ }^{* *}$ at the $5 \%$ level, and ${ }^{*}$ at the $10 \%$ level. 
Table 4: Impact of First Nonattainment on Log Coal Prices

\begin{tabular}{|c|c|c|c|}
\hline Dep. Var.: Log Coal Price & (1) & (2) & (3) \\
\hline First NA & $\begin{array}{l}0.047^{\text {** }} \\
(0.020)\end{array}$ & & \\
\hline First NA $\times 1$ [Built Before 1963] & & $\begin{array}{l}0.050^{* *} \\
(0.024)\end{array}$ & \\
\hline First NA $\times 1$ [Built Between 1963-1971] & & $\begin{array}{c}0.035 \\
(0.024)\end{array}$ & \\
\hline First $\mathrm{NA} \times 1[$ Years in $\mathrm{NA} \leq 5]$ & & & $\begin{array}{c}0.034^{*} \\
(0.018)\end{array}$ \\
\hline First NA $\times 1[$ Years in $N A \in[6,10]]$ & & & $\begin{array}{c}0.072^{* * *} \\
(0.026)\end{array}$ \\
\hline First NA $\times 1$ [Years in $\mathrm{NA}>10]$ & & & $\begin{array}{c}0.097^{* * *} \\
(0.034)\end{array}$ \\
\hline $\mathrm{R}^{2}$ & 0.913 & 0.913 & 0.913 \\
\hline Mean of Dep. Var. & 3.624 & 3.624 & 3.624 \\
\hline Number of Obs. & 11,432 & 11,432 & 11,432 \\
\hline Number of Plants & 371 & 371 & 371 \\
\hline Plant FE & $\mathrm{Y}$ & $\mathrm{Y}$ & $\mathrm{Y}$ \\
\hline State By Year FE & Y & Y & Y \\
\hline Vintage Group By Year FE & $\mathrm{Y}$ & Y & Y \\
\hline
\end{tabular}

Notes: This table presents the estimated impact of first nonttainment on the log of coal prices per ton. The unit of observation for the regressions in this table is plant-year, focusing on coal plants built before 1972. All specifications include plant fixed effects, state by year fixed effects, and vintage group by year fixed effects; plants built before 1963 are in vintage group 1 while plants built between 1963-1971 are in vintage group 2. In Column 2, we interact first nonattainment with two indicators denoting whether the plant was built before 1963 versus built between 1963-1971. In Column 3, we consider first nonattainment interacted with three indicators denoting whether the cumulative number of years that the plant has faced nonattainment up to the year-of-sample was less than 5 years, between 6-10 years, or more than 10 years. Standard errors in parentheses are two-way clustered by county and year. *** denotes statistical significance at the $1 \%$ level, ${ }^{* *}$ at the $5 \%$ level, and $*$ at the $10 \%$ level. 
Table 5: Impact of First Nonattainment on the Installation of FGD Technology

Dep. Var. 1[FGD]

First NA

First NA $\times 1$ [Built Before 1963]

First NA $\times 1[$ Built Between 1963-1971]

$\mathrm{R}^{2}$

Mean of Dep. Var.

Number of Obs.

Number of Plants

Plant FE

State By Year FE

Vintage Group By Year FE
0.014

$(0.016)$

$(1)$

$(2)$

\begin{tabular}{cc} 
& $0.034^{* *}$ \\
& $(0.016)$ \\
& -0.074 \\
& $(0.047)$ \\
& \\
0.619 & 0.621 \\
0.029 & 0.029 \\
12,757 & 12,757 \\
373 & 373 \\
$\mathrm{Y}$ & $\mathrm{Y}$ \\
$\mathrm{Y}$ & $\mathrm{Y}$ \\
$\mathrm{Y}$ & $\mathrm{Y}$ \\
\hline
\end{tabular}

Notes: This table presents regression results measuring whether the installation of flue gas desulfurization (FGD) technology is impacted by first nonattainment. The unit of observation for these regressions is plant-year, focusing on coal plants built before 1972. The dependent variable is an indicator variable that is equal to one if the plant has at least one FGD system installed by the year-of-sample. The indicator variable "First NA" is equal to one for any year on or after the first year that the plant faced nonattainment with the NAAQS for any pollutant. The specifications include plant fixed effects, state by year fixed effects, and vintage group by year fixed effects; plants built before 1963 are in vintage group 1 while plants built between 1963-1971 are in vintage group 2. Standard errors in parentheses are two-way clustered by county and year. *** denotes statistical significance at the $1 \%$ level, ${ }^{* *}$ at the $5 \%$ level, and $*$ at the $10 \%$ level. 


\title{
Online Appendix (Not For Publication)
}

\section{"Impacts of the Clean Air Act on the Power Sector from 1938-1994: Anticipation and Adaptation"}

\author{
Karen Clay, Akshaya Jha, \\ Joshua Lewis, and Edson Severnini*
}

This online appendix provides additional information supporting the description and discussion of the setting, data, methods, and results. Appendix Section A presents additional background information. Appendix Section $B$ more fully develops the conceptual framework included in the paper. Appendix Section $C$ provides further details on the data sources and construction of the final dataset, and presents additional descriptive figures and tables. Appendix Section D reports results from a variety of robustness checks and sensitivity analyses.

\footnotetext{
*Karen Clay: Carnegie Mellon University (Heinz College) and NBER, 4800 Forbes Avenue, Pittsburgh, PA 15213. Email: kclay@andrew.cmu.edu. Akshaya Jha: Carnegie Mellon University (Heinz College), 4800 Forbes Avenue, Pittsburgh, PA 15213. Email: akshayaj@andrew.cmu.edu. Joshua Lewis: Université de Montréal, 3150, rue Jean-Brillant, Montréal, QC, H3T 1N8. Email: joshua.lewis@umontreal.ca. Edson Severnini: Carnegie Mellon University (Heinz College), IZA and NBER, 4800 Forbes Avenue, Pittsburgh, PA 15213. Email: edsons@andrew.cmu.edu.
} 


\section{A Additional Background Information}

This appendix section provides further information supporting the description of the historical setting in Section 2. Appendix Section A.1 presents the figures and tables mentioned in the text while Appendix Section A.2 provides historical evidence on how one large electric utility responded to the 1970 Clean Air Act. This appendix section includes the figures and tables outlined below.

- Figure A.1. Trends in Plant Capacity and Stack Height

- Figure A.2. Histogram of First Year with FGD or FGP

- Figure A.3. Patents Related to Power Systems and Electrical Lighting

- Figure A.4 Real Construction Cost Index For Coal-Fired Power Plants

- Figure A.5. Trends in Scrubber Adoption

- Figure A.6. Trends in Total Suspended Particulates by County Attainment Status

- Figure A.7 Trends in Power Plant Thermal Efficiency

- Table A.1. Installation of FGD and FGP Technology By Plant Vintage

- Table A.2. Where Electric Utilities Site Plants Before and After the Clean Air Act

- Table A.3. Pollution Abatement Strategies: The Case of the Tennessee Valley Authority

- Table A.4. Number of Years in Operation By County Attainment Status 


\section{A.1 Additional Background Figures and Tables}

The figures and tables in this appendix subsection provide information on a variety of actions taken by electric utilities aimed at reducing pollution emissions from power plants. Appendix Figure A.1 shows that the electricity generating capacity of the average power plant grew beginning in 1950. Electric utilities also increasingly put taller smokestacks on their plants to send emissions farther away. Appendix Figure A.2 depicts histograms of the year of adoption of flue gas particulate (FGP) collectors and flue gas desulfurization (FGD) technology. Several plants adopted FGP collectors even before 1950, but FGD technology only became commercially available in the early 1970s. Appendix Figure A.3 provides evidence suggesting that the number of patents pertaining to power systems increases with the passage of the Clean Air Act of 1963. Appendix Figure A.4 depicts an index for real construction costs of fossil fuel power plants. Appendix Figure A.5 shows that power plants ramp up efforts to install FGD technology (i.e., scrubbers) rapidly in the 1970s, after the passage of the $1970 \mathrm{CAA}$ and its amendments in 1977. Appendix Figure A.6 displays trends in the concentration levels of total suspended particulates (TSP). Lastly, Appendix Figure A.7 displays the national average thermal efficiency of fossil-fuel steam-electric plants over 1938-1994.

Appendix Table A.1 documents that: (1) both plants built between 1963-1971 and plants built after 1972 are more likely to install FGP technology than plants built before 1963, but (2) only post-1972 plants are more likely to install FGD systems than pre-1963 plants. The estimates in Appendix Table A.2 suggest that electric utilities chose to avoid locations with pollution monitors when siting fossil-fuel power plants after the passing of the 1963 CAA. Appendix Table A.3 lists the different strategies to comply with the CAA employed by the Tennessee Valley Authority. Appendix Table A.4 provides descriptive evidence suggesting that electric utilities kept older plants facing nonattainment in operation longer to avoid building new plants that would be subject to stricter environmental regulations regardless of attainment status.

\section{A.2 Tennessee Valley Authority: An Example}

To illustrate the variety of strategies used by electric utilities to reduce emissions, we present the case of the ten coal-fired power plants owned by the Tennessee Valley Au- 
thority (TVA). These plants were built before 1972, but only complied with the 1970 Clean Air Act (CAA) after TVA and EPA reached a settlement in 1979-80 (GAO, 1980). Appendix Table A.3 shows that many plants ended up switching to coal with lower sulfur content. Several plants combined that strategy with coal washing, electrostatic precipitators, baghouses, and scrubbers. The U.S. Government Accountability Office estimated that the total cost of the consent decree over the lifespan of the projects was over $\$ 14$ billion (2020 USD). Capital costs comprised 14\% of that amount, operating and maintenance costs $30 \%$, and the incremental fuel costs $56 \%$. 
Figure A.1: Trends in Plant Capacity and Stack Height

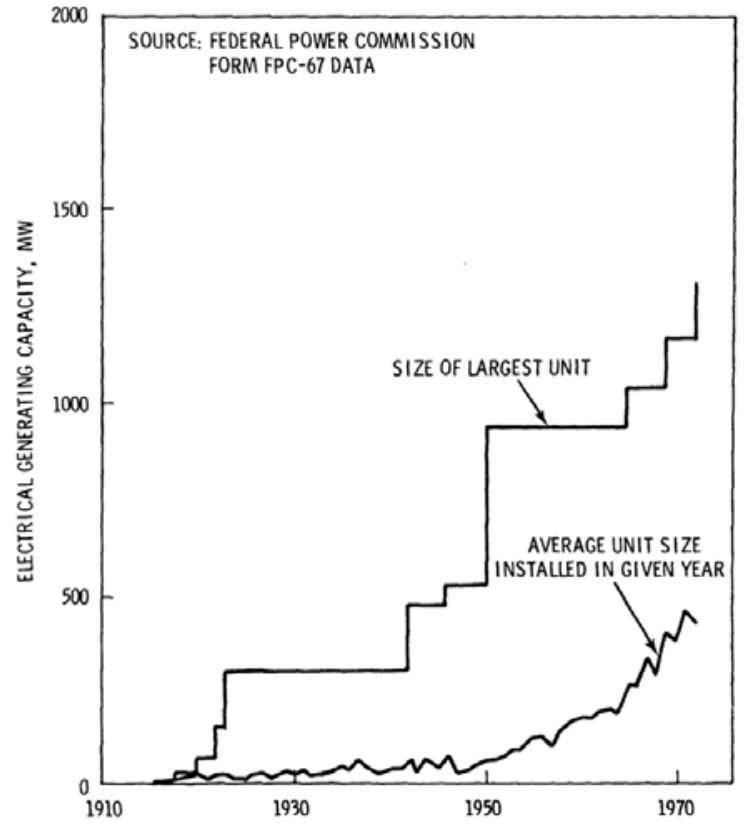

(a) Trends in Plant Size

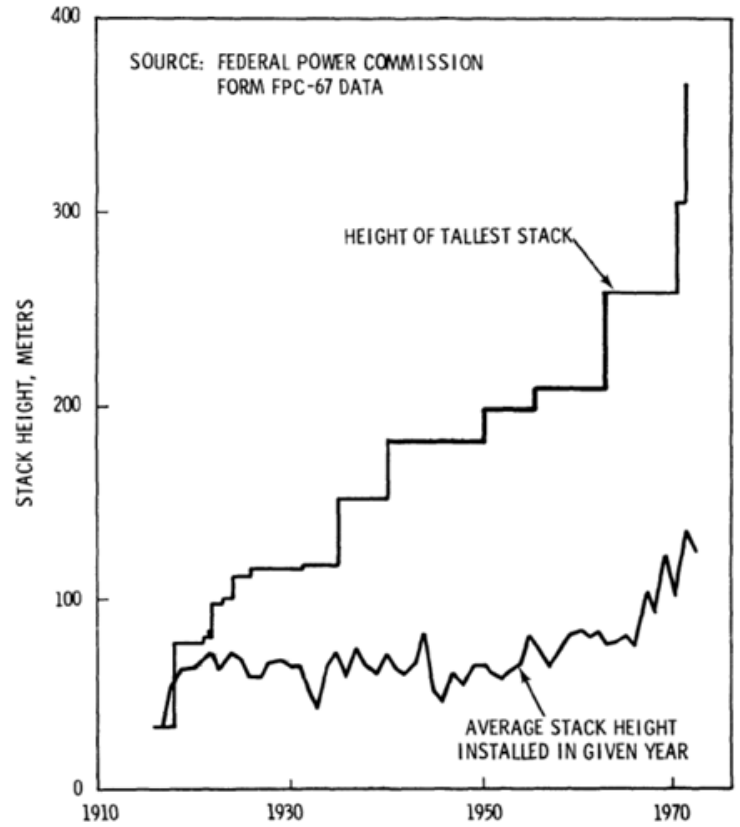

(b) Trends in Smokestack Height

Notes: This figure displays trends in plant size and smokestack height. Panel (a) documents the average and maximum capacities (in MW) of electricity generating units in each year. Panel (b) documents the average and maximum smokestack height (in meters) of electricity generating units in each year. The data used to construct these figures come from Federal Power Commission Form FPC-67. Source: Figures 3 and 4, EPA (1976c). 
Figure A.2: Histogram of First Year with FGP or FGD

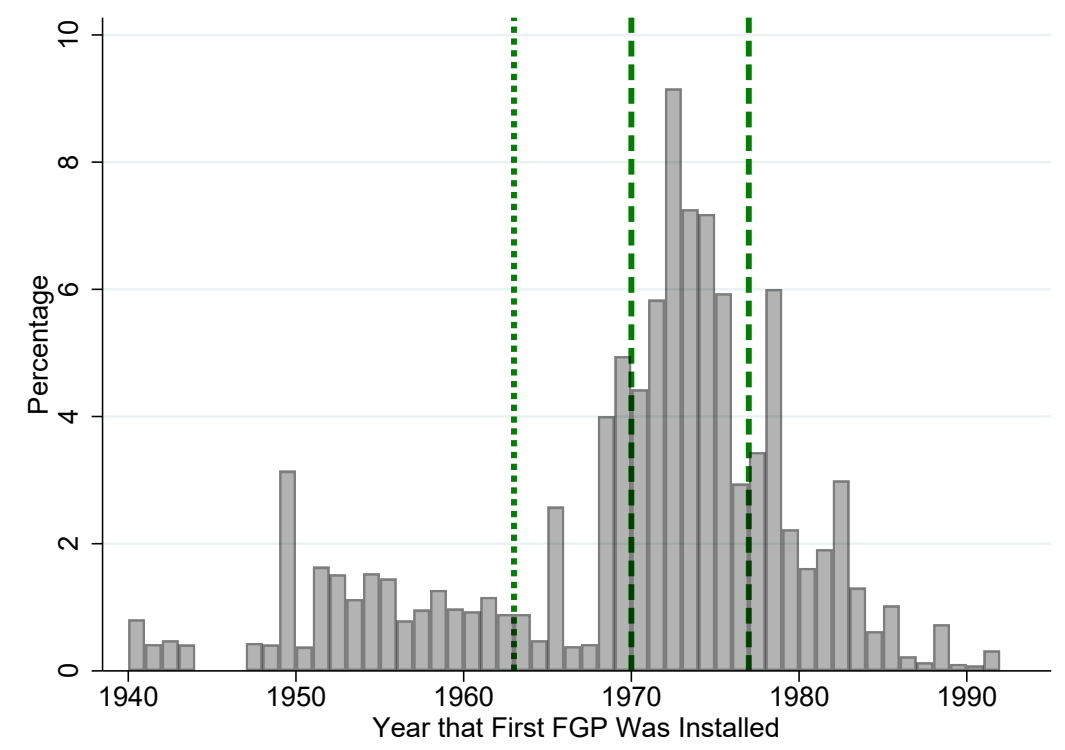

(a) FGP Adoption

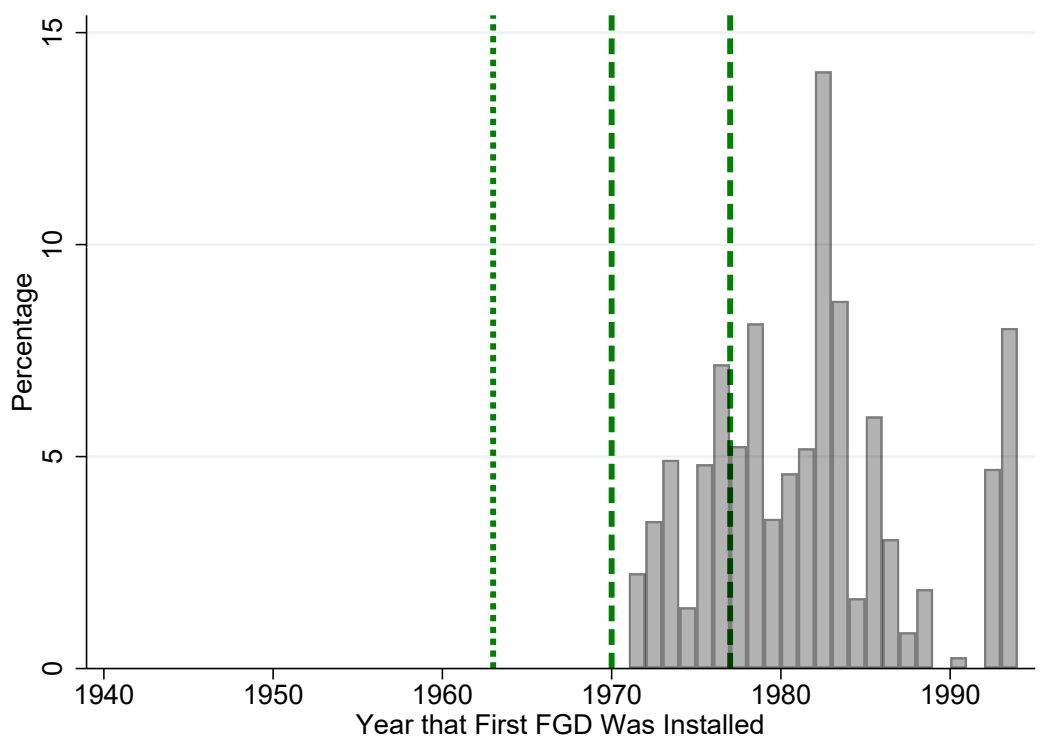

(b) FGD Adoption

Notes: This figure displays the timeline of adoption of pollution abatement technology. Panel (a) plots the plant-level distribution of the year that the first flue gas particulate (FGP) collector was installed on the plant. Panel (b) plots the plant-level distribution of the year that the first flue gas desulfurization (FGD) system was installed on the plant. These histograms focus on coal plants. The short-dashed green line denotes the Clean Air Act (CAA) of 1963 while the two dashed green lines denote the 1970 CAA and its amendments in 1977 respectively. Data on the installation year of each FGP and FGD come from Form EIA-767 administered by the Energy Information Administration. 
Figure A.3: Patents Related to Power Systems and Electrical Lighting

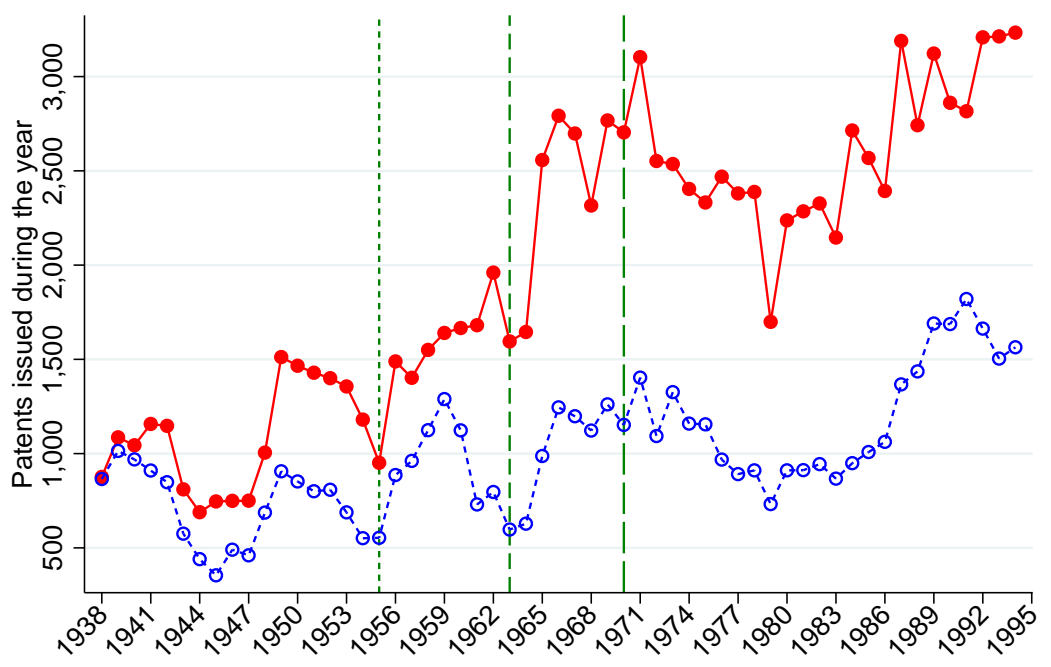

$\longrightarrow$ Power systems $\quad$----@--- Electrical lighting

(a) Trends in the Number of Patents Issued

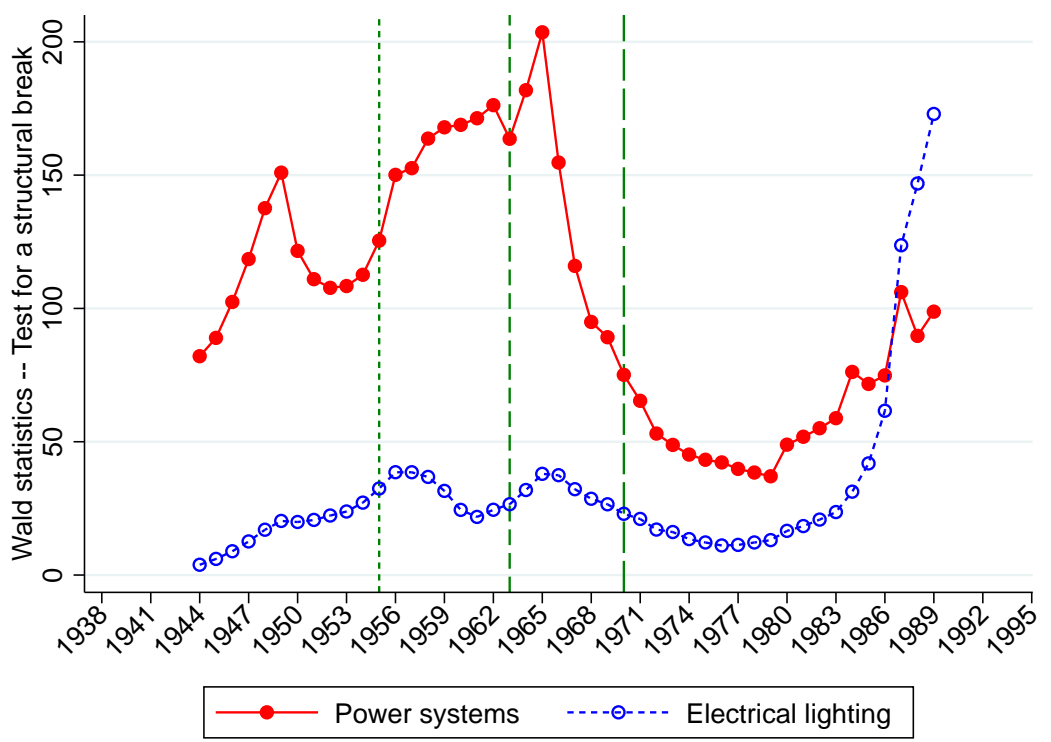

(b) Wald Statistics for Tests of Unknown Structural Break

Notes: This figure displays trends in patents for categories pertaining to electricity. Panel (a) plots the number of patents issued during the year for two categories: (i) "power systems," which includes power plants, electrical generator, and single generator systems, and (ii) "electrical lighting," which includes electric lamp and discharge devices, illumination, and coherent light generators. For a complete description of these categories, visit https://historicip.com/nber/. Panel (b) plots the Wald statistics of tests for a structural break in time-series data with an unknown break date, with an equal left and right trimming percentage of ten percent. The break is estimated to happen in 1965 for power systems and in 1989 for electrical light - the electrical lighting category appears to be a good "control group" for power systems. The short-dashed vertical green line refers to the Air Pollution Control Act of 1955, the dashed vertical green line refers to the Clean Air Act of 1963, and the longdashed vertical green line refers to the Clean Air Act of 1970. Data Source: The Historical Patent Data Files from the U.S. Patent and Trademark Office, available at https://www.uspto.gov/learningand-resources/electronic-data-products/historical-patent-data-files. 
Figure A.4: Real Construction Cost Index For Coal-Fired Power Plants

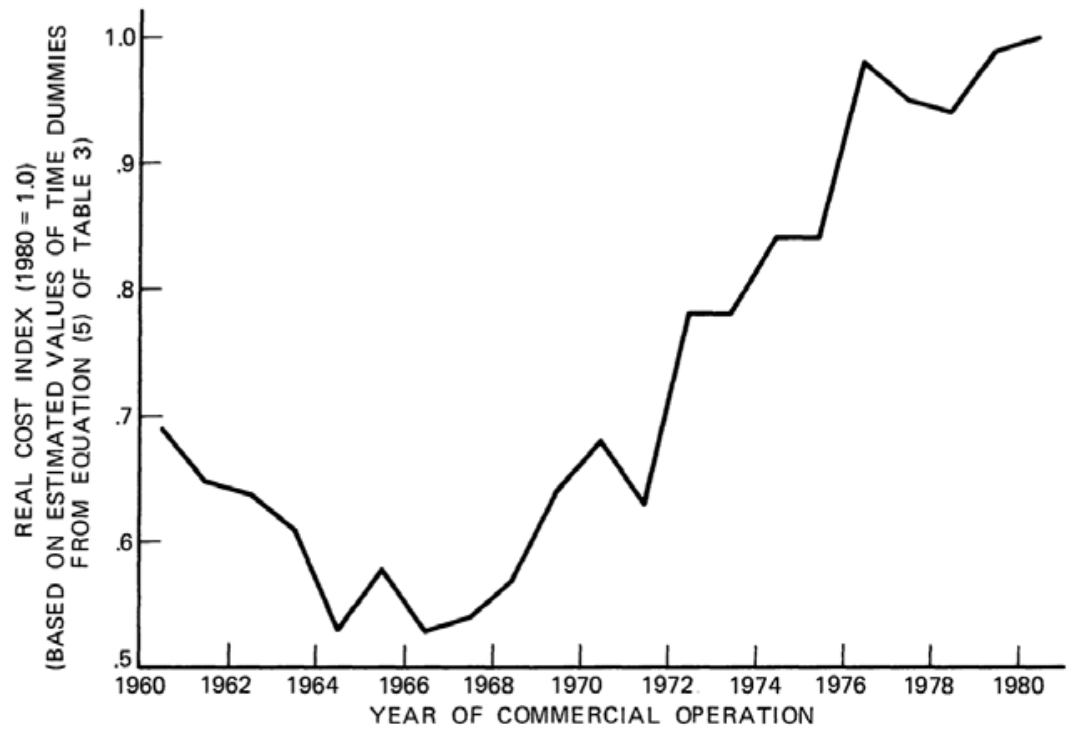

Notes: This figure reproduces Figure 2 from Joskow and Rose (1985). It plots an index of construction costs per kilowatt for coal-fired electricity generating units. Construction costs decline during the early 1960s, stabilize in the mid 1960s, and then increase starting around 1966 to a level that by 1980 is substantially higher than the level in 1960 . 
Figure A.5: Trends in Scrubber Adoption

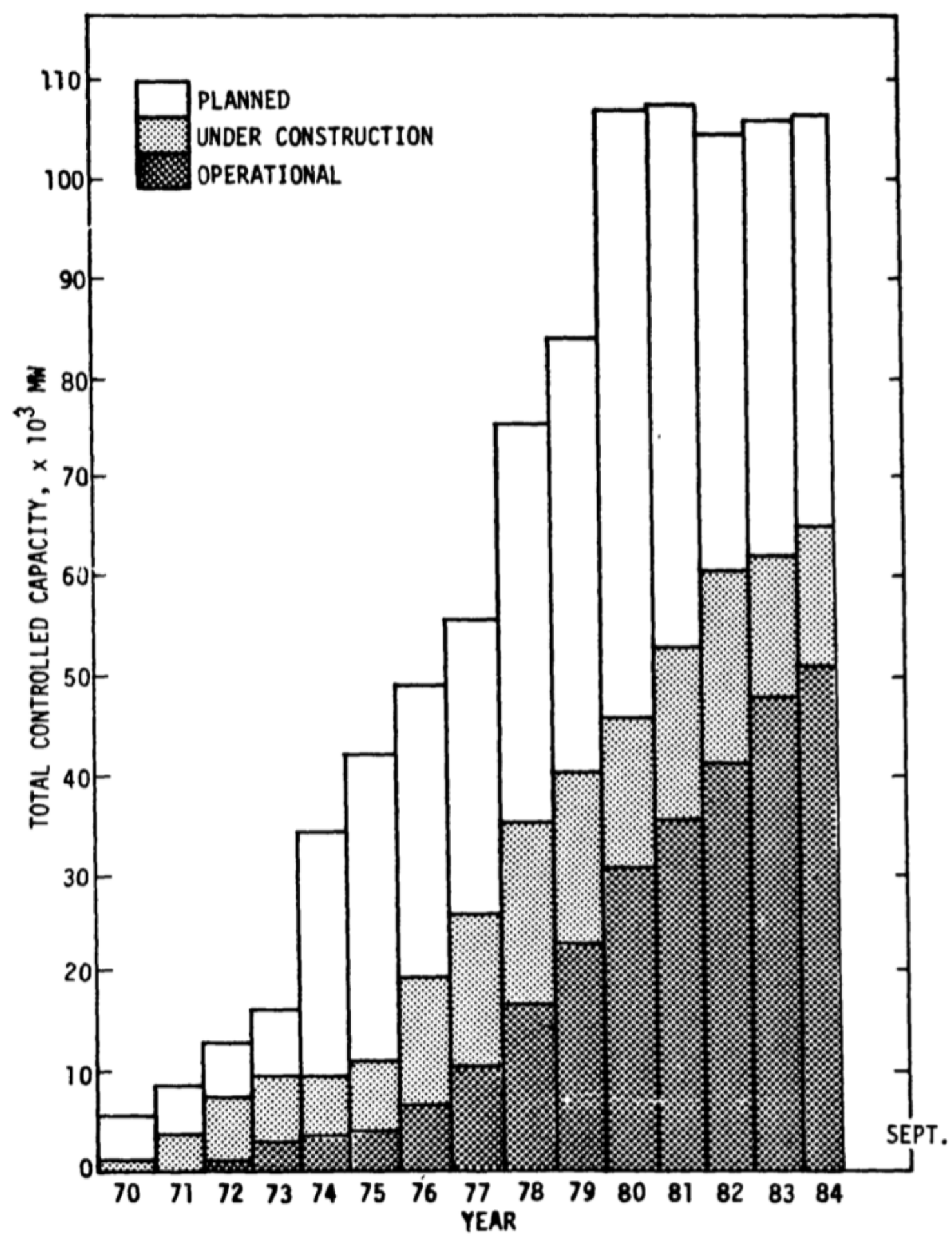

Notes: This figure presents the annual total amount of electricity generating capacity whose pollution emissions are "controlled" by flue gas desulfurization technology (i.e., a scrubber), separately for generation units in operation, under construction, and planned. This figure spans the sample period December 1970 through September 1984. Source: Figure 2, EPA (1984). 
Figure A.6: Trends in Total Suspended Particulates by County Attainment Status

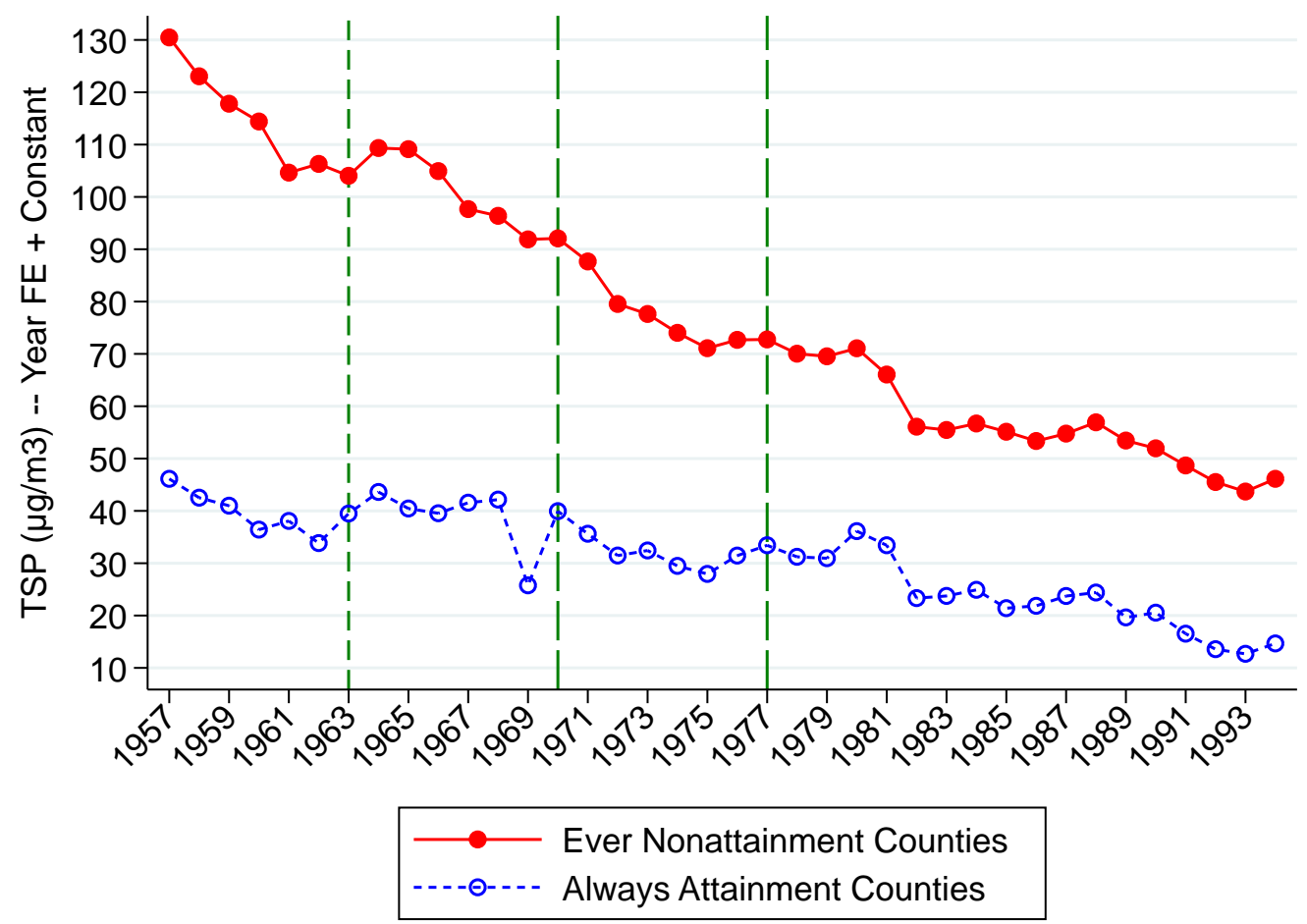

Notes: This figure displays trends in total suspended particulates (TSP) by county attainment status. Specifically, it plots the estimated coefficients from a regression of TSP on year fixed effects interacted with attainment status, controlling for pollution monitor fixed effects. A county is categorized as "ever nonattainment" if it was in nonattainment with the NAAQS for any pollutant in any year between 1972-1994; a county is categorized as "always attainment" if it never faced nonattainment between 1972-1994. The green vertical dashed line refers to the passage of the Clean Air Act of 1963, and the long-dashed lines to the Clean Air Act of 1970 and its amendments in 1977. Data on TSP concentration levels, which start in 1957, were provided by the EPA under a Freedom of Information Act (FOIA) request. 
Figure A.7: Trends in Power Plant Thermal Efficiency

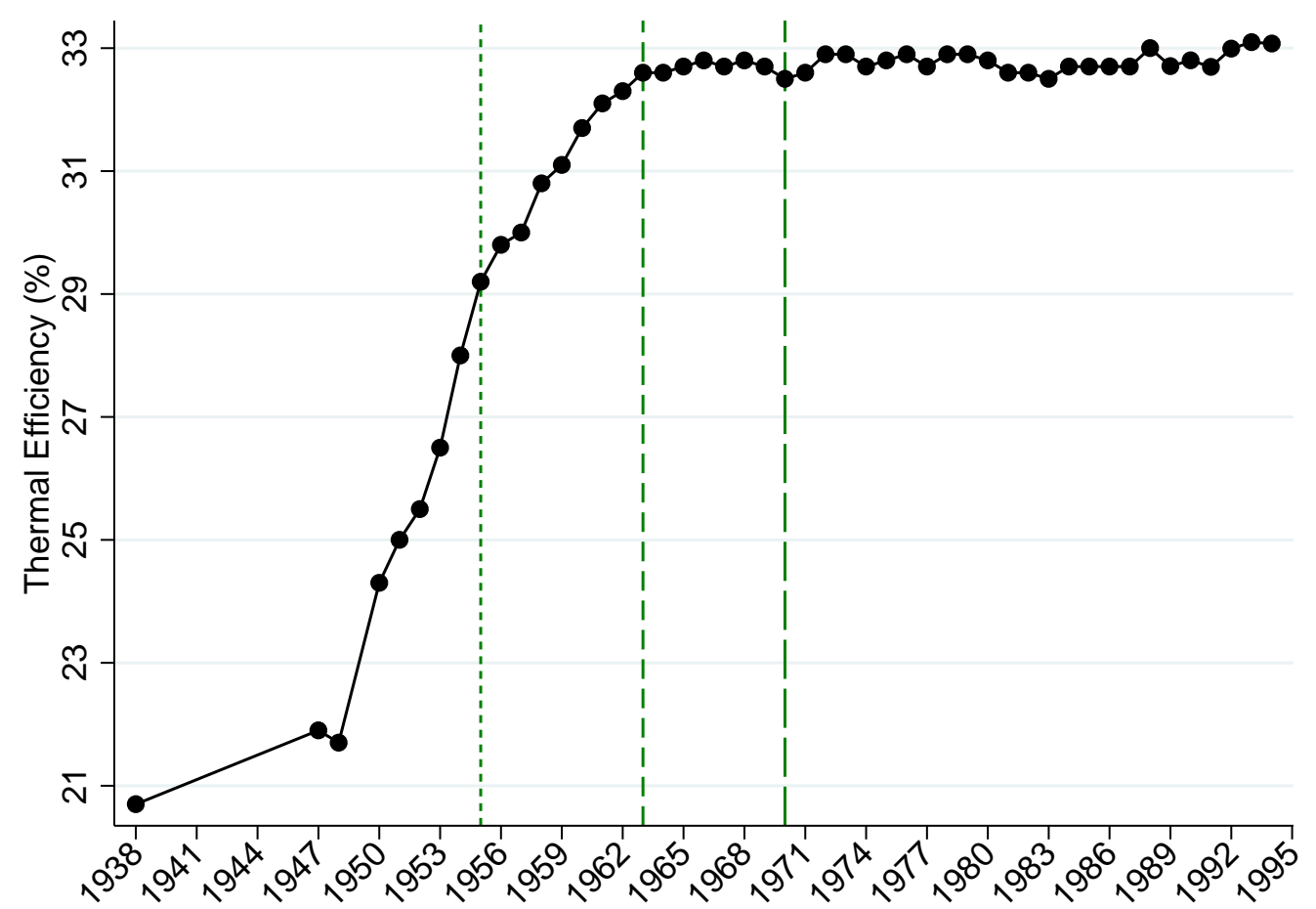

Notes: This figure displays the national average thermal efficiency of fossil-fueled steam-electric plants from 1938-1994. 100\% thermal efficiency corresponds to 3,412 BTU of heat input energy producing $1 \mathrm{kWh}$ of electricity. The data sources for this figure are (i) for the period 1938-1955: FPC 1965 Report (FPC, 1966), Table 9, p.xxxi; (ii) for the period 1956-1988: EIA 1990 Report (EIA, 1992), Table 11, p.37; and (iii) for the period 1989-1994: MER February 2021 (EIA, 2021), Table A6, p.215. The short-dashed vertical green line represents the Air Pollution Control Act of 1955, the vertical dashed green line represents the Clean Air Act of 1963, and the long-dashed vertical green line represents the Clean Air Act of 1970. 
Table A.1: Installation of FGD and FGP Technology By Plant Vintage

\begin{tabular}{lcc}
\hline \hline Dep. Var. & 1[FGP] & 1[FGD] \\
& & \\
1[Built Between 1963-1971] & $0.057^{*}$ & 0.024 \\
& $(0.032)$ & $(0.023)$ \\
& & \\
1[Built After 1972] & $0.093^{* * *}$ & $0.298^{* * *}$ \\
& $(0.023)$ & $(0.050)$ \\
Evernonattainment Indicator & $\mathrm{Y}$ & $\mathrm{Y}$ \\
Year FE & $\mathrm{Y}$ & $\mathrm{Y}$ \\
$\mathrm{R}^{2}$ & 1 & 0 \\
Mean of Dep. Var. & 1 & 0 \\
Number of Obs. & 14,184 & 14,184 \\
Number of Plants & 496 & 496 \\
\hline \hline
\end{tabular}

Notes: This table presents regression results measuring whether the installation of flue gas particulate (FGP) collectors and flue gas desulfurization (FGD) technology is different across plant vintages. The unit of observation for these regressions is plant-year, focusing on coal plants. The dependent variable for Column 1 (Column 2) is an indicator variable that is equal to one if the plant has at least one FGP (FGD) system installed by the year-of-sample. We control for an indicator for whether the plant ever faced nonattainment between 1972-1994 and year fixed effects. Standard errors in parentheses are two-way clustered by county and year. *** denotes statistical significance at the $1 \%$ level, ** at the $5 \%$ level, and * at the $10 \%$ level. 
Table A.2: Where Electric Utilities Site Plants Before and After the Clean Air Act

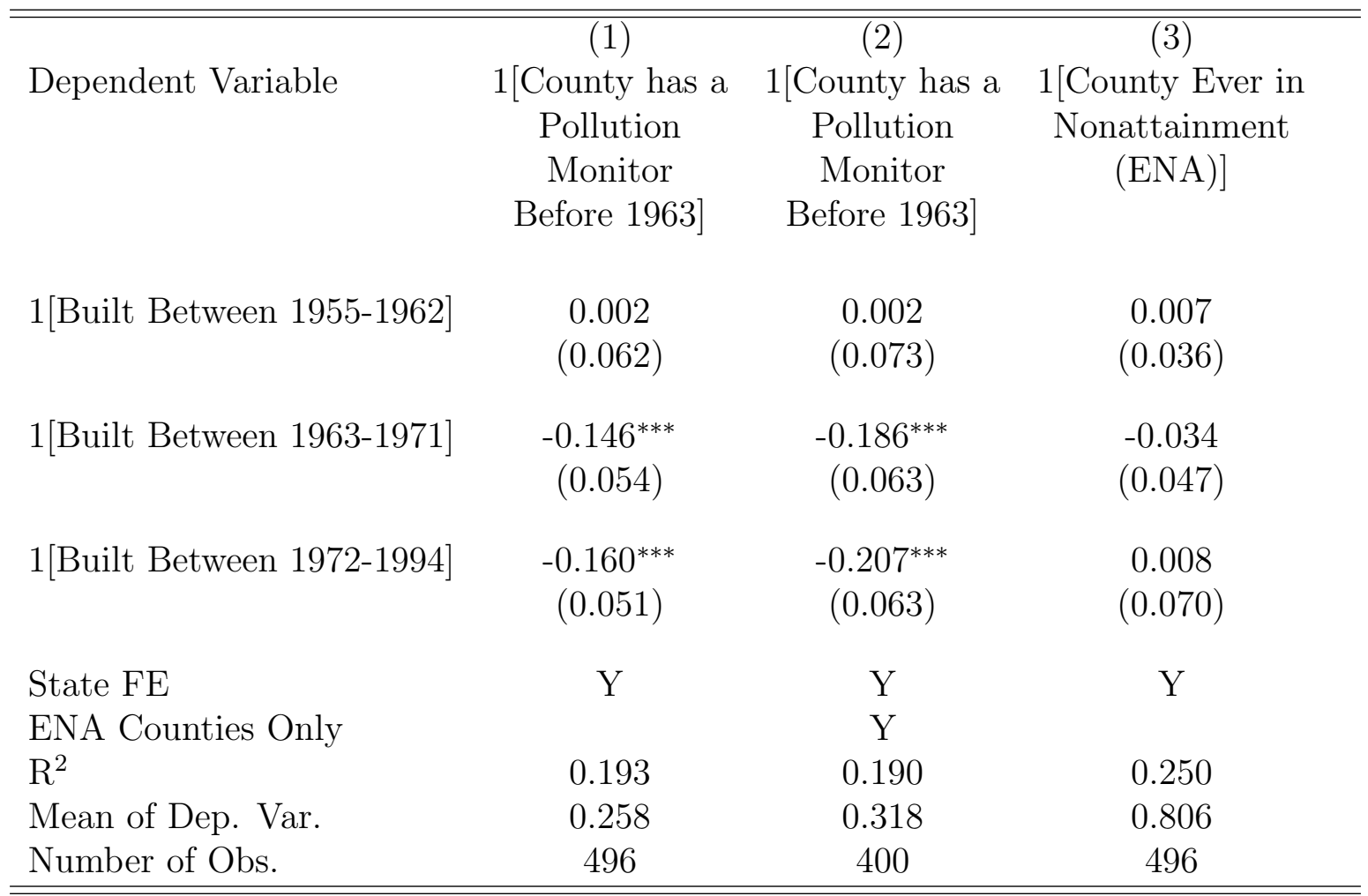

Notes: This table reports estimates from linear probability models that explore whether electric utilities are less likely to site their coal-fired power plants in counties that are more likely to face nonattainment in the future. We estimate separate effects for plants built between 1955-1962, 19631971, and 1972-1994; the (omitted) reference vintage group is plants built before 1954. The unit of observation for these regressions is a plant. In columns 1 and 2 , the dependent variable is an indicator for whether the county where the plant was built had at least one pollution monitor measuring air pollution within its boundaries before the passage of the Clean Air Act of 1963. Column 2 restricts the sample to counties that were ever out of attainment with the NAAQS for any pollutant between 1972-1994. For reference, 128 coal plants that opened between 1938-1994 were built in counties that had at least one pollution monitor operating in at least one year during the baseline years 1957-1962. In column 3, the dependent variable is an indicator for whether the county where the plant was built was ever in nonattainment with the NAAQS between 1972-1994. Information on the location of the network of pollution monitoring stations was obtained through a FOIA request submitted to the U.S. EPA. Standard errors in parentheses are clustered by state. ${ }^{* * *}$ denotes statistical significance at the $1 \%$ level, ${ }^{* *}$ at the $5 \%$ level, and ${ }^{*}$ at the $10 \%$ level. 
Table A.3: Pollution Abatement Strategies: The Case of the Tennessee Valley Authority

\begin{tabular}{|c|c|c|c|c|c|}
\hline Coal Plant & County & State & Attainment in 1978 & Compliance Method & $\begin{array}{c}\text { Compliance Cost } \\
\text { (millions of } 2020 \text { USD) }\end{array}$ \\
\hline Allen & Shelby & $\mathrm{TN}$ & No & Medium Sulfur Coal & 271.46 \\
\hline Colbert & Colbert & $\mathrm{AL}$ & No & Medium Sulfur Coal & 531.26 \\
\hline Cumberland & Stewart & $\mathrm{TN}$ & Yes & $\begin{array}{l}\text { Coal Washing } \\
\text { Electrostatic Precipitators }\end{array}$ & $1,842.92$ \\
\hline Gallatin & Sumner & $\mathrm{TN}$ & No & $\begin{array}{l}\text { Medium Sulfur Coal } \\
\text { Electrostatic Precipitators }\end{array}$ & 421.89 \\
\hline Johnsonville & Humphreys & $\mathrm{TN}$ & No & Medium Sulfur Coal & $1,107.55$ \\
\hline Kingston & Roane & $\mathrm{TN}$ & No & Low Sulfur Coal & $1,007.10$ \\
\hline $\begin{array}{l}\text { Paradise } \\
\text { Unit } 3\end{array}$ & Muhlenberg & KY & No & $\begin{array}{c}\text { Coal Washing and Partial Scrubbing } \\
\text { Electrostatic Precipitators }\end{array}$ & $3,715.81$ \\
\hline Shawnee & McCracken & KY & No & Low Sulfur Coal, Baghouses & $2,771.06$ \\
\hline Watts Bar & Rhea & $\mathrm{TN}$ & Yes & Medium Sulfur Coal & Not Available \\
\hline Widows Creek Units 1-6 & Jackson & $\mathrm{AL}$ & No & Low Sulfur Coal & 564.05 \\
\hline Widows Creek Units 7-8 & Jackson & $\mathrm{AL}$ & No & Scrubbing and Medium Sulfur Coal & $1,990.54$ \\
\hline Total & & & & & $14,223.67$ \\
\hline
\end{tabular}

Notes: This table provides the pollution abatement strategy of each of the ten coal-fired power plants owned by the Tennessee Valley Authority (TVA), as agreed upon in the clean air settlement between TVA and EPA in 1979-80. All ten plants were built before 1972, the year that the 1970 Clean Air Act was implemented. The costs in the last column were estimated by the U.S. Government Accountability Office (GAO), and refer to the total cost of the consent decree over the lifespan of the projects. This table was compiled using information from GAO (1980). 
Table A.4: Number of Years in Operation By County Attainment Status

\begin{tabular}{|c|c|c|c|c|}
\hline $\begin{aligned} \text { Dep. Var.: Log of the Number of Years } \\
\text { that the Plant Operates }\end{aligned}$ & (1) & $(2)$ & $(3)$ & $(4)$ \\
\hline Ever Nonattainment & $\begin{array}{c}0.035 \\
(0.071)\end{array}$ & $\begin{array}{l}0.627^{* *} \\
(0.284)\end{array}$ & & \\
\hline ENA $\times 1[$ Built Before 1963] & $\begin{array}{c}0.490^{* * *} \\
(0.055)\end{array}$ & $\begin{array}{c}0.162 \\
(0.269)\end{array}$ & & \\
\hline Number of Years in Nonattainment & & & $\begin{array}{l}-0.002 \\
(0.003)\end{array}$ & $\begin{array}{l}0.042^{*} \\
(0.022)\end{array}$ \\
\hline \# of Years in NA $\times 1$ [Built Before 1963] & & & $\begin{array}{c}0.026^{* * *} \\
(0.003)\end{array}$ & $\begin{array}{c}0.017 \\
(0.021)\end{array}$ \\
\hline Capacity (GW) & $\begin{array}{c}0.059 \\
(0.066)\end{array}$ & $\begin{array}{l}0.905^{* *} \\
(0.356)\end{array}$ & $\begin{array}{l}-0.037 \\
(0.063)\end{array}$ & $\begin{array}{l}0.679^{* *} \\
(0.322)\end{array}$ \\
\hline Constant & $\begin{array}{c}3.199^{* * *} \\
(0.056)\end{array}$ & $\begin{array}{c}3.417^{* * *} \\
(0.101)\end{array}$ & $\begin{array}{c}3.349^{* * *} \\
(0.043)\end{array}$ & $\begin{array}{c}3.560^{* * *} \\
(0.086)\end{array}$ \\
\hline Mean of Dep. Var. & 3.516 & 3.516 & 3.516 & 3.516 \\
\hline Number of Obs. & 373 & 373 & 373 & 373 \\
\hline Censored Model? & & $\mathrm{Y}$ & & $\mathrm{Y}$ \\
\hline
\end{tabular}

Notes: This table reports estimates of the relationship between the number of years each plant is in operation and measures of attainment status with the NAAQS for any pollutant. The unit of observation for all of the regressions in this table is a power plant, considering all coal plants built before 1972. The dependent variable considered for all regressions is the log of the last year the plant is recorded as producing positive output in our dataset minus the first year the plant is recorded as producing positive output plus one. The independent variable of interest in Columns 1 and 2 is an indicator variable that is equal to one if the plant ever faced nonattainment between 1972-1994. The independent variable of interest in Columns 3 and 4 is the count of the number of years that the plant faced nonattainment between 1972-1994. We also interact the relevant independent variable with an indicator for plants built before 1963. All specifications control for the plant's capacity in its first year of operation. In Columns 1 and 3, we estimate the model using ordinary least squares. In Columns 2 and 4, we use a censored regression model that accounts for the fact that some plants are still in operation at the end of our sample period. Heteroskedasticity-consistent standard errors are reported in parentheses. *** denotes statistical significance at the $1 \%$ level, ** at the $5 \%$ level, and $*$ at the $10 \%$ level. 


\section{B Details on the Theoretical Framework}

This appendix section provides more details on the model presented in Section 3. At $t=0$, the plant opens and must decide how to allocate capacity, $\theta$, across each production technology. This decision takes into account the probabilities that the plant will encounter future environmental regulation in periods $t=1$ and $t=2, \lambda_{1}$ and $\lambda_{2}$, as well as the expected stringency of the regulation, $(1-\delta)$. Plants have full information regarding their future adjustment costs $c$ if regulation is enacted. Depending on these parameters, plants make decisions at $t=0$ with full knowledge that they will ex-post respond to regulation in one of the three possible ways: (1) Always adjust (AA): Adjust capacity if regulation passes in $t=1$ or $t=2$; (2) Never adjust (NA): Do not adjust capacity if regulation passes in $t=1$ or $t=2$; (3) Sometimes adjust (SA): Adjust capacity if regulation passes at $t=1$, but do not adjust capacity if regulation passes at $t=2 .{ }^{1}$

Case 1: Always adjust (AA) - Adjust capacity if regulation passes at $t=1$ or $t=2$

In this case, the plant chooses capacity, $\theta$, at $t=0$ with full knowledge that capacity will be re-optimized (at cost $c$ ) if regulation is ever passed. The plant's $t=0$ problem is:

$$
\begin{aligned}
\max _{\theta} & \left(1-\lambda_{1}-\lambda_{2}\right)(1+\beta)\left(\Pi_{D}(\theta)+\Pi_{C}(1-\theta)\right) \\
& +\lambda_{1}\left[(1+\beta)\left(\delta \Pi_{D}(\hat{\theta})+\Pi_{C}(1-\hat{\theta})\right)-c\right] \\
& +\lambda_{2}\left[\Pi_{D}(\theta)+\Pi_{C}(1-\theta)+\beta\left(\delta \Pi_{D}(\hat{\theta})+\Pi_{C}(1-\hat{\theta})-c\right)\right]
\end{aligned}
$$

With probability $\left(1-\lambda_{1}-\lambda_{2}\right)$ regulation will never pass, in which case the initial capacity allocation, $\theta$, determines profit levels for both $t=1$, 2. Regulation is passed at $t=1$ with probability $\lambda_{1}$, in which case the plant re-optimizes capacity to $\hat{\theta}$ and the choice of $\theta$ has no impact on profits. With probability $\lambda_{2}$, regulation is passed at $t=2$, in which case $\theta$ affects profits only at $t=1$. The first order condition implies the following solution:

$$
\Pi_{D}^{\prime}\left(\theta_{A A}^{*}\right)=\Pi_{C}^{\prime}\left(1-\theta_{A A}^{*}\right)
$$

Case 2: Never adjust (NA) - Do not adjust capacity if regulation passes at $t=1$ or $t=2$

\footnotetext{
${ }^{1}$ For simplicity, we assume that the producer's choice of capacity allocation at $t=0$ does not impact the probability they face regulation in $t=1$ or $t=2$.
} 
In this case, the plant chooses capacity $\theta$ at $t=0$ with full knowledge that capacity will never be re-optimized if regulation is passed. The plant's $t=0$ problem is:

$$
\begin{aligned}
\max _{\theta} & \left(1-\lambda_{1}-\lambda_{2}\right)(1+\beta)\left(\Pi_{D}(\theta)+\Pi_{C}(1-\theta)\right) \\
& +\lambda_{1}(1+\beta)\left(\delta \Pi_{D}(\theta)+\Pi_{C}(1-\theta)\right) \\
& +\lambda_{2}\left[(1+\beta \delta) \Pi_{D}(\theta)+(1+\beta) \Pi_{C}(1-\theta)\right]
\end{aligned}
$$

In this case, the choice of $\theta$ determines the plant's profits regardless of whether and when regulation is passed. The first order condition implies the following solution:

$$
\left[1-\lambda_{1}(1-\delta)-\lambda_{2}(1-\delta) \frac{\beta}{1+\beta}\right] \Pi_{D}^{\prime}\left(\theta_{N A}^{*}\right)=\Pi_{C}^{\prime}\left(1-\theta_{N A}^{*}\right)
$$

Case 3: Sometimes adjust (SA) - Adjust capacity if regulation passes at $t=1$, do not adjust capacity if regulation passes at $t=2$

In this case, the plant chooses capacity $\theta$ at $t=0$ with full knowledge that capacity will be adjusted if regulation is passed at $t=1$ but not if regulation is passed at $t=2$. The plant's $t=0$ problem is:

$$
\begin{aligned}
\max _{\theta} & \left(1-\lambda_{1}-\lambda_{2}\right)(1+\beta)\left(\Pi_{D}(\theta)+\Pi_{C}(1-\theta)\right) \\
& +\lambda_{1}\left[(1+\beta)\left(\delta \Pi_{D}(\hat{\theta})+\Pi_{C}(1-\hat{\theta})\right)-c\right] \\
& +\lambda_{2}\left[(1+\beta \delta) \Pi_{D}(\theta)+(1+\beta) \Pi_{C}(1-\theta)\right]
\end{aligned}
$$

In this case, the choice of $\theta$ determines the plant's profits if regulation is never adopted and if regulation is adopted at $t=2$. The first order condition implies the following solution:

$$
\left[1-\frac{\lambda_{2}}{1-\lambda_{1}}(1-\delta) \frac{\beta}{1+\beta}\right] \Pi_{D}^{\prime}\left(\theta_{S A}^{*}\right)=\Pi_{C}^{\prime}\left(1-\theta_{S A}^{*}\right) .
$$




\section{Data Construction and Data Description}

This appendix section provides further details on data sources, data construction, and data description, supporting the broad overview given in Section 4. Appendix Section C.1 discusses the digitization of historical information on fossil-fuel-fired power plants. Appendix Section C.2 describes the variables used in the estimation of our measure of pollution-unadjusted total factor productivity (PU-TFP), and provides the estimates of the parameters of the production function. Appendix Section C.3 presents additional descriptive figures and tables. The outline of all of the figures and tables in this appendix section is below.

- Figure C.1. Sample Data for Four Power Plants from the 1957 FPC Report

- Figure C.2. Map of Counties with Fossil-Fuel-Fired Power Plants

- Figure C.3. Proportion of Electricity Generation Produced in Nonattainment Counties

- Figure C.4. Annual Total Electricity Generating Capacity by Source Type

- Figure C.5. Annual Total Electricity Generation and Capacity for Coal Power Plants By Vintage and Attainment Status

- Figure C.6. Annual Total Electricity Generation and Capacity for Coal Power Plants by Vintage and Years in Nonattainment

- Figure C.7. Annual Average Total Factor Productivity for Coal Power Plants by Attainment Status

- Figure C.8. Annual Average Total Factor Productivity for Coal Power Plants by Vintage and Years in Nonattainment

- Figure C.9. County-Level Distribution of the Number of Years Facing Nonattainment

- Table C.1. Number of Plants by Attainment Status and Vintage 
- Table C.2. Attainment Status versus Lagged Attainment Status

- Table C.3. Summary Statistics: PU-TFP, Ouput, Inputs, and Attainment Status

- Table C.4. Production Function Estimates: Different Methods and Functional Forms 


\section{C.1 Data Construction}

We digitized power plant level data from the Federal Power Commission (FPC) reports for the years 1938-1981. ${ }^{2}$ Most of the digitization was funded by the NSF grant SES 1627432. We hired undergraduates and Master's students to manually enter the information from the historical reports. Then, a different set of students checked the accuracy of the information entered by the first group, and made corrections if needed.

Beginning in 1938, detailed annual data are available for large steam power plants. Steam power plants include coal-fired, gas-fired, and oil-fired power plants. The number of power plants listed in the first report, which covers all years between 1938-1947, increases from 151 in 1938 to 200 in 1947. The number of plants listed in subsequent annual volumes is 277 in 1950, 528 in 1960, 553 in 1970, and 647 in $1980 .^{3}$

The title of the FPC report for the years 1938-1947 is Steam-Electric Plant Construction Cost and Annual Production Expenses, 1938-1947 (Single Volume). The title of the FPC report for each subsequent year between 1948 and 1978 is Steam-Electric Plant Construction Cost and Annual Production Expenses (Annual Supplements). Finally, the title of the relevant report for each year between 1979-1981 is Thermal-Electric Plant Construction Cost and Annual Production Expenses (Annual Supplements). As an example, we present a page from the 1957 report in Appendix Figure C.1.

Starting in 1982, the annual reports include only a small sample of steam-electric power plants. For this reason, we collect data from several other sources to construct an annual plant-level data-set from 1982-1994 that can be appended to the 1938-1981 data-set built by digitizing the annual reports from the FPC:

- Each plant's capacity in each year as well as each plant's latitude/longitude coordinates, state and county come from the eGrid database administered by the USEPA. ${ }^{4}$ - http://www.epa.gov/egrid/download-data

\footnotetext{
${ }^{2}$ In 1977, Congress replaced FPC with the Federal Energy Regulatory Commission (FERC).

${ }^{3}$ The plants reported in 1938 accounted for $59 \%$ of the capacity and $75 \%$ of the generation of utilityowned, fossil-fuel-fired steam-electric plants in the United States. The corresponding percentage of capacity covered in the years 1947, 1950, 1960, 1970, and 1980 are $65 \%, 70 \%, 90 \%, 93 \%$, and $92 \%$ respectively. The corresponding percentage of generation covered in the years 1947, 1950, 1960, 1970, and 1980 are $73 \%, 80 \%, 94 \%, 96 \%$, and $91 \%$ respectively.

${ }^{4}$ We used data from Form EIA-860 to supplement capacity where it was not listed in eGrid because the plant shut down before 1996.
} 
- Annual plant-level total generation and consumption by fuel type come from Form EIA-759 which later became Form EIA-906.

- http://www.eia.gov/electricity/data/eia923/eia906u.html

- The year of installation of each flue gas desulfurization (FGD) technology and flue gas particulate (FGP) collector for each plant is from Form EIA-767.

- http://www.eia.gov/electricity/data/eiar67/

- Annual total quantity of fuel purchased by each plant and annual average fuel prices for each plant are from Form EIA-423.

- http://www.eia.gov/electricity/data/eia423/

- Annual plant-level data on number of employees and nonfuel expenses come from FERC Form 1 (investor-owned utilities), EIA Form 412 (municipal and other government utilities), and RUS Forms 7 and 12 (electric cooperatives). ${ }^{5}$

-http://www.ferc.gov/industries-data/electric/general-information/electricindustry-forms/form-1-electric-utility-annual.

-https://www.eia.gov/electricity/data/eia412/

-https://www.rd.usda.gov/files/UEP_Support_DCS.pdf

\section{C.2 Estimation of Total Factor Productivity}

We estimate pollution-unadjusted total factor productivity (PU-TFP) using the procedure developed by Ackerberg, Caves and Frazer (2015). We use data on each plant's output and inputs in each year. Our measure of output is annual plant-level net electricity generation in MWh. The first input, capacity, is the total nameplate capacity of the plant in the year in MW. The second input, labor, is a count of full-time equivalent employees at the plant in the year. The final input, fuel, is the quantity of fuel consumed

\footnotetext{
${ }^{5}$ Most of these data were generously provided by Ron Shadbegian and other researchers at the USEPA. We use data from Fabrizio, Rose and Wolfram (2007) to supplement number of employees and nonfuel expenses.
} 
by the plant in the year in mmBTU. ${ }^{6}$

In robustness checks, we also consider nonfuel_costs as an input when estimating PUTFP. Nonfuel costs include all nonfuel operations and maintenance expenses, such as those for coolants, repairs, maintenance supervision, and engineering. As pointed out by Fabrizio, Rose and Wolfram (2007), this variable is less than ideal as a measure of the materials used in the production process, both because it reflects expenditures rather than quantities, and because it includes the wage bill for the employees counted in labor. Namely, as nonfuel costs include payroll costs, both nonfuel_costs and labor would vary with changes in staffing.

We assume a Leontief production function as in Fabrizio, Rose and Wolfram (2007). In particular, fuel is assumed to be a perfect complement for a function of the other two inputs, capital and labor. We also follow the literature and assume that the function determining how capital and labor map to output is translog (Atkinson and Halvorsen, 1976; Christensen and Greene, 1976; Boisvert, 1982; Gollop and Roberts, 1983; Carlson et al., 2000). Appendix Table C.4 reports the estimates of the parameters of the production function.

Since we use the method developed by Ackerberg, Caves and Frazer (2015) to estimate PU-TFP, we are implicitly assuming that the plant first chooses capacity. At this point, it can also choose to install pollution abatement technology. Then, a productivity shock is realized, after which the plant chooses labor. Finally, an idiosyncratic shock is realized, after which fuel is chosen. This last shock captures a variety of different short-run shocks to the level of output required by the plant such as unexpectedly high electricity demand or binding transmission constraints limiting the amount of electricity that can flow from the plant to demand centers.

\footnotetext{
${ }^{6}$ de Roux et al. (2021) raise the issue that quantity-based TFP measures are potentially biased when there are quality differences in inputs or outputs. However, in our setting, electricity is a homogeneous output. The technology used to generate electricity is also quite similar across coal-fired power plants. The skills required for workers to operate a coal plant are also plausibly similar. The only input that differs in quality is fuel - high-sulfur, high-heat content versus low-sulfur, low-heat content coal. However, we measure input fuel use in units of heat (mmBtu) rather than units of weight (tons), so the aforementioned quality differences are less relevant for our estimation of productivity.
} 


\section{C.3 Additional Descriptive Figures and Tables}

Appendix Figure C.2 shows a map of the United States with all of the counties with at least one fossil fuel power plant shaded in red. Appendix Figure C.3 plots the share of annual electricity generation from fossil-fuel-fired plants located in counties in nonattainment for each pollutant and overall, separately for existing plants and new plants. Appendix Figure C.4 displays the annual total electricity generating capacity for each source type, including nuclear and hydro. Appendix Figures C.5 and C.6 show the trends in annual electricity generation and electricity generating capacity by vintage and different bins defined by attainment status.

Appendix Figures C.7 and C.8 display trends in annual pollution-unadjusted total factor productivity by vintage and attainment status. Appendix Figure C.9 presents the county-level distribution of the number of years that a county has been out of attainment between 1972-1994.

Appendix Table C.1 reports the number of plants in the sample by vintage and attainment status. Appendix Table C.2 shows the empirical probabilities of transitioning from nonattainment to attainment status, and vice versa. Appendix Table C.3 presents summary statistics for the main variables used in the analysis. 
Figure C.1: Sample Data for Four Power Plants from the 1957 FPC Report

\begin{tabular}{|c|c|c|c|c|c|c|c|c|c|}
\hline \multicolumn{2}{|c|}{ Name of Utility } & \multicolumn{2}{|c|}{$\begin{array}{l}\text { KEN BRDPCRD GAS } \\
\text { ARD EDISON LIGET } \\
\text { COMPANY }\end{array}$} & \multicolumn{6}{|c|}{ CONBUERRS PONGR COMPNTY } \\
\hline $\begin{array}{l}\text { Lie. } \\
\text { No. }\end{array}$ & $\begin{array}{l}\text { Name of Plant } \\
\text { Region and Power Supply Area } \\
\text { Locition of Pleat }\end{array}$ & \multicolumn{2}{|c|}{$\begin{array}{c}\text { Cannon Stroet } \\
\text { I-2 } \\
\text { Nev Bedford, mas. }\end{array}$} & \multicolumn{2}{|c|}{$\begin{array}{l}\text { B. C. Cobb } \\
\text { II-11 } \\
\text { Mukregan, M1ch. }\end{array}$} & \multicolumn{2}{|c|}{$\begin{array}{l}\text { Bryce B. Morron } \\
\text { II-11 } \\
\text { Kainmazoo, Mich. }\end{array}$} & \multicolumn{2}{|c|}{$\begin{array}{c}\text { 8aginav River } \\
\text { II-11 } \\
\text { 211wakee, Mich. }\end{array}$} \\
\hline \begin{tabular}{l|}
1 \\
2 \\
3 \\
4 \\
5 \\
6 \\
7
\end{tabular} & 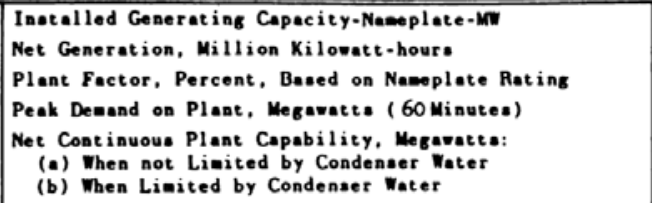 & \multicolumn{2}{|c|}{$\begin{array}{r}137.5 \\
555.7 \\
46 \\
126.4 \\
147.0 \\
147.0\end{array}$} & \multicolumn{2}{|c|}{$\begin{array}{r}510.5 \\
2,785.7 \\
-. \\
523.9 \\
504.0 \\
5 R\end{array}$} & \multicolumn{2}{|c|}{$\begin{array}{r}186.0 \\
679.3 \\
42 \\
209.5 \\
192.0 \\
\text { NR }\end{array}$} & \multicolumn{2}{|c|}{$\begin{array}{r}140.0 \\
166.9 \\
14 \\
154.0 \\
151.0 \\
\mathbb{R}\end{array}$} \\
\hline \begin{tabular}{r|}
8 \\
9 \\
10 \\
11
\end{tabular} & $\begin{array}{l}\text { COST OF PLANT: (Thousends of Dollars) } \\
\text { Lend and Land Right: } \\
\text { Structures and Iaprovements } \\
\text { Equipmeat }\end{array}$ & \multicolumn{2}{|c|}{$\begin{array}{r}613 \\
3,418 \\
13,061\end{array}$} & \multicolumn{2}{|c|}{$\begin{array}{r}143 \\
16,816 \\
46,637\end{array}$} & \multicolumn{2}{|c|}{$\begin{array}{r}291 \\
3,453 \\
11,641\end{array}$} & \multicolumn{2}{|c|}{$\begin{array}{r}2,637 \\
10,019\end{array}$} \\
\hline $\begin{array}{l}12 \\
13\end{array}$ & $\begin{array}{l}\text { Total Cost } \\
\text { Cost per Kilowatt of Inatelled Capacity }\end{array}$ & \multicolumn{2}{|c|}{$\begin{array}{r}17,092 \\
124\end{array}$} & \multicolumn{2}{|c|}{$\begin{array}{r}63,596 \\
125\end{array}$} & \multicolumn{2}{|c|}{$\begin{array}{r}15,385 \\
83\end{array}$} & \multicolumn{2}{|c|}{$\begin{array}{r}12,665 \\
90\end{array}$} \\
\hline 14 & PROOUCTION EXPENSES: & 31000 & $\underset{k=b}{M i 110}$ & 81000 & $\underset{k \rightarrow h}{M_{i} l l,}$ & 81000 & $\underset{k \in h}{M i 11,}$ & 81000 & $M_{k=1}$ \\
\hline $\begin{array}{l}15 \\
16 \\
17 \\
18 \\
19 \\
20\end{array}$ & 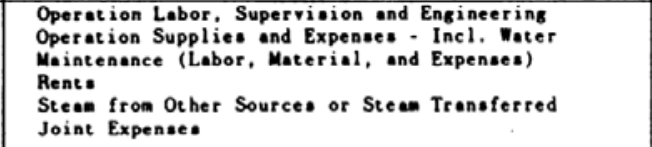 & $\begin{array}{r}424 \\
68 \\
361 \\
(23) \\
(10)\end{array}$ & $\begin{array}{l}.77 \\
.12 \\
.65 \\
(.04) \\
(.08)\end{array}$ & $\begin{array}{r}581 \\
136 \\
465 \\
(3)\end{array}$ & $\begin{array}{l}.21 \\
.05 \\
.16\end{array}$ & $\begin{array}{r}388 \\
49 \\
277\end{array}$ & $\begin{array}{l}.57 \\
.07 \\
.41\end{array}$ & $\begin{array}{r}441 \\
43 \\
377 \\
2\end{array}$ & $\begin{array}{l}2.64 \\
.26 \\
2.26 \\
.01\end{array}$ \\
\hline $\begin{array}{l}21 \\
22\end{array}$ & $\begin{array}{l}\text { Total, Exclusive of Fuel } \\
\text { Fuel }\end{array}$ & $\begin{array}{r}820 \\
3,424 \\
\end{array}$ & $\begin{array}{l}1.48 \\
6.16\end{array}$ & $\begin{array}{l}1,179 \\
8,801\end{array}$ & $\begin{array}{l}0.42 \\
3.16\end{array}$ & $\begin{array}{r}714 \\
2,918\end{array}$ & $\begin{array}{l}1.05 \\
4.30\end{array}$ & $\begin{array}{r}863 \\
1,089\end{array}$ & $\begin{array}{l}5.17 \\
6.52\end{array}$ \\
\hline 23 & Total Production Expenaes & 4,244 & 7.64 & 9,980 & 3.58 & 3,632 & 5.35 & 1,952 & 11.69 \\
\hline 24 & Production Expenses (except fuel) per Kilowatt & 5. & 96 & - & & & 83 & 6. & 16 \\
\hline
\end{tabular}

\begin{tabular}{|c|c|c|c|c|c|c|c|c|c|c|c|c|c|c|}
\hline 25 & \multicolumn{6}{|l|}{ FUEL USED: } & Ouentity & coot & \multicolumn{2}{|l|}{ Quenticy } & Quenticy & Cost & Oasotity & cost \\
\hline $\begin{array}{l}26 \\
27 \\
28\end{array}$ & \multicolumn{6}{|c|}{$\begin{array}{l}\text { Cool consumed, } 1000 \text { cons of } 2000 \text { lbs. and Cost per ion } \\
\text { Beu per Pound and Cost per Million Bu } \\
\text { Coat per Ton, As delivered, f,o.b. Plant }\end{array}$} & $\begin{array}{r}126.5 \\
13,962 \\
\end{array}$ & \begin{tabular}{|l|}
11.73 \\
42.00 \\
11.80
\end{tabular} & \multirow{3}{*}{\multicolumn{2}{|c|}{\begin{tabular}{|r|r|}
$1,142.5$ & 7.65 \\
12,033 & 31.80 \\
& 7.65 \\
\end{tabular}}} & \multirow[t]{3}{*}{$\begin{array}{r}318.3 \\
12,604\end{array}$} & \multirow[t]{3}{*}{\begin{tabular}{|r|}
9.09 \\
36.10 \\
8.91 \\
\end{tabular}} & \multirow[t]{3}{*}{$\begin{array}{r}126.2 \\
13,106 \\
\end{array}$} & \multirow[t]{3}{*}{$\begin{array}{r}9.03 \\
34.40 \\
9.29\end{array}$} \\
\hline & \multicolumn{6}{|c|}{$\begin{array}{l}\text { Oil consumed, } 1000 \text { bbls. of } 12 \text { gels. and Cost per bbl. } \\
\text { Buu per Gallon end Coot per Million Bev } \\
\text { Cost per Barrel, as delivered, f.o.b. Plant }\end{array}$} & $\begin{array}{r}150.2 \\
151,648\end{array}$ & $\begin{array}{r}2.97 \\
46.32 \\
3.05\end{array}$ & & & & & & \\
\hline $\begin{array}{l}32 \\
33 \\
34 \\
35 \\
36 \\
37 \\
\end{array}$ & \multicolumn{6}{|c|}{$\begin{array}{l}\text { Gas consumed, Million cu.ft., and Cose per } 1000 \text { cu.ft. } \\
\text { Beu per Cubic Fook and Cost per Million Beu }\end{array}$} & $\begin{array}{r}3,901.2 \\
1,000\end{array}$ & $\begin{array}{l}37.73 \\
37.73\end{array}$ & & & & & & \\
\hline 38 & \multicolumn{6}{|c|}{$\begin{array}{l}\text { Average Btu per Kilowatt-hour Net Generation } \\
\text { Average Nubber of Employees }\end{array}$} & \multicolumn{2}{|c|}{$\begin{array}{c}15,111 \\
119 \\
\end{array}$} & \multicolumn{2}{|c|}{9,853} & \multicolumn{2}{|c|}{$\begin{array}{c}11,747 \\
96\end{array}$} & \multicolumn{2}{|c|}{$\begin{array}{l}17,215 \\
130 \\
\end{array}$} \\
\hline $\begin{array}{r}40 \\
41 \\
\end{array}$ & \multicolumn{6}{|c|}{$\begin{array}{l}\text { Type of Conatruction } \\
\text { Initial Year of Plant Operation }\end{array}$} & \multicolumn{2}{|c|}{$\begin{array}{c}\text { Convent 10na 1 } \\
1916 \\
\end{array}$} & \multicolumn{2}{|c|}{$\begin{array}{c}\text { Convent 1onal } \\
1948 \\
\end{array}$} & \multicolumn{2}{|c|}{$\begin{array}{c}\text { Convent 1onal } 1 \\
1939 \\
\end{array}$} & \multicolumn{2}{|c|}{$\begin{array}{c}\text { Convent 1onal } \\
1924 \\
\end{array}$} \\
\hline \multicolumn{15}{|c|}{ CHANGES OR ADDITIONS IN 1957} \\
\hline \multicolumn{7}{|c|}{ TURBO - GENERUTOR CHARACTERISTICS } & \multicolumn{8}{|c|}{ BOILER CHURACTERISTICS } \\
\hline Unit & $m$ & P.F. & P.s.I. & A.P.M. & $k r$. & Yoer & No. & $\begin{array}{l}\text { boo } 1 \text { bo: } \\
\text { ber How }\end{array}$ & P.s.1. & Heat $\mathbf{F}$. & namoe 8 . & & Fuol & Year \\
\hline 1 & 156.2 & 85 & $\begin{array}{r}\text { 2,000 } \\
\text { (Added }\end{array}$ & $\begin{array}{r}3,600 \\
\text { March, }\end{array}$ & $\begin{array}{l}18.0 \\
957)^{\circ}\end{array}$ & 1957 & 1 & 1,050 . & 2,300 & 1,050 & 1,000 & Pulv. & $\operatorname{col} 1$ & 1957 \\
\hline
\end{tabular}

Source: Federal Power Commission Report "Steam-Electric Plant Construction Cost and Annual Production Expenses - Tenth Annual Supplement", 1957. 
Figure C.2: Map of Counties with Fossil-Fuel-Fired Power Plants

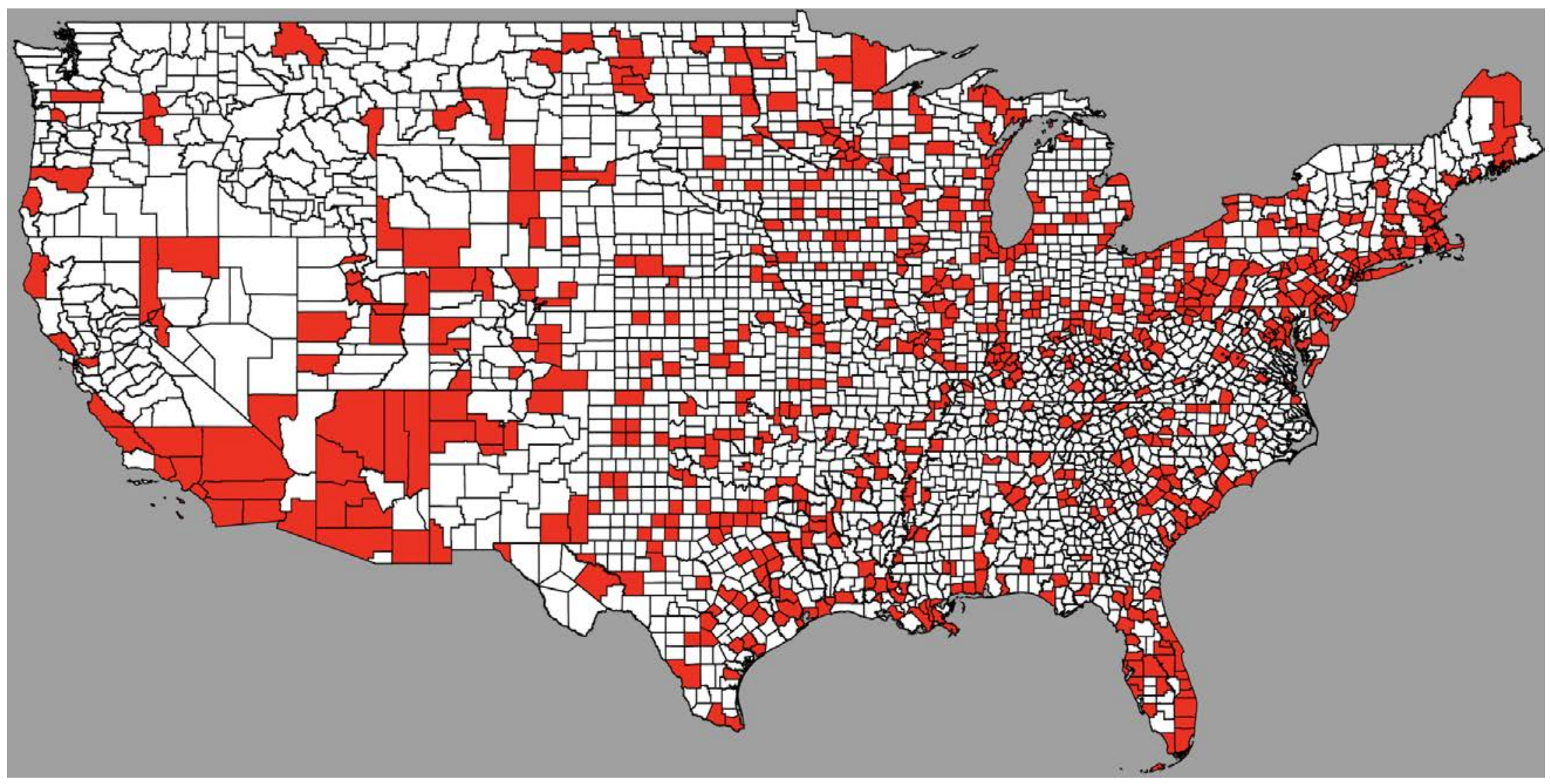

Notes: This figure displays which counties had fossil-fuel-fired power plants at any point between 1938-1994. The counties shaded in red were home to at least one fossil-fuel plant in our sample. There were no power plants in any year of our sample located in the counties shaded in white. 
Figure C.3: Proportion of Electricity Generation Produced in Nonattainment Counties

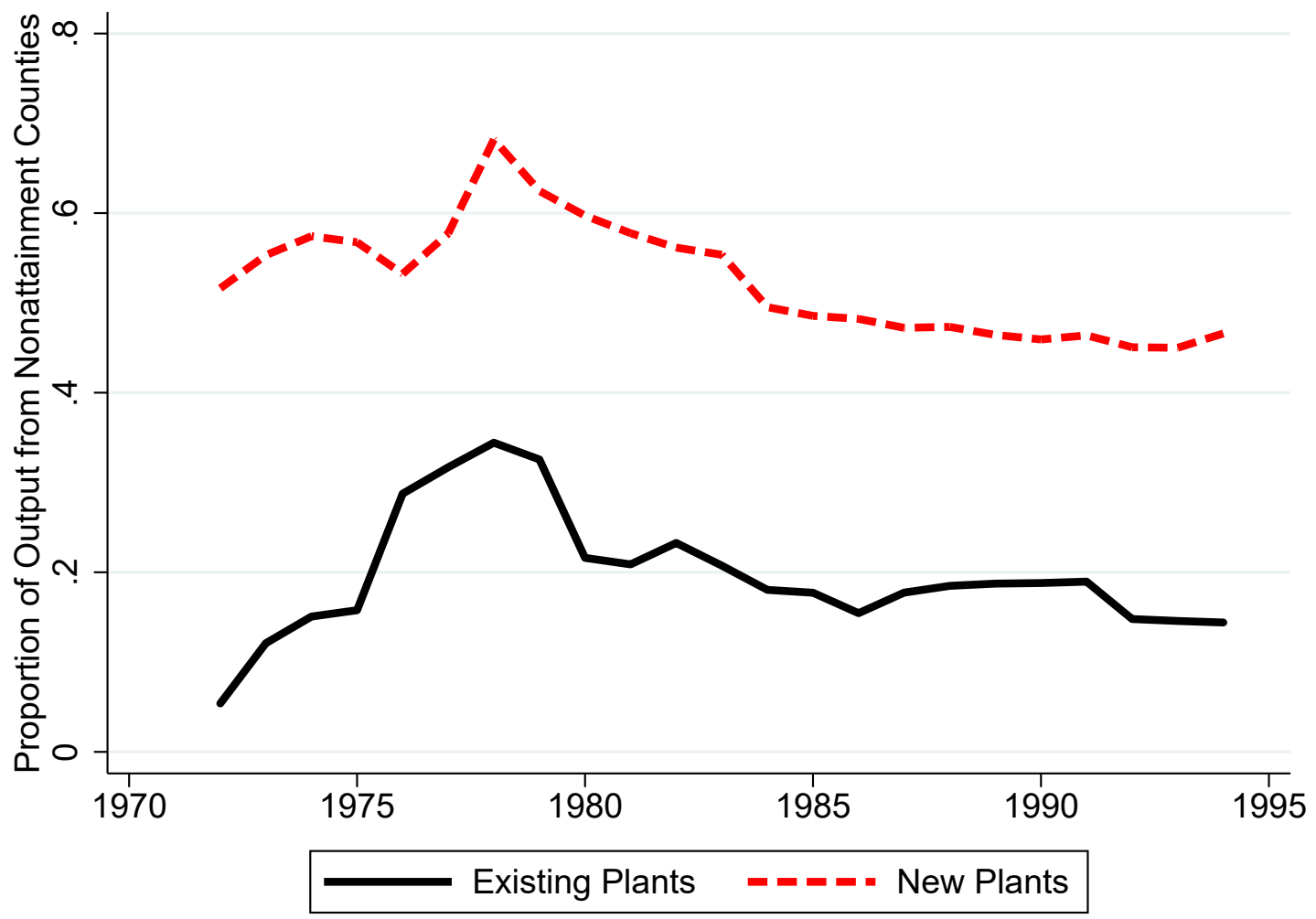

(a) Share of Output from Nonattainment Counties: Any Pollutant Standard

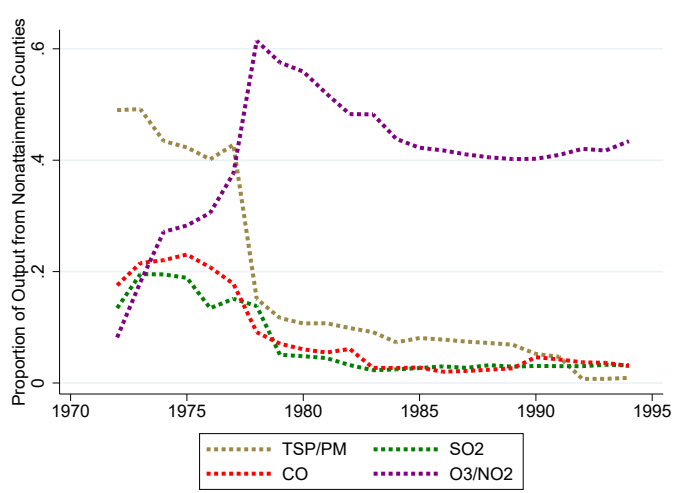

(b) Share of Output from Nonattainment Counties by Pollutant - Existing Plants

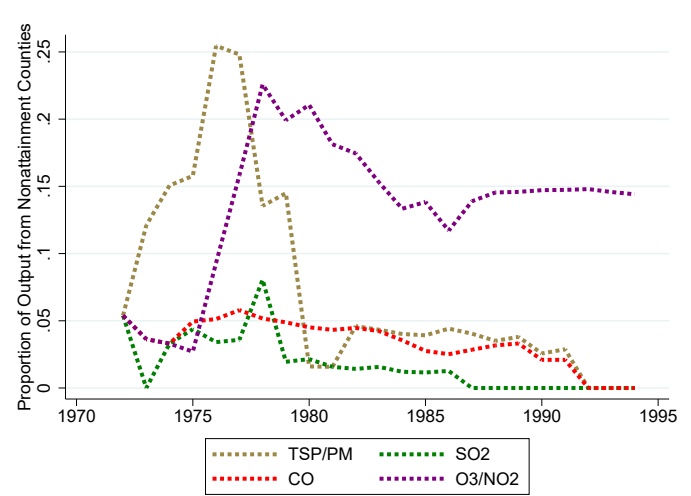

(c) Share of Output from Nonattainment Counties by Pollutant - New Plants

Notes: The top panel of this figure documents the annual aggregate proportion of electricity production from coal plants in counties out of attainment with the NAAQS for any pollutant. The bottom panels document the annual aggregate proportion of electricity production from coal plants in counties out of attainment with the NAAQS for each pollutant, separately for "existing" plants built before 1972 and "new" plants built after 1972. "TSP/PM" refers to standards pertaining to either total suspended particulates (TSP) or particulate matter (PM), "SO2" refers to the standard associated with sulfur dioxide, "CO" refers to the standard associated with carbon monoxide, and "O3/NO2" refers the standards pertaining to either ambient ozone $\left(\mathrm{O}_{3}\right)$ or nitrogen dioxide $\left(\mathrm{NO}_{2}\right)$. 
Figure C.4: Annual Total Electricity Generating Capacity by Source Type

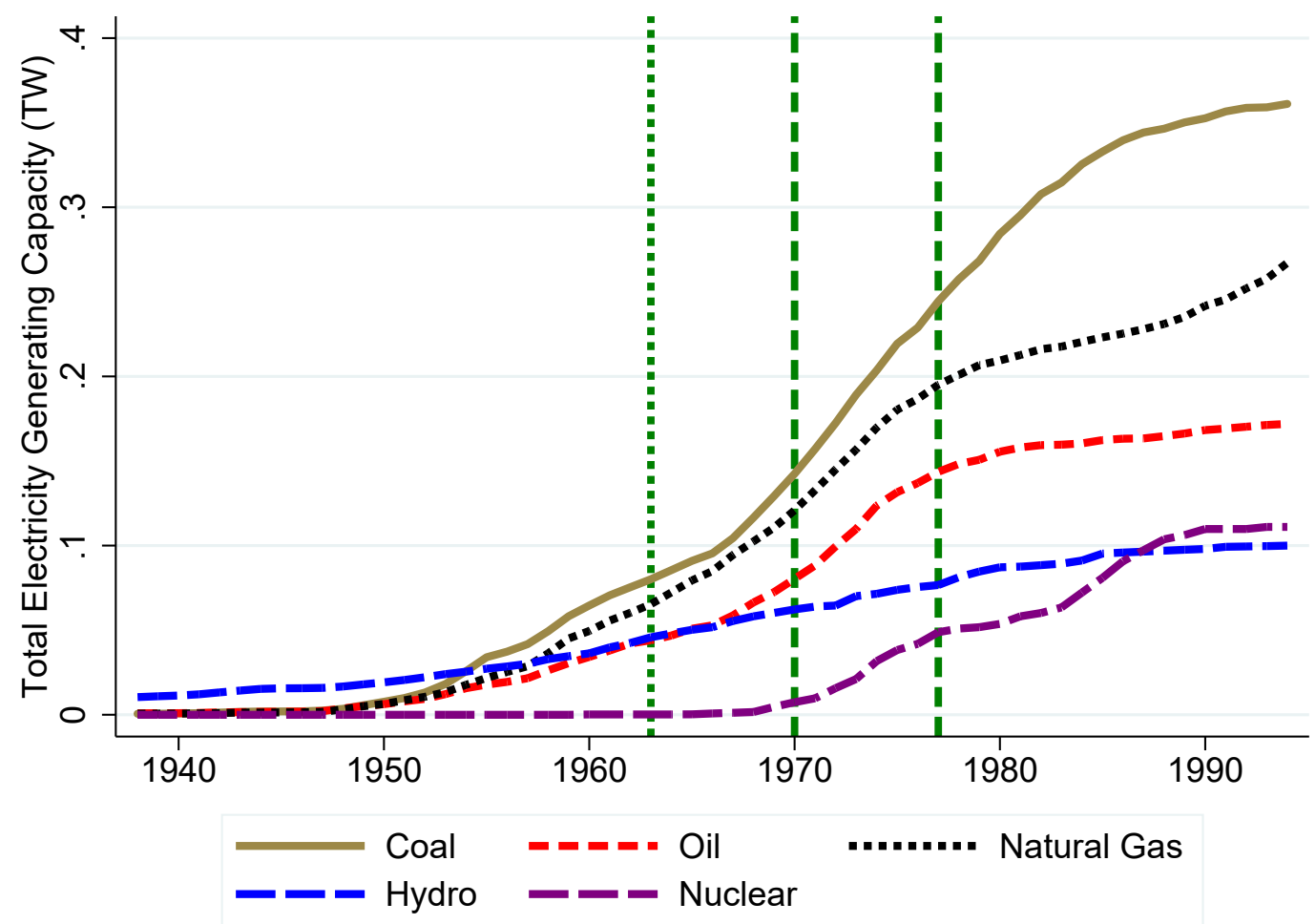

Notes: This figure documents annual national total electricity production capacity by source type. The data underlying this figure come from the eGrid database administered by the USEPA. The thin dashed vertical green line represents the Clean Air Act of 1963 while the thicker vertical green lines represent the 1970 Clean Air Act and its amendments in 1977. 
Figure C.5: Annual Total Electricity Generation and Capacity for Coal Power Plants By Vintage and Attainment Status

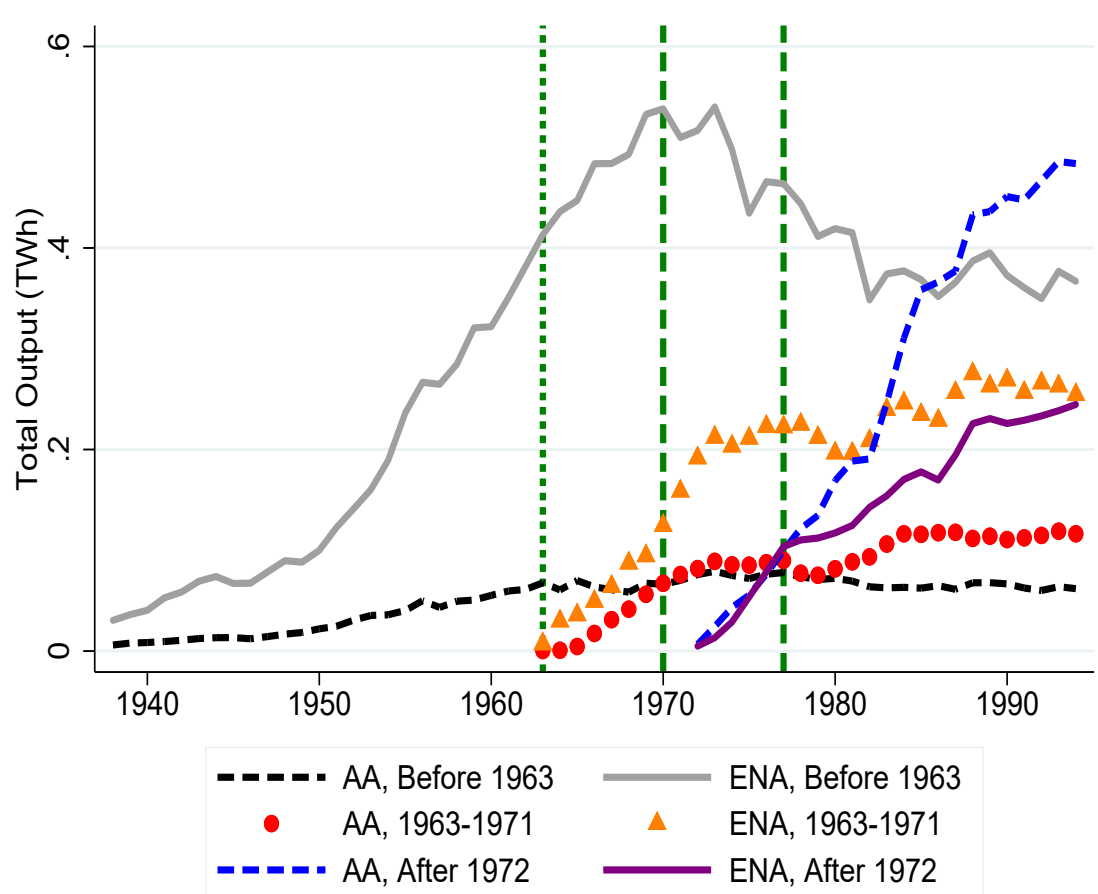

(a) Total Output

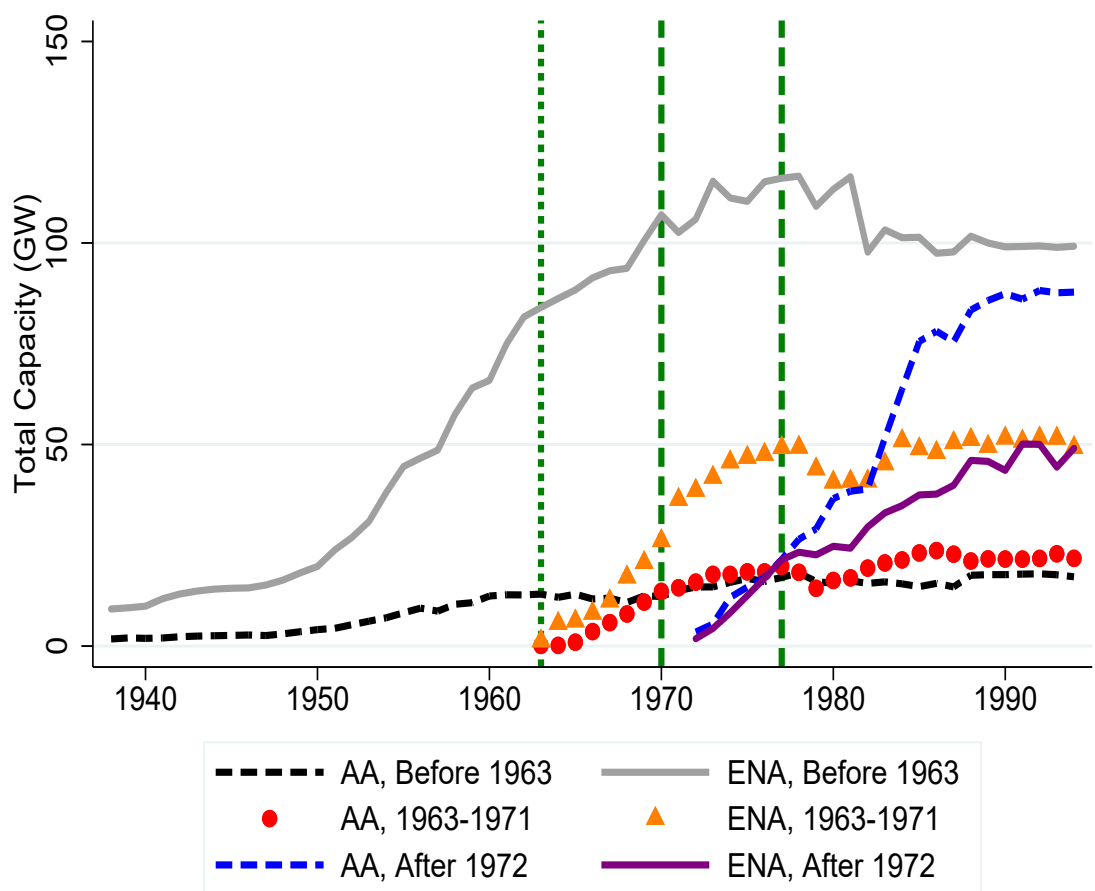

(b) Total Capacity

Notes: The left panel of this figure documents the annual total electricity generation produced by coal plants in the United States. The right panel plots annual total coal-fired electricity generating capacity. Plants are located either in "ever-nonattainment" (ENA) counties that went out of attainment with the National Ambient Air Quality Standards (NAAQS) at least once during our 1938-1994 sample period or in "always-attainment" (AA) counties that never went out of attainment between 1938-1994. We consider three plant vintage groups: plants built before 1963, plants built between 1963-1971, and plants built after 1972. The short-dashed green vertical line represents the passage of the Clean Air Act of 1963 and the dashed green vertical lines represent the passing of the Clean Air Act of 1970 and its amendments in 1977. 
Figure C.6: Annual Total Electricity Generation and Capacity for Coal Power Plants by Vintage and Years in Nonattainment

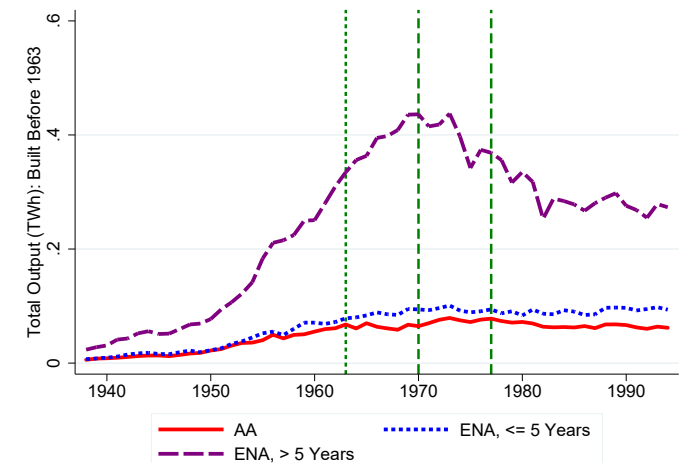

(a) Output - Built Before 1963

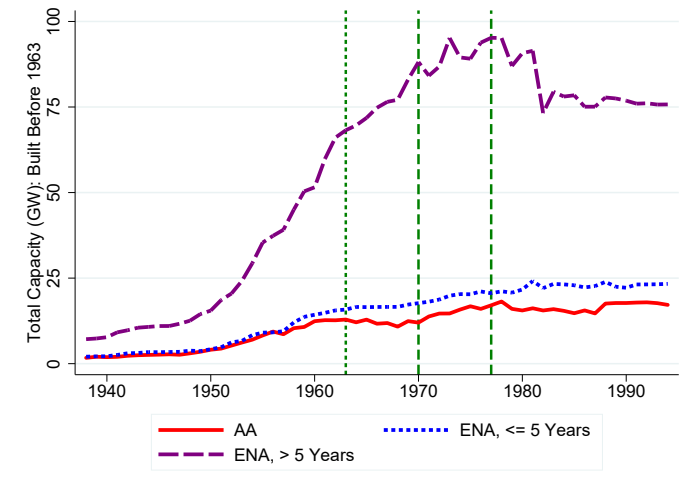

(d) Capacity - Built Before 1963

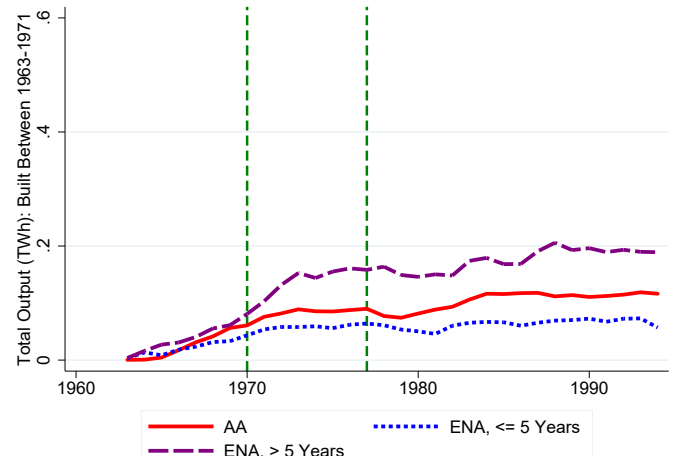

(b) Output - Built Between 1963-1971

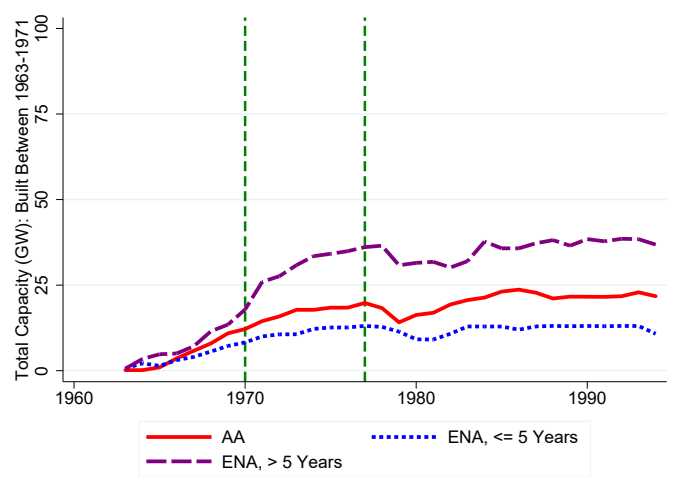

(e) Capacity - Built Between 1963-1971

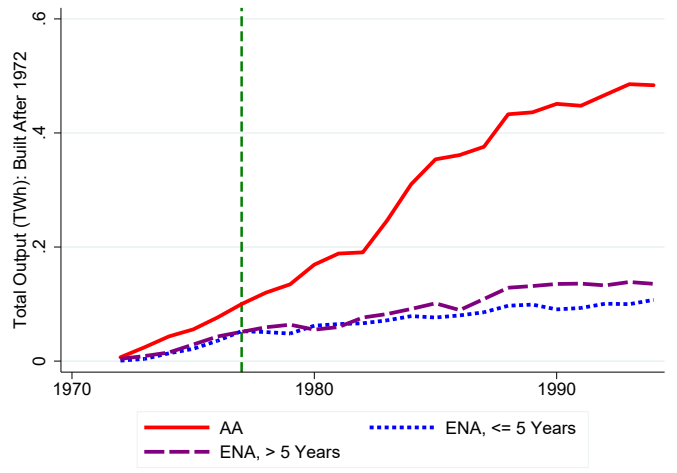

(c) Output - Built After 1972

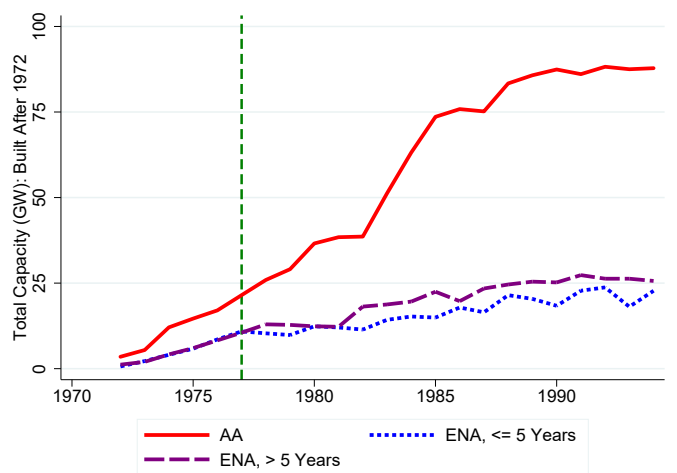

(f) Capacity - Built After 1972

Notes: This figure documents annual total electricity generation and annual total electricity generating capacity for coal plants in the United States. We consider three vintage groups based on whether the plant was built before 1963, between 1963-1971, or after 1972. We consider three regulatory status categories: always-attainment (AA) - counties that never went out of attainment with the NAAQS for any pollutant between 1938-1994; ever-nonattainment for less than five years (ENA, $\leq 5$ Years) - counties that went out of attainment with the NAAQS for less than five years between 1938-1994; and ever-nonattainment for more than five years (ENA, >5 Years) - counties that went out of attainment with the NAAQS for more than five years. The thin dashed vertical green line represents the Clean Air Act of 1963 while the thicker green vertical lines represent the 1970 Clean Air Act and its amendments in 1977. 
Figure C.7: Annual Average Total Factor Productivity for Coal Power Plants by Vintage and Attainment Status

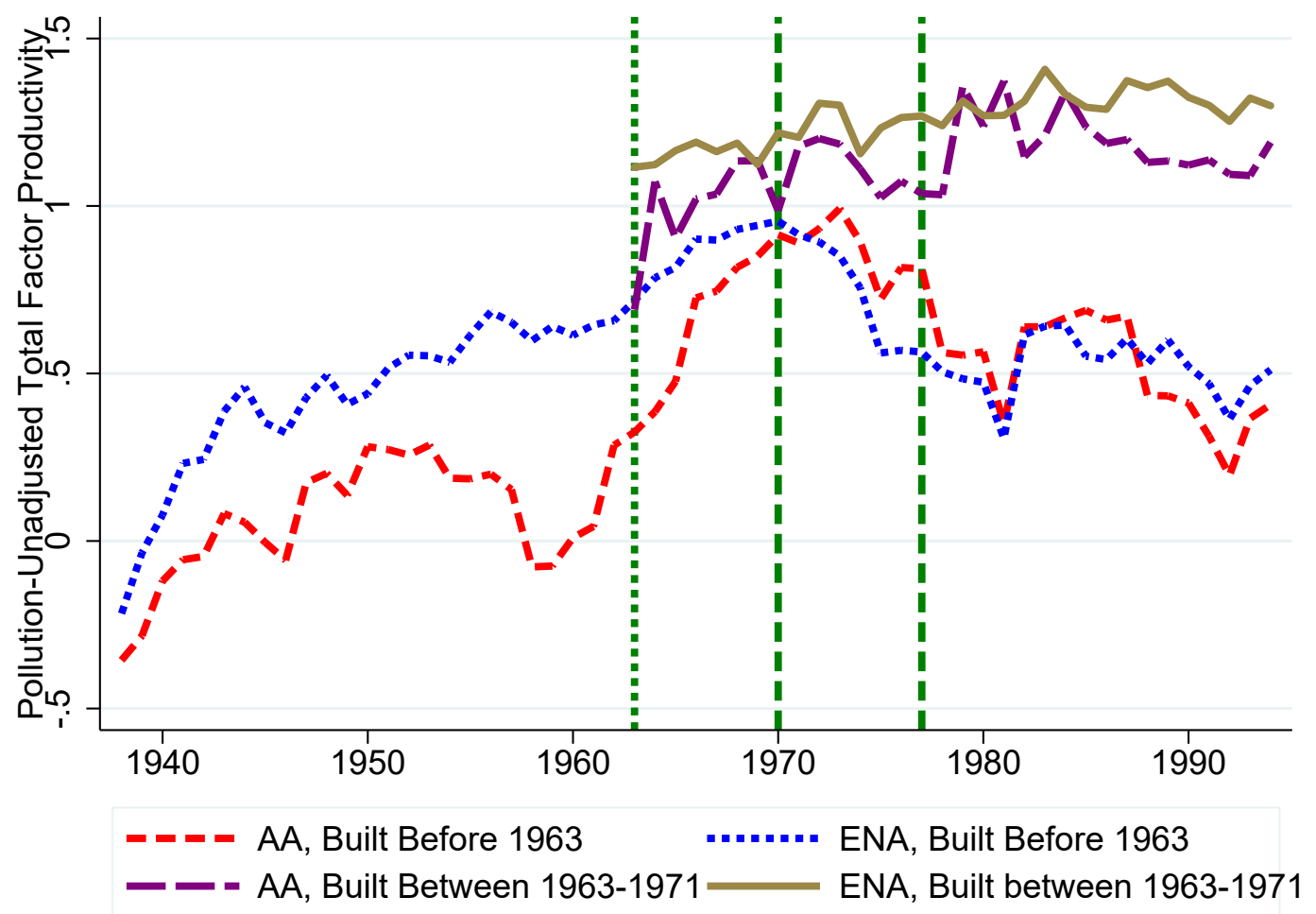

Notes: This figure plots annual average pollution-unadjusted total factor productivity separately for coal plants built before 1963 versus built between 1963-1971 located in always-attainment ("AA") counties versus ever-nonattainment ("ENA") counties. "AA" counties never faced nonattainment between 1938-1994 while "ENA" counties faced nonattainment at least once between 1938-1994. The thin dashed vertical green line represents the Clean Air Act of 1963 while the thicker green vertical lines represent the 1970 Clean Air Act and its amendments in 1977. 
Figure C.8: Annual Average Total Factor Productivity for Coal Power Plants by Vintage and Years in Nonattainment

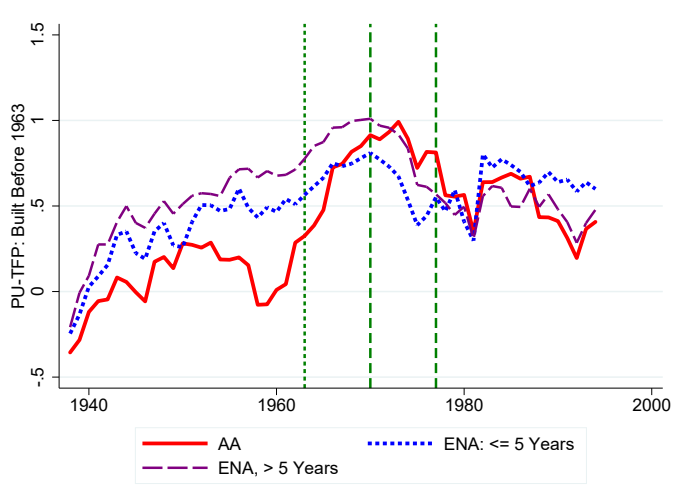

(a) PU-TFP - Built Before 1963

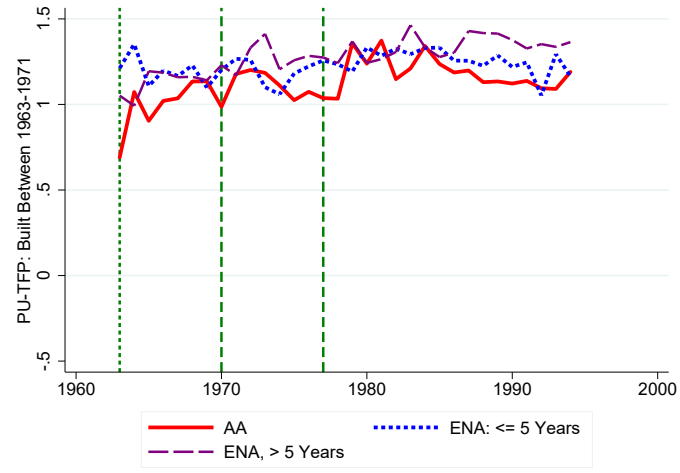

(b) PU-TFP - Built Between 1963-1971

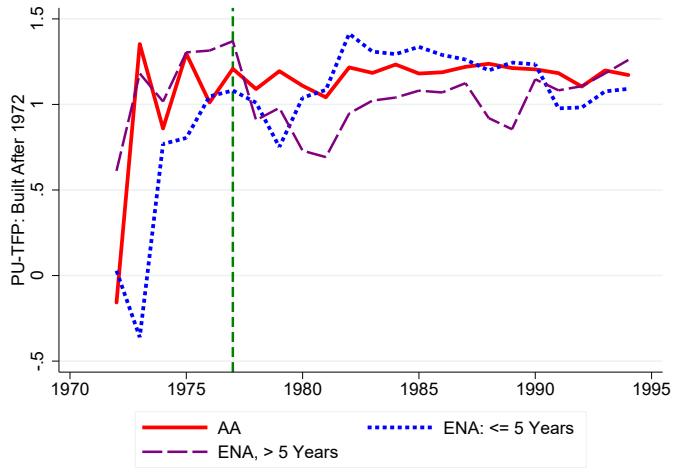

(c) PU-TFP - Built After 1972

Notes: This figure documents annual average pollution-unadjusted total factor productivity (PU-TFP) for coal-fired power plants in the United States. We consider three vintage categories based on whether the plant was built before 1963, between 1963-1971, or after 1972. We consider three regulatory status categories: "always-attainment" (AA) - counties that never went out of attainment with the NAAQS for any pollutant between 1938-1994; "ever-nonattainment" for less than five years (ENA, $\leq 5$ Years) - counties that went out of attainment with the NAAQS for less than five years between 1938-1994; and ENA for more than five years - counties that went out of attainment with the NAAQS for more than five years. The thin dashed vertical green line represents the Clean Air Act of 1963 while the thicker green vertical lines represent the 1970 Clean Air Act and its amendments in 1977. 
Figure C.9: County-Level Distribution of the Number of Years Facing Nonattainment

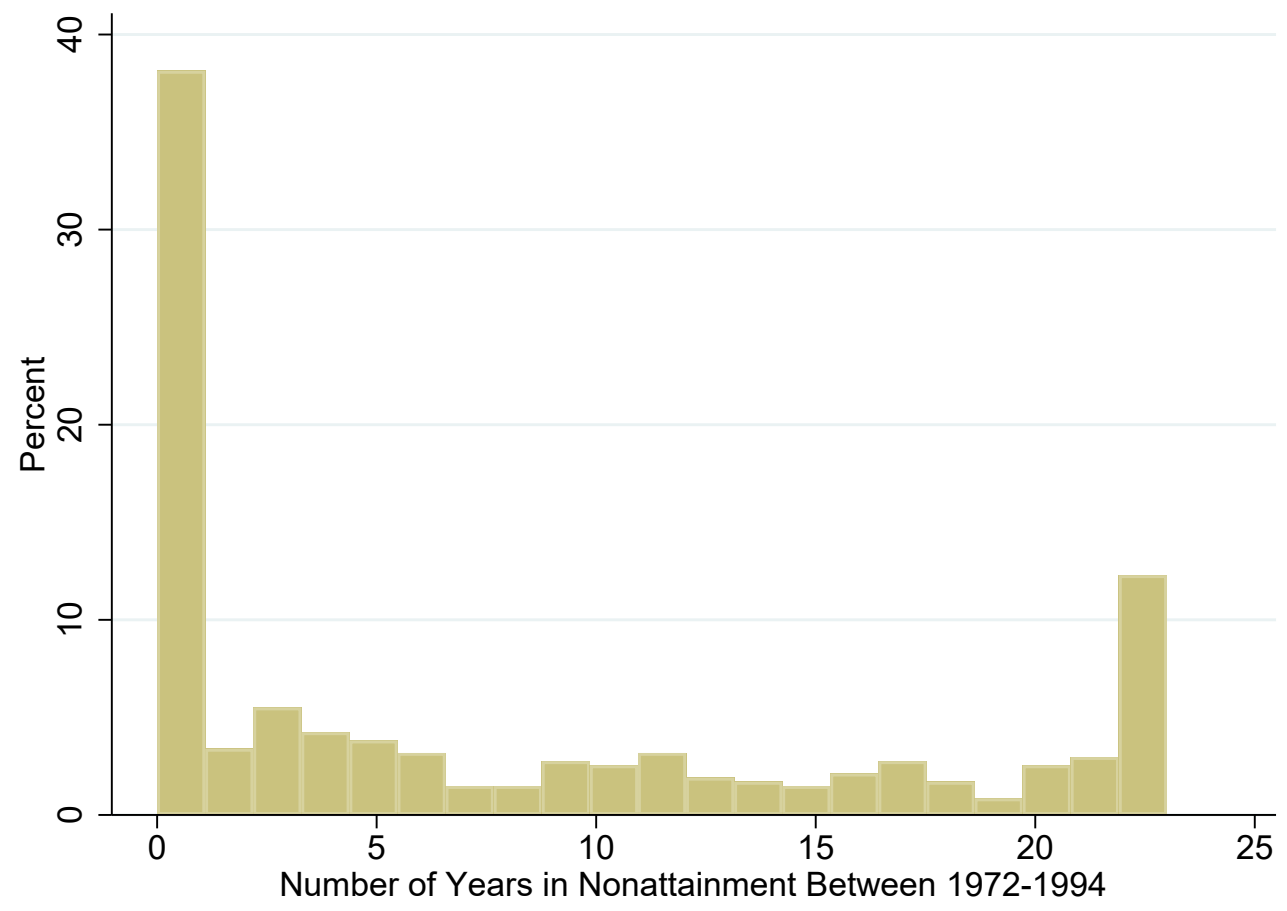

Notes: This histogram plots the distribution of the number of years that the county was in nonattainment between 1972-1994. The unit of observation for this histogram is a county, considering only counties that were home to at least one fossil-fuel power plant in our sample spanning 1938-1994. 
Table C.1: Number of Plants by Attainment Status and Vintage

\begin{tabular}{|c|c|c|c|}
\hline \multicolumn{4}{|c|}{ Panel A. Number of Coal-Fired Power Plants } \\
\hline & Built Before 1963 & Built Between 1963-1971 & Built After 1972 \\
\hline Always Attainment & 91 & 25 & 83 \\
\hline Ever Nonattainment & 214 & 43 & 40 \\
\hline Total & 305 & 68 & 123 \\
\hline \multicolumn{4}{|c|}{ Panel B. Proportion By Vintage } \\
\hline & Built Before 1963 & Built Between 1963-1971 & Built After 1972 \\
\hline Always Attainment & 0.30 & 0.37 & 0.67 \\
\hline Ever Nonattainment & 0.70 & 0.63 & 0.33 \\
\hline
\end{tabular}

Notes: The top panel of this table lists the number of coal power plants in our sample in each cell defined by the intersection of attainment status and vintage. The bottom panel lists the proportion of coal plants in a given vintage group in each attainment status. The first row of each panel focuses on plants that never faced nonattainment between 1972-1994 while the second row focuses on plants that faced nonattainment at least once between 1972-1994. The first, second and third columns of each panel consider plants built before 1963, plants built between 1963-1971, and plants built after 1972 respectively.

Table C.2: Attainment Status versus Lagged Attainment Status

\begin{tabular}{lcc}
\hline \hline Panel A. Number of Observations From 1972-1994 \\
& Attainment in Year $t$ & Nonattainment in Year $t$ \\
Attainment in Year $t-1$ & 3,766 & 333 \\
Nonattainment in Year $t-1$ & 182 & 3,107 \\
\hline Panel B. Conditional Probability & Attainment in Year $t$ & Nonattainment in Year $t$ \\
\multicolumn{4}{c}{ Attainment in Year $t-1$} & 0.92 & 0.08 \\
Nonattainment in Year $t-1$ & 0.06 & 0.94 \\
\hline \hline
\end{tabular}

Notes: The top panel of this table lists the number of observations in each of the four categories defined by attainment status in years $t$ and $t-1$. The bottom panel lists the probabilities of being in attainment and nonattainment in year $t$ conditional on being in attainment or nonattainment in year $t-1$. The unit of observation underlying this table is plant-year, considering all coal plants over the sample period 1972-1994. 
Table C.3: Summary Statistics: PU-TFP, Ouput, Inputs, and Attainment Status

\begin{tabular}{|c|c|c|c|}
\hline \multicolumn{4}{|c|}{ Panel A: Power Plant Operations, Sample Period 1938-1994 } \\
\hline Variable & No. of Obs. & Mean & Std. Dev. \\
\hline Log Pollution-Unadjusted Total Factor Productivity & 12,757 & 0.65 & 0.76 \\
\hline Electricity Output (GWh) & 12,757 & $2,211.89$ & $2,604.16$ \\
\hline Electricity Generating Capacity (MW) & 12,757 & 487.97 & 517.77 \\
\hline Number of Employees & 12,757 & 159.83 & 125.36 \\
\hline Fuel Burned (in Billion BTU) & 12,757 & $22,787.20$ & $25,299.95$ \\
\hline \multicolumn{4}{|c|}{ Panel B: Indicator for NAAQS Noncompliance, Sample Period 1972-1994 } \\
\hline Variable & No. of Obs. & Mean & Std. Dev. \\
\hline $1[$ Out of Attainment with any NAAQS] & 6,052 & 0.52 & 0.50 \\
\hline $1[$ Out of Attainment with NAAQS: TSP or PM] & 6,052 & 0.17 & 0.38 \\
\hline $1\left[\right.$ Out of Attainment with NAAQS: $\left.\mathrm{SO}_{2}\right]$ & 6,052 & 0.07 & 0.26 \\
\hline $1[$ Out of Attainment with NAAQS: CO] & 6,052 & 0.12 & 0.33 \\
\hline 1[Out of Attainment with NAAQS: $\mathrm{O}_{3}$ or $\left.\mathrm{NO}_{2}\right]$ & 6,052 & 0.41 & 0.49 \\
\hline
\end{tabular}

Notes: This table presents summary statistics pertaining to our difference-in-differences regressions assessing the impact of nonattainment on power plant operations. We estimate annual plant-level PU-TFP based on a Leontiff function of: (1) a translog production function of capital (electricity generating capacity) and labor (average number of employees), and (2) fuel (heat input in billions of BTU of fuel burned) using the estimation procedure developed by Ackerberg, Caves and Frazer (2015). 
Table C.4: Production Function Estimates: Different Methods and Functional Forms

\begin{tabular}{|c|c|c|c|c|}
\hline Dep. Var.: Log Output & (1) & $(2)$ & (3) & (4) \\
\hline \multicolumn{5}{|c|}{ Panel A. Estimated Parameters } \\
\hline Log Labor (l) & $\begin{array}{c}1.078^{* * *} \\
(0.004)\end{array}$ & $\begin{array}{c}1.437^{* * *} \\
(0.010)\end{array}$ & $\begin{array}{c}1.625^{* * *} \\
(0.002)\end{array}$ & $\begin{array}{c}2.105^{* * *} \\
(0.010)\end{array}$ \\
\hline Log Capacity (k) & $\begin{array}{c}0.608^{* * *} \\
(0.005)\end{array}$ & $\begin{array}{c}-0.045^{* * *} \\
(0.015)\end{array}$ & $\begin{array}{c}0.272^{* * *} \\
(0.002)\end{array}$ & $\begin{array}{c}-0.354^{* * *} \\
(0.011)\end{array}$ \\
\hline $1 \times 1$ & $\begin{array}{c}-0.052^{* * *} \\
(0.002)\end{array}$ & $\begin{array}{c}-0.027 \\
(0.018)\end{array}$ & $\begin{array}{c}-0.172^{* * *} \\
(0.001)\end{array}$ & $\begin{array}{c}-0.122^{* * *} \\
(0.011)\end{array}$ \\
\hline $\mathrm{l} \times \mathrm{k}$ & $\begin{array}{c}-0.049^{* * *} \\
(0.001)\end{array}$ & $\begin{array}{c}-0.114^{* * *} \\
(0.011)\end{array}$ & $\begin{array}{c}0.076^{* * *} \\
(0.000)\end{array}$ & $\begin{array}{c}-0.144^{* * *} \\
(0.018)\end{array}$ \\
\hline $\mathrm{k} \times \mathrm{k}$ & $\begin{array}{l}0.011^{* *} \\
(0.005)\end{array}$ & $\begin{array}{c}-0.015^{* *} \\
(0.007)\end{array}$ & $\begin{array}{l}0.011^{* *} \\
(0.004)\end{array}$ & $\begin{array}{l}-0.006 \\
(0.010)\end{array}$ \\
\hline Nonfuel Expenses & & Y & & $\mathrm{Y}$ \\
\hline Fuel Types Considered & & & All & All \\
\hline Number of Obs. & 15,153 & 15,082 & 22,067 & 22,011 \\
\hline Number of Plants & 521 & 521 & 790 & 790 \\
\hline \multicolumn{5}{|c|}{ Panel B. Post-Estimation Elasticities } \\
\hline Log Employees & 0.33 & 0.54 & 0.49 & 0.30 \\
\hline Log Capacity & 0.51 & 0.38 & 0.74 & 0.61 \\
\hline Log Nonfuel Expenses & & 0.38 & & 0.39 \\
\hline
\end{tabular}

Notes: This table reports the production function estimates that are used to construct pollutionunadjusted total factor productivity (PU-TFP). Panel A presents the estimated parameters of the production function with capital (electricity generating capacity), labor (average number of employees), and fuel (the heat input in mmBTU from the fuel burned) using the estimation procedure developed by Ackerberg, Caves and Frazer (2015). We consider specifications with and without nonfuel cost, which refers to all operating expenses other than those associated with fuel. We estimate productivity focusing only on coal plants in Columns 1 and 2 and pooling across coal, oil, and gas plants in Columns 3 and 4 . Our preferred specification, which is the basis for the PU-TFP measure used in the main analysis, is presented in column 1. Panel B reports implied elasticities for each input. The unit of observation for all of these analyses is plant-year. ${ }^{* * *}$ denotes statistical significance at the $1 \%$ level, ${ }^{* *}$ at the $5 \%$ level, and ${ }^{*}$ at the $10 \%$ level. Standard errors in parentheses are calculated by bootstrapping. 


\section{Additional Results}

This appendix section reports additional estimates in support of the main findings in the paper. They shed light on the mechanisms behind the main findings, consider heterogeneity in the estimated effects, or test the robustness of the main results.

Appendix Figure D.1 examines how the estimated impacts of nonattainment on power plant outcomes for plants of different vintages vary by the first year of data in the analysis. This figure highlights the importance of utilizing data from well before the Clean Air Act (CAA) of 1970 or even the 1963 CAA.

Appendix Figure D.2 presents event study estimates of the impacts of nonattainment on productivity including only plant fixed effects and year fixed effects (i.e., not including state-by-year fixed effects). These estimates are presented both for plants built before 1963 and between 1963-1971, using both the traditional two-way fixed effects approach and the methodology specified in Callaway and Sant'Anna (2021).

Appendix Table D.1 compares estimates using the full 1938-1994 sample period to results based solely on post-1972 data.

Appendix Table D.2 reports the results of the Goodman-Bacon decomposition. These results indicate that the bulk of the impacts of first nonattainment on plant operations come from a comparison of plants that ever versus never faced nonattainment between 1972-1994. This highlights again the importance of estimating the effects of nonattainment including data from before the implementation of the CAA in 1972.

Appendix Table D.3 reports heterogeneous impacts of nonattainment by the first year that the county faces nonattainment, These results suggest again that the bulk of the impacts are driven by the initial county-level designations of attainment status in 1972 .

Appendix Table D.4 reports the estimated impacts of nonattainment on power plant outcomes for more granular vintage groups. For reference, the main analysis estimates separate effects only for plants built before 1963 versus plants built between 1963-1971.

Appendix Table D.5 reproduces the main estimates of the impacts of nonattainment on plant operations from Table 1 using the definitions of nonattainment between 19721977 based on Air Quality Control Regions constructed by Cropper et al. (2022).

Appendix Table D.6 documents robustness to alternative specifications and samples 
while Appendix Table D.7 checks whether the estimated impact of nonattainment on pollution-unadjusted total factor productivity (PU-TFP) changes if we estimate PU-TFP including a measure of input materials or consider alternative production functions. Appendix Table D.8 examines the heterogeneity of the main results by the plant's primary fuel type. Appendix Table D.9 investigates the effects of nonattainment with the standards for specific pollutants rather than focusing on nonattainment with any pollutant standard.

Appendix Table D.10 examines how annual statewide electricity generating capacity by source responds to the proportion of counties in nonattainment in the state in the year.

The outline of the figures and tables in this appendix section is below.

- Figure D.1. Impacts of Nonattainment on Power Plant Productivity by Vintage and Initial Sample Year

- Figure D.2. Event Study Analysis of the Impacts of First Year in Nonattainment on Power Plant Productivity - Alternative Specifications

- Table D.1. Comparison of Estimates for Existing and New Plants: Using Sample Periods 1938-1994 versus 1972-1994

- Table D.2. Results of the Goodman-Bacon Decomposition for First Nonattainment

- Table D.3. Impacts of Nonattainment on Power Plant Outcomes by First Year in Nonattainment

- Table D.4. Impacts of Nonattainment on Power Plant Outcomes by Additional Vintage Groups

- Table D.5. Impacts of Nonattainment on Power Plant Operations from 1938-1994: AQCR-Based Attainment Status

- Table D.6. Impacts of Nonattainment on Power Plant Productivity from Alternative Specifications and Samples 
- Table D.7. Impacts of Nonattainment on PU-TFP Estimated Using Alternative Production Functions and Specifications

- Table D.8. Impacts of Nonattainment on Power Plant Outcomes by Primary Fuel Type

- Table D.9. Impacts of Nonattainment on Power Plant Outcomes By Pollutant Standard

- Table D.10. Impact of Proportion of Counties in Nonattainment on State-Level Capacity 
Figure D.1: Impacts of Nonattainment on Power Plant Productivity by Vintage and Initial Sample Year

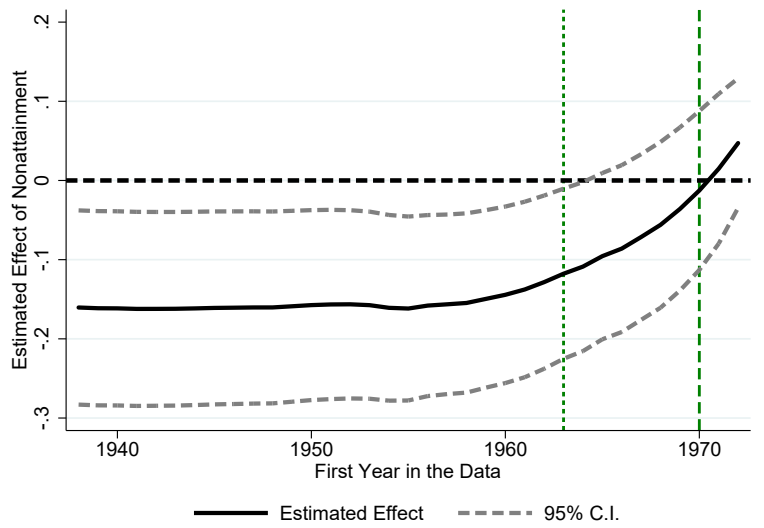

(a) Effects on Log PU-TFP Built Before 1963

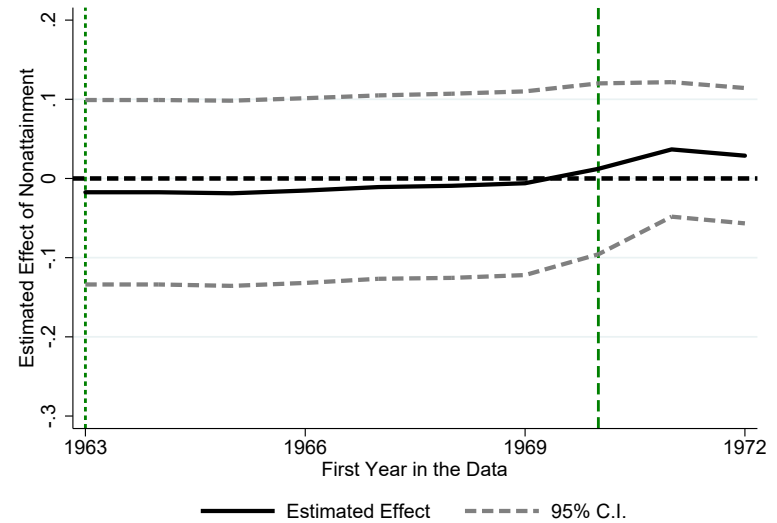

(b) Effects on Log PU-TFP Built Between 1963-1971

Notes: This figure displays the estimated impacts of nonattainment on the log of pollutionunadjusted total factor productivity (PU-TFP) by initial sample year, separately for coal plants built before 1963 (left panel) and for coal plants built between 1963-1971 (right panel). Namely, for initial year X on the $\mathrm{X}$-axis, we artificially restrict the sample period used to estimate the relevant effect to X-1994 (e.g., the effect for initial year 1950 is estimated using data from 1950-1994). The short-dashed green vertical line represents the passage of the Clean Air Act of 1963 and the dashed green vertical line represents the Clean Air Act of 1970. All specifications include plant fixed effects and state by year fixed effects. The $95 \%$ confidence intervals reported in these figures are based on standard errors that are two-way clustered by county and year. 
Figure D.2: Event Study Analysis of the Impacts of First Year in Nonattainment on Power Plant Productivity - Alternative Specifications

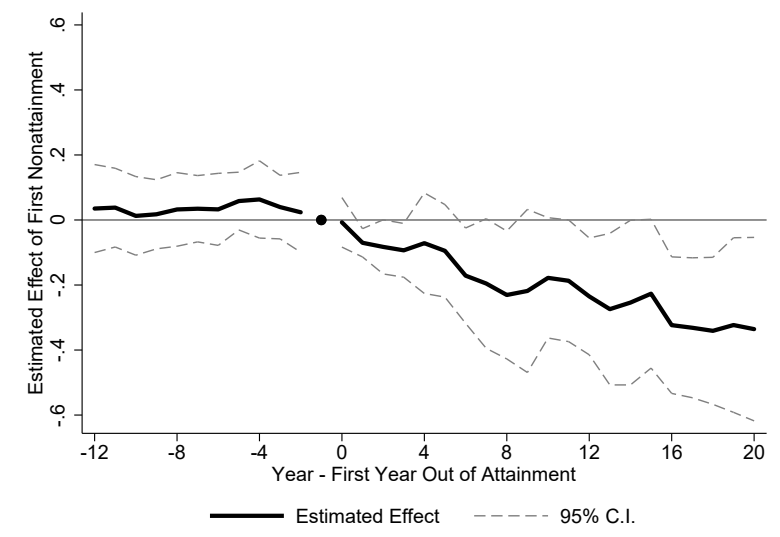

(a) Log PU-TFP, Built Before 1963, Replacing State-by-Year FE with Year FE

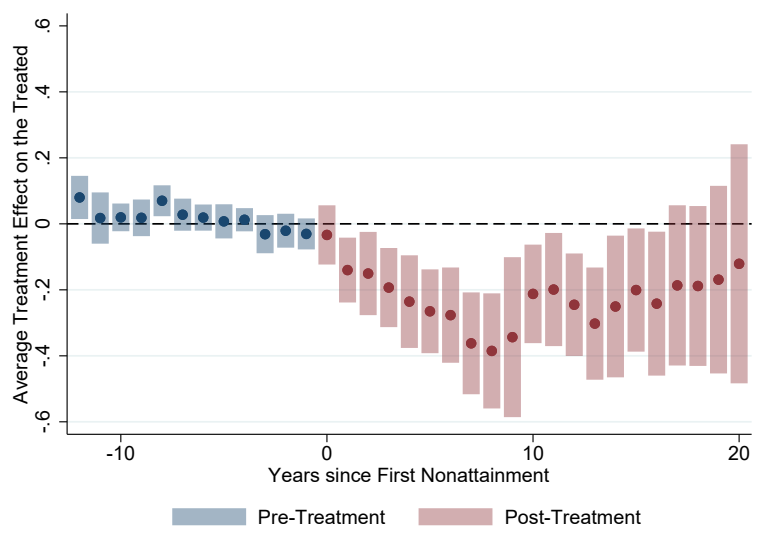

(c) Effects on Log PU-TFP Built Before 1963

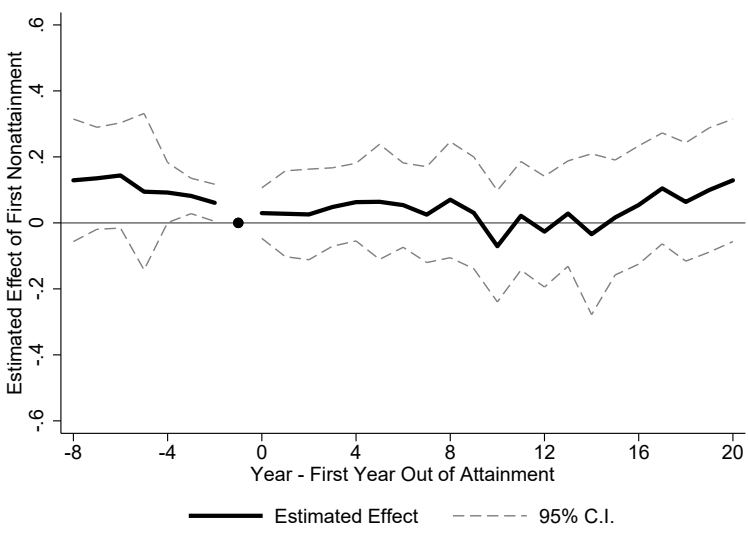

(b) Log PU-TFP, Built Between 1963-1971, Replacing State-by-Year FE with Year FE

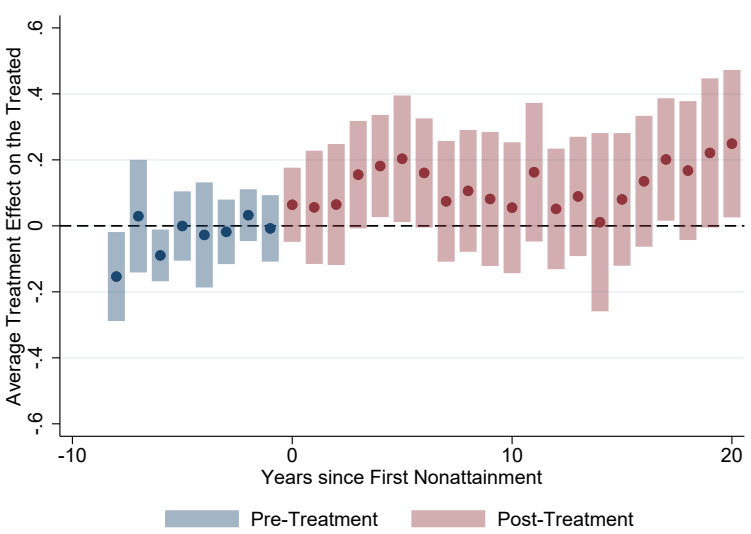

(d) Effects on Log PU-TFP Built Between 1963-1971

Notes: These event study figures plot the estimated effect of first nonattainment on the $\log$ of pollution-unadjusted total factor productivity (PU-TFP) separately for each event year. The top two panels are based on the traditional event study specification while the bottom two panels present estimates from the methodology specified in Callaway and Sant'Anna (2021). The period of analysis is 1938-1994. All specifications include plant fixed effects and year fixed effects. The $95 \%$ confidence intervals reported in these figures are based on standard errors that are two-way clustered by county and year. The left panels are estimated using coal plants built before 1963 and the right panels focus on coal plants built between 1963-1971. 
Table D.1: Comparison of Estimates for Existing and New Plants Using Sample Periods 1938-1994 versus 1972-1994

\begin{tabular}{lcccc}
\hline \hline Dep. Variable: Log PU-TFP & $(1)$ & $(2)$ & $(3)$ & $(4)$ \\
Nonattainment & & & & \\
& $-0.135^{* *}$ & $-0.136^{* *}$ & 0.048 & 0.053 \\
& $(0.054)$ & $(0.055)$ & $(0.033)$ & $(0.115)$ \\
$\mathrm{R}^{2}$ & & & & \\
Mean of Dep. Var. & 0.707 & 0.695 & 0.824 & 0.881 \\
Number of Obs. & 0.653 & 0.702 & 0.734 & 1.133 \\
Number of Plants & 12,757 & 11,947 & 6,052 & 1,427 \\
Plant FE & 373 & 324 & 324 & 123 \\
State By Year FE & $\mathrm{Y}$ & $\mathrm{Y}$ & $\mathrm{Y}$ & $\mathrm{Y}$ \\
Vintage Group By Year FE & $\mathrm{Y}$ & $\mathrm{Y}$ & $\mathrm{Y}$ & $\mathrm{Y}$ \\
Type of Plant & Existing & Existing & Existing & New \\
Sample Period & $1938-1994$ & $1938-1994$ & $1972-1994$ & $1972-1994$ \\
\hline \hline
\end{tabular}

Notes: This table reports the estimated impacts of nonattainment on the log of pollution-unadjusted total factor productivity (PU-TFP) of existing and new coal plants over alternative periods of analysis. The unit of observation for the regressions in this table is plant-year. For all specifications, "nonattainment" is defined as the county being out of attainment with the NAAQS for any pollutant in the year. Column 1 is estimated for the sample period 1938-1994 considering all "existing" coal plants built before 1972. Column 2 is estimated for the sample period 1938-1994 considering all "existing" coal plants that operated in at least one year between 1972-1994. Column 3 is estimated for the sample period 1972-1994 focusing on all "existing" coal plants. Column 4 is estimated for the sample period 1972-1994 focusing on all "new" coal plants built after 1972. All specifications include plant fixed effects, state by year fixed effects, and vintage group by year fixed effects; plants built before 1963 are in vintage group 1, plants built between 1963-1971 are in vintage group 2, and plants built after 1972 are in vintage group 3. Standard errors in parentheses are two-way clustered by county and year. ${ }^{* * *}$ denotes statistical significance at the $1 \%$ level, ${ }^{* *}$ at the $5 \%$ level, and ${ }^{*}$ at the $10 \%$ level. 
Table D.2: Results of the Goodman-Bacon Decomposition for First Nonattainment

\begin{tabular}{lccccc}
\hline \hline Dep. Var. (in Logs) & $(1)$ & $(2)$ & $(3)$ & $(4)$ & $(5)$ \\
OU-TFP & Output & Fuel Use & No. Employees & Capacity \\
& -0.125 & -0.207 & -0.324 & -0.074 & -0.113 \\
DD Est.: T vs. Never Treated & -0.181 & -0.305 & -0.423 & -0.125 & -0.163 \\
DD Est.: Timing Groups & -0.053 & -0.081 & -0.196 & -0.008 & -0.050 \\
DD Est.: Within Residual Component & 0.609 & 0.590 & 0.357 & -0.189 & 0.053 \\
Weights: T vs. Never Treated & 0.561 & 0.561 & 0.561 & 0.561 & 0.561 \\
Weights: Timing Groups & 0.439 & 0.439 & 0.439 & 0.439 & 0.439 \\
Weights: Within Residual Component & 0.000 & 0.000 & 0.000 & 0.000 & 0.000 \\
Number of Obs. & 2,730 & 2,730 & 2,730 & 2,730 & 2,730 \\
Number of Plants & 130 & 130 & 130 & 130 & 130 \\
\hline \hline
\end{tabular}

Notes: This table reports the results from running the Goodman-Bacon decomposition on panel regressions of first nonattainment on plant outcomes (Goodman-Bacon, 2021). The decomposition requires a strongly balanced panel. We consider only coal plants built before 1972. To construct the panel, we include only plants with consecutive observations for 10 years before and after 1972 . Plant-year observations must have data listed for output, electricity generating capacity, number of employees, and input energy for the whole 21 year span in order to be included. The overall DD estimate is reported in the first row. The unit of observation in this analysis is plant-year, and the regressions include plant fixed effects and vintage-group-by-year fixed effects; plants built before 1963 versus built between 1963-1971 are in vintage groups 1 and 2 respectively. For all specifications, "first nonattainment" is an indicator variable that is equal to one for each year on or after the first year that the plant faced nonattainment with the NAAQS for any pollutant. The GoodmanBacon method decomposes the overall difference-in-differences ("DD") effect of first nonattainment into three components: (i) counties that ever face nonattainment versus counties that never face nonattainment during our 1938-1994 sample period ("T vs. Never Treated"), (ii) counties that first face nonattainment earlier, using counties first facing nonattainment later as controls ("Earlier $\mathrm{T}$ vs. Later C"), and (iii) counties that first face nonattainment later, using counties first facing nonattainment earlier as controls ("Later T vs. Earlier C"). For each component, the decomposition provides both the DD estimate and the weight of this estimate in calculating the overall DD estimate. 
Table D.3: Impacts of Nonattainment on Outcomes by First Year in Nonattainment

\begin{tabular}{lccccc}
\hline \hline Dep. Var. (in Logs) & $(1)$ & $(2)$ & $(3)$ & $(4)$ & $(5)$ \\
& PU-TFP & Output & Fuel Use & No. Employees & $\begin{array}{c}\text { Capacity } \\
\text { First NA in 1972-1977 }\end{array}$ \\
& $-0.160^{* * *}$ & $-0.274^{* * *}$ & $-0.251^{* * *}$ & $-0.092^{* *}$ & $-0.178^{* * *}$ \\
& $(0.059)$ & $(0.087)$ & $(0.081)$ & $(0.042)$ & $(0.062)$ \\
First NA in 1978-1994 & 0.073 & 0.058 & 0.023 & -0.015 & -0.027 \\
& $(0.069)$ & $(0.117)$ & $(0.140)$ & $(0.099)$ & $(0.119)$ \\
$\mathrm{R}^{2}$ & 0.708 & 0.835 & 0.781 & 0.861 & 0.906 \\
Mean of Dep. Var. & 0.653 & 7.007 & 16.307 & 4.779 & 5.631 \\
Number of Obs. & 12,757 & 12,757 & 12,757 & 12,757 & 12,757 \\
Number of Plants & 373 & 373 & 373 & 373 & 373 \\
Plant FE & $\mathrm{Y}$ & $\mathrm{Y}$ & $\mathrm{Y}$ & $\mathrm{Y}$ & $\mathrm{Y}$ \\
State By Year FE & $\mathrm{Y}$ & $\mathrm{Y}$ & $\mathrm{Y}$ & $\mathrm{Y}$ & $\mathrm{Y}$ \\
Vintage Group by Year FE & $\mathrm{Y}$ & $\mathrm{Y}$ & $\mathrm{Y}$ & $\mathrm{Y}$ & $\mathrm{Y}$ \\
\hline \hline
\end{tabular}

Notes: This table measures how annual plant-level outcomes change with nonattainment interacted with two bins associated with whether the first year that the plant faced nonattainment was in 19721977 or 1978-1994. For all specifications, "nonattainment" (NA) is defined as the county being out of attainment with the NAAQS for any pollutant in the year. PU-TFP stands for pollution-unadjusted total factor productivity. The unit of observation for these regressions is plant-year, considering only coal plants built before 1972. Standard errors in parentheses are two-way clustered by county and year. ${ }^{* * *}$ denotes statistical significance at the $1 \%$ level, ${ }^{* *}$ at the $5 \%$ level, and ${ }^{*}$ at the $10 \%$ level. 
Table D.4: Impacts of Nonattainment on Power Plant Outcomes By Additional Vintage Groups

\begin{tabular}{lccccc}
\hline \hline & $(1)$ & $(2)$ & $(3)$ & $(4)$ & $(5)$ \\
Dep. Var. (in Logs) & PU-TFP & Output & Fuel Use & No. Employees & Capacity \\
NA $\times 1$ [Built Before 1955] & $-0.164^{* *}$ & $-0.273^{* * *}$ & $-0.261^{* * *}$ & $-0.117^{* *}$ & $-0.169^{* *}$ \\
& $(0.071)$ & $(0.102)$ & $(0.096)$ & $(0.044)$ & $(0.067)$ \\
$\mathrm{NA} \times 1$ [Built Between 1955-1962] & $-0.188^{* *}$ & $-0.281^{* *}$ & $-0.268^{* *}$ & -0.004 & $-0.180^{*}$ \\
& $(0.073)$ & $(0.121)$ & $(0.107)$ & $(0.082)$ & $(0.106)$ \\
& & & & & \\
$\mathrm{NA} \times 1$ [Built Between 1963-1966] & 0.001 & -0.079 & -0.044 & -0.038 & -0.083 \\
& $(0.089)$ & $(0.123)$ & $(0.129)$ & $(0.082)$ & $(0.088)$ \\
$\mathrm{NA} \times 1$ [Built Between 1967-1971] & 0.103 & 0.061 & 0.128 & 0.021 & -0.052 \\
& $(0.063)$ & $(0.090)$ & $(0.103)$ & $(0.072)$ & $(0.073)$ \\
& & & & & \\
$\mathrm{R}^{2}$ & 0.714 & 0.841 & 0.787 & 0.873 & 0.909 \\
Mean of Dep. Var. & 0.653 & 7.007 & 16.307 & 4.779 & 5.631 \\
Number of Obs. & 12,757 & 12,757 & 12,757 & 12,757 & 12,757 \\
Number of Plants & 373 & 373 & 373 & 373 & 373 \\
Plant FE & $\mathrm{Y}$ & $\mathrm{Y}$ & $\mathrm{Y}$ & $\mathrm{Y}$ & $\mathrm{Y}$ \\
State By Year FE & $\mathrm{Y}$ & $\mathrm{Y}$ & $\mathrm{Y}$ & $\mathrm{Y}$ & $\mathrm{Y}$ \\
Vintage Group By Year FE & $\mathrm{Y}$ & $\mathrm{Y}$ & $\mathrm{Y}$ & $\mathrm{Y}$ & $\mathrm{Y}$ \\
\hline \hline
\end{tabular}

Number of Plants by Vintage Group: There are 229 plants built before 1955, 76 plants built between 1955 and 1962, 32 plants built between 1963 and 1967, and 36 plants built between 1967 and 1971.

Notes: This table reports the impacts of nonattainment on power plant operations by additional vintage groups. For reference, in the main analysis, we consider only two vintage groups: plants built before 1963 and plants built between 1963-1971. In contrast, the specifications in this table present separate estimates for vintage groups defined by whether the plant was built before 1955, between 1955-1962, between 1963-1966, or between 1967-1971. The unit of observation for the regressions in this table is plant-year, and the estimation considers all coal plants that were built before 1972. For all specifications, "nonattainment" (NA) is defined as the county being out of attainment with the NAAQS for any pollutant in the year. All specifications include plant fixed effects, state by year fixed effects, and vintage group by year fixed effects; plants built before 1955, between between 1955-1962, between 1963-1967, and after 1967 are in vintage groups 1, 2, 3, and 4 respectively. Standard errors in parentheses are two-way clustered by county and year. $* * *$ denotes statistical significance at the $1 \%$ level, ** at the $5 \%$ level, and $*$ at the $10 \%$ level. 
Table D.5: Impacts of Nonattainment on Power Plant Operations from 1938-1994: AQCR-Based Attainment Status

\begin{tabular}{|c|c|c|c|c|c|}
\hline Dep. Var. (in Logs): & $\begin{array}{c}(1) \\
\text { PU-TFP }\end{array}$ & $\begin{array}{c}(2) \\
\text { Output }\end{array}$ & $\begin{array}{c}(3) \\
\text { Fuel Use }\end{array}$ & $\begin{array}{c}(4) \\
\text { No. Employees }\end{array}$ & $\begin{array}{c}(5) \\
\text { Capacity }\end{array}$ \\
\hline \multicolumn{6}{|l|}{ Panel A. Average Effects } \\
\hline Nonattainment & $\begin{array}{c}-0.177^{* * *} \\
(0.062)\end{array}$ & $\begin{array}{c}-0.272^{* * *} \\
(0.092)\end{array}$ & $\begin{array}{c}-0.250^{* * *} \\
(0.087)\end{array}$ & $\begin{array}{l}-0.066 \\
(0.046)\end{array}$ & $\begin{array}{c}-0.163^{* *} \\
(0.069)\end{array}$ \\
\hline $\mathrm{R}^{2}$ & 0.707 & 0.834 & 0.781 & 0.861 & 0.906 \\
\hline \multicolumn{6}{|l|}{ Panel B. Effects by Plant Vintage } \\
\hline $\mathrm{NA} \times 1$ [Built Before 1963] & $\begin{array}{c}-0.221^{* * *} \\
(0.069)\end{array}$ & $\begin{array}{c}-0.330^{* * *} \\
(0.102)\end{array}$ & $\begin{array}{c}-0.317^{* * *} \\
(0.097)\end{array}$ & $\begin{array}{l}-0.084^{*} \\
(0.050)\end{array}$ & $\begin{array}{c}-0.189^{* *} \\
(0.076)\end{array}$ \\
\hline NA $\times 1$ [Built Between 1963-1971] & $\begin{array}{c}0.047 \\
(0.064)\end{array}$ & $\begin{array}{c}0.020 \\
(0.088)\end{array}$ & $\begin{array}{c}0.086 \\
(0.090)\end{array}$ & $\begin{array}{c}0.030 \\
(0.068)\end{array}$ & $\begin{array}{l}-0.035 \\
(0.069)\end{array}$ \\
\hline $\mathrm{R}^{2}$ & 0.708 & 0.835 & 0.781 & 0.861 & 0.906 \\
\hline Plant FE & $\mathrm{Y}$ & $\mathrm{Y}$ & $\mathrm{Y}$ & $\mathrm{Y}$ & $\mathrm{Y}$ \\
\hline State By Year FE & Y & Y & Y & Y & Y \\
\hline Vintage Group By Year FE & Y & $\mathrm{Y}$ & $\mathrm{Y}$ & $\mathrm{Y}$ & Y \\
\hline Mean Dep. Var. & 7.006 & 0.654 & 16.306 & 4.779 & 5.631 \\
\hline Number of Obs. & 12,729 & 12,729 & 12,729 & 12,729 & 12,729 \\
\hline Number of Plants & 373 & 373 & 373 & 373 & 373 \\
\hline
\end{tabular}

Notes: This table reports the impacts of nonattainment on power plant operations over the period 1938-1994. In contrast with Table D.5, nonattainment from 1972-1977 is measured using the definitions based on Air Quality Control Regions constructed by Cropper et al. (2022). The unit of observation for the regressions in this table is plant-year, and the estimation considers all coal plants that were built before 1972. Panel A estimates how annual plant-level outcomes change with the attainment status of the county where the plant is located. Panel B estimates the impact of nonattainment on outcomes separately for plants built before 1963 versus plants built between 1963-1971. For all specifications, "nonattainment" is defined as the county being out of attainment with the NAAQS for any pollutant in the year. All specifications include plant fixed effects, state by year fixed effects, and vintage group by year fixed effects; plants built before 1963 are in vintage group 1 while plants built between 1963-1971 are in vintage group 2. PU-TFP stands for pollution-unadjusted total factor productivity, and NA for nonattainment. Standard errors in parentheses are two-way clustered by county and year. *** denotes statistical significance at the $1 \%$ level, ${ }^{* *}$ at the $5 \%$ level, and $*$ at the $10 \%$ level. 
Table D.6: Impacts of Nonattainment on Power Plant Productivity from Alternative Specifications and Samples

\begin{tabular}{lcccc}
\hline \hline Dep. Var.: Log PU-TFP & $\begin{array}{c}(1) \\
\text { Primary }\end{array}$ & $\begin{array}{c}(2) \\
\text { Larger }\end{array}$ & $\begin{array}{c}(3) \\
\text { One Plant } \\
\text { Utilities }\end{array}$ & $\begin{array}{c}(4) \\
\text { No State } \\
\text { Standard }\end{array}$ \\
Nonattainment & $-0.135^{* *}$ & $-0.122^{* *}$ & $-0.275^{*}$ & $-0.145^{* *}$ \\
& $(0.054)$ & $(0.056)$ & $(0.160)$ & $(0.059)$ \\
$\mathrm{R}^{2}$ & & & & \\
Mean of Dep. Var. & 0.707 & 0.710 & 0.866 & 0.708 \\
Number of Obs. & 0.653 & 0.848 & 0.500 & 0.637 \\
Number of Plants & 12,757 & 9,558 & 2,024 & 10,981 \\
Plant FE & 373 & 289 & 128 & 315 \\
State By Year FE & $\mathrm{Y}$ & $\mathrm{Y}$ & $\mathrm{Y}$ & $\mathrm{Y}$ \\
Vintage Group by Year FE & $\mathrm{Y}$ & $\mathrm{Y}$ & $\mathrm{Y}$ & $\mathrm{Y}$ \\
\hline \hline
\end{tabular}

Notes: This table presents estimates of the impact of nonattainment on the log of pollutionunadjusted total factor productivity (PU-TFP). The unit of observation for these regressions is plant-year, considering only coal plants built before 1972. For all specifications, "nonattainment" is defined as the county being out of attainment with the NAAQS for any pollutant in the year. All specifications include plant fixed effects, state by year fixed effects, and vintage group by year fixed effects; plants built before 1963 are in vintage group 1 while plants built between 1963-1971 are in vintage group 2. For Column 2, we drop observations with capacity in the bottom $25 \%$ of the distribution of capacity. Column 3 focuses on utilities that own only one coal-fired plant built before 1972. Column 4 drops plants located in the ten states that had state-level air quality standards by 1966 - California, Colorado, Delaware, Missouri, Montana, New York, Oregon, Pennsylvania, South Carolina, and Texas (Stern, 1982). Standard errors in parentheses are two-way clustered by county and year. ${ }^{* * *}$ denotes statistical significance at the $1 \%$ level, ${ }^{* *}$ at the $5 \%$ level, and ${ }^{*}$ at the $10 \%$ level. 
Table D.7: Impacts of Nonattainment on PU-TFP Estimated Using Alternative Production Functions and Specifications

\begin{tabular}{|c|c|c|c|c|}
\hline Dep. Var.: Log PU-TFP & (1) & $(2)$ & $(3)$ & $(4)$ \\
\hline NA $\times 1$ [Built Before 1963] & $\begin{array}{c}-0.172^{* * *} \\
(0.061)\end{array}$ & $\begin{array}{c}-0.090^{*} \\
(0.047)\end{array}$ & $\begin{array}{c}-0.092^{*} \\
(0.051)\end{array}$ & $\begin{array}{c}-0.097^{*} \\
(0.051)\end{array}$ \\
\hline $\mathrm{NA} \times 1[$ Built Between 1963-1971] & $\begin{array}{c}0.064 \\
(0.059)\end{array}$ & $\begin{array}{c}0.043 \\
(0.071)\end{array}$ & $\begin{array}{c}0.072 \\
(0.055)\end{array}$ & $\begin{array}{c}0.071 \\
(0.055)\end{array}$ \\
\hline $\mathrm{R}^{2}$ & 0.708 & 0.749 & 0.585 & 0.581 \\
\hline Mean of Dep. Var. & 0.653 & -4.809 & 0.843 & 1.022 \\
\hline Number of Obs. & 12,757 & 12,757 & 12,757 & 12,757 \\
\hline Number of Plants & 373 & 373 & 373 & 373 \\
\hline Plant FE & $\mathrm{Y}$ & $\mathrm{Y}$ & $\mathrm{Y}$ & $\mathrm{Y}$ \\
\hline State By Year FE & $\mathrm{Y}$ & Y & $\mathrm{Y}$ & $\mathrm{Y}$ \\
\hline Vintage Group By Year FE & $\mathrm{Y}$ & $\mathrm{Y}$ & $\mathrm{Y}$ & $\mathrm{Y}$ \\
\hline Functional Form & Translog & Translog & CD & CD \\
\hline Estimation Method & $\mathrm{ACF}$ & $\mathrm{ACF}$ & $\mathrm{ACF}$ & $\mathrm{ACF}$ \\
\hline Includes Nonfuel Expenses & & $\mathrm{Y}$ & & $\mathrm{Y}$ \\
\hline
\end{tabular}

Notes: This table presents estimates of the impact of nonattainment on pollution-unadjusted total factor productivity (PU-TFP). The unit of observation for these regressions is plant-year, considering only plants built before 1972. We estimate separate effects for plants built before 1963 and plants built between 1963-1971. For all specifications, "nonattainment" (NA) is defined as the county being out of attainment with the NAAQS for any pollutant in the year. We estimate PU-TFP using the methodology developed by Ackerberg, Caves and Frazer (2015). The first two columns estimate PU-TFP assuming that the function relating capital and labor to output is translog while the next two columns are based on the assumption that this function is Cobb-Douglas (CD). Finally, the even columns include nonfuel expenditures as a measure of materials when estimating PU-TFP while the odd columns estimate PU-TFP without including any measure of materials. Standard errors in parentheses are two-way clustered by county and year. *** denotes statistical significance at the $1 \%$ level, ${ }^{* *}$ at the $5 \%$ level, and ${ }^{*}$ at the $10 \%$ level. 
Table D.8: Impacts of Nonattainment on Power Plant Outcomes by Primary Fuel Type

\begin{tabular}{lccccc}
\hline \hline Dep. Var. (in Logs) & $(1)$ & $(2)$ & $(3)$ & $(4)$ & $(5)$ \\
NA $\times 1$ [Coal Plant] & PU-TFP & Output & Fuel Use & No. Employees & Capacity \\
& $-0.103^{* *}$ & $-0.240^{* * *}$ & $-0.236^{* * *}$ & $-0.090^{* *}$ & $-0.165^{* * *}$ \\
& $(0.051)$ & $(0.082)$ & $(0.076)$ & $(0.039)$ & $(0.057)$ \\
$\mathrm{NA} \times 1$ [Oil Plant] & -0.048 & 0.072 & 0.043 & 0.118 & 0.035 \\
& $(0.107)$ & $(0.144)$ & $(0.233)$ & $(0.104)$ & $(0.089)$ \\
& & & & & \\
& $-0.218^{* * *}$ & $-0.227^{* *}$ & 0.204 & 0.049 & -0.062 \\
& $(0.079)$ & $(0.109)$ & $(0.210)$ & $(0.051)$ & $(0.076)$ \\
& & & & & \\
RA $\times 1$ [Gas Plant] & 0.624 & 0.821 & 0.701 & 0.865 & 0.908 \\
Mean of Dep. Var. & -0.702 & 6.788 & 15.757 & 4.506 & 5.507 \\
Number of Obs. & 20,038 & 20,038 & 20,038 & 20,038 & 20,038 \\
Number of Plants & 624 & 624 & 624 & 624 & 624 \\
Plant FE & $\mathrm{Y}$ & $\mathrm{Y}$ & $\mathrm{Y}$ & $\mathrm{Y}$ & $\mathrm{Y}$ \\
State By Year FE & $\mathrm{Y}$ & $\mathrm{Y}$ & $\mathrm{Y}$ & $\mathrm{Y}$ & $\mathrm{Y}$ \\
Fuel Type By Year FE & $\mathrm{Y}$ & $\mathrm{Y}$ & $\mathrm{Y}$ & $\mathrm{Y}$ & $\mathrm{Y}$ \\
Vintage Group By Year FE & $\mathrm{Y}$ & $\mathrm{Y}$ & $\mathrm{Y}$ & $\mathrm{Y}$ \\
\hline \hline
\end{tabular}

Number of Plants by Primary Fuel Type: Focusing on plants built before 1972, there are 373 coalfired plants, 63 oil-fired plants, and 188 gas-fired plants.

Notes: This table measures how annual plant-level outcomes change with nonattainment interacted with three bins associated with whether the primary fuel burned by the plant was coal, natural gas, or oil. We define each plant's fuel type by calculating the plant's aggregate total heat input from each fuel in its first five years of operation, picking the fuel corresponding to the largest aggregate heat input. For all specifications, "nonattainment" (NA) is defined as the county being out of attainment with the NAAQS for any pollutant in the year. PU-TFP stands for pollution-unadjusted total factor productivity. The unit of observation for these regressions is plant-year, considering only plants built before 1972. All specifications include plant fixed effects, state by year fixed effects, fuel type by year fixed effects and vintage group by year fixed effects; plants built before 1963 are in vintage group 1 while plants built between 1963-1971 are in vintage group 2. Standard errors in parentheses are two-way clustered by county and year. ${ }^{* * *}$ denotes statistical significance at the $1 \%$ level, ${ }^{* *}$ at the $5 \%$ level, and * at the $10 \%$ level. 
Table D.9: Impacts of Nonattainment on Power Plant Outcomes By Pollutant Standard

\begin{tabular}{|c|c|c|c|c|c|}
\hline Dep. Var. (in Logs) & $\begin{array}{c}(1) \\
\text { PU-TFP }\end{array}$ & $\begin{array}{c}\text { (2) } \\
\text { Output }\end{array}$ & $\begin{array}{c}\text { (3) } \\
\text { Fuel Use }\end{array}$ & $\begin{array}{c}(4) \\
\text { No. Employees }\end{array}$ & $\begin{array}{c}(5) \\
\text { Capacity }\end{array}$ \\
\hline NA: TSP or PM & $\begin{array}{l}-0.014 \\
(0.024)\end{array}$ & $\begin{array}{l}-0.008 \\
(0.039)\end{array}$ & $\begin{array}{l}-0.009 \\
(0.054)\end{array}$ & $\begin{array}{l}-0.002 \\
(0.034)\end{array}$ & $\begin{array}{c}0.011 \\
(0.050)\end{array}$ \\
\hline NA: SO2 & $\begin{array}{c}0.024 \\
(0.066)\end{array}$ & $\begin{array}{c}0.045 \\
(0.092)\end{array}$ & $\begin{array}{c}0.040 \\
(0.086)\end{array}$ & $\begin{array}{c}0.035 \\
(0.044)\end{array}$ & $\begin{array}{c}0.027 \\
(0.066)\end{array}$ \\
\hline $\mathrm{NA}: \mathrm{CO}$ & $\begin{array}{l}-0.057 \\
(0.070)\end{array}$ & $\begin{array}{l}-0.223^{*} \\
(0.117)\end{array}$ & $\begin{array}{l}-0.191^{*} \\
(0.098)\end{array}$ & $\begin{array}{c}-0.181^{* * *} \\
(0.056)\end{array}$ & $\begin{array}{c}-0.241^{* *} \\
(0.098)\end{array}$ \\
\hline $\mathrm{NA}: \mathrm{O}_{3}$ or $\mathrm{NO}_{2}$ & $\begin{array}{c}-0.155^{* *} \\
(0.059)\end{array}$ & $\begin{array}{c}-0.209^{* *} \\
(0.079)\end{array}$ & $\begin{array}{c}-0.186^{* *} \\
(0.071)\end{array}$ & $\begin{array}{l}-0.035 \\
(0.039)\end{array}$ & $\begin{array}{l}-0.095^{*} \\
(0.054)\end{array}$ \\
\hline $\mathrm{R}^{2}$ & 0.708 & 0.835 & 0.781 & 0.862 & 0.906 \\
\hline Mean of Dep. Var. & 0.653 & 7.007 & 16.307 & 4.779 & 5.631 \\
\hline Number of Obs. & 12,757 & 12,757 & 12,757 & 12,757 & 12,757 \\
\hline Number of Plants & 373 & 373 & 373 & 373 & 373 \\
\hline Plant FE & $\mathrm{Y}$ & $\mathrm{Y}$ & $\mathrm{Y}$ & $\mathrm{Y}$ & $\mathrm{Y}$ \\
\hline State By Year FE & $\mathrm{Y}$ & $\mathrm{Y}$ & $\mathrm{Y}$ & Y & $\mathrm{Y}$ \\
\hline Fuel Type By Year FE & $\mathrm{Y}$ & $\mathrm{Y}$ & $\mathrm{Y}$ & $\mathrm{Y}$ & $\mathrm{Y}$ \\
\hline Vintage Group By Year FE & $\mathrm{Y}$ & $\mathrm{Y}$ & $\mathrm{Y}$ & $\mathrm{Y}$ & $\mathrm{Y}$ \\
\hline
\end{tabular}

Notes: This table presents our regression results measuring how annual plant-level outcomes change when the county this plant is located in moves in and out of compliance with the NAAQS associated with each of four sets of pollutants: total suspended particulates or particulate matter (TSP or PM), sulfur dioxide $\left(\mathrm{SO}_{2}\right)$, carbon monoxide $(\mathrm{CO})$, and nitrogen dioxide or ozone $\left(\mathrm{NO}_{2}\right.$ or $\left.\mathrm{O}_{3}\right)$. There are separate standards for $\mathrm{O}_{3}$ and $\mathrm{NO}_{2}$, but we group these two standards together because the vast majority of counties that were in nonattainment for $\mathrm{NO}_{2}$ were also in nonattainment for $\mathrm{O}_{3}$. PU-TFP stands for pollution-unadjusted total factor productivity, and NA for nonattainment. The unit of observation for these regressions is plant-year, considering only coal plants built before 1972 . Standard errors in parentheses are two-way clustered by county and year. *** denotes statistical significance at the $1 \%$ level, ${ }^{* *}$ at the $5 \%$ level, and * at the $10 \%$ level. 
Table D.10: Impact of Proportion of Counties in Nonattainment on State-Level Capacity

\begin{tabular}{|c|c|c|c|c|}
\hline & $(1)$ & $(2)$ & $(3)$ & $(4)$ \\
\hline Dep. Variable: Capacity (in MW) & $\begin{array}{c}\text { Fossil Fuel: } \\
\text { ST or IC }\end{array}$ & $\begin{array}{l}\text { Fossil Fuel: } \\
\text { GT or CC }\end{array}$ & Nuclear & Hydro \\
\hline Prop. in Nonattainment & $\begin{array}{l}3972.5^{*} \\
(2182.9)\end{array}$ & $\begin{array}{c}1321.3^{* * *} \\
(491.2)\end{array}$ & $\begin{array}{c}1450.4^{* *} \\
(713.2)\end{array}$ & $\begin{array}{l}-501.5 \\
(948.7)\end{array}$ \\
\hline $\mathrm{R}^{2}$ & 0.687 & 0.581 & 0.539 & 0.705 \\
\hline Mean of Dep. Var. & $4,249.4$ & 588.3 & 607.1 & $1,087.9$ \\
\hline Number of Obs. & 2,736 & 2,736 & 2,736 & 2,736 \\
\hline Number of States & 48 & 48 & 48 & 48 \\
\hline State FE & $\mathrm{Y}$ & $\mathrm{Y}$ & $\mathrm{Y}$ & $\mathrm{Y}$ \\
\hline Year FE & $\mathrm{Y}$ & $\mathrm{Y}$ & $\mathrm{Y}$ & Y \\
\hline
\end{tabular}

Notes: This table presents estimates of the impact of annual state-level proportion of counties in nonattainment on annual state-level electricity generating capacity. Specifically, the independent variable of interest is the population-weighted proportion of counties in the state in nonattainment with the NAAQS for any pollutant in each year. The unit of observation for these regressions is stateyear, excluding Alaska and Hawaii. All specifications include state fixed effects and year fixed effects. The dependent variable considered in Columns 1,2, 3 and 4 is the annual state-level electricity generating capacity aggregating over fossil-fuel-fired sources using either steam turbines (ST) or internal combustion (IC), fossil-fuel-fired sources using either gas turbines (GT) or combined-cycle technology (CC), nuclear sources, and hydro sources respectively. Standard errors in parentheses are two-way clustered by state and year. *** denotes statistical significance at the $1 \%$ level, ** at the $5 \%$ level, and * at the $10 \%$ level. 